\title{
Article
}

\section{Flowback cleanup mechanisms of post- hydraulic fracturing in unconventional natural gas reservoirs}

Nasriani, Hamid Reza and Jamiolahmady, Mahmoud

Available at http://clok.uclan.ac.uk/28293/

Nasriani, Hamid Reza ORCID: 0000-0001-9556-7218 and Jamiolahmady, Mahmoud (2019) Flowback cleanup mechanisms of post-hydraulic fracturing in unconventional natural gas reservoirs. Journal of Natural Gas Science and Engineering, 66 . pp. 316-342. ISSN 1875-5100

It is advisable to refer to the publisher's version if you intend to cite from the work. http://dx.doi.org/10.1016/j.jngse.2019.04.006

For more information about UCLan's research in this area go to http://www.uclan.ac.uk/researchgroups/ and search for <name of research Group>.

For information about Research generally at UCLan please go to http://www.uclan.ac.uk/research/

All outputs in CLoK are protected by Intellectual Property Rights law, including Copyright law. Copyright, IPR and Moral Rights for the works on this site are retained by the individual authors and/or other copyright owners. Terms and conditions for use of this material are defined in the policies page.

\section{CLoK}

Central Lancashire online Knowledge www.clok.uclan.ac.uk

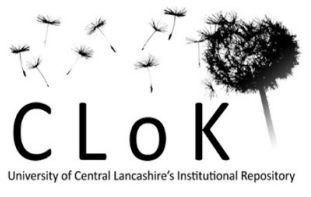




\section{Accepted Manuscript}

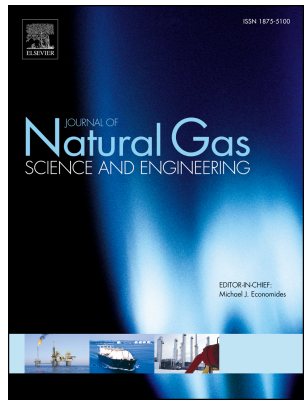

Flowback cleanup mechanisms of post-hydraulic fracturing in unconventional natural gas reservoirs

Hamid Reza Nasriani, Mahmoud Jamiolahmady

PII: $\quad$ S1875-5100(19)30101-5

DOI: $\quad$ https://doi.org/10.1016/j.jngse.2019.04.006

Reference: JNGSE 2870

To appear in: Journal of Natural Gas Science and Engineering

Received Date: 25 September 2018

Revised Date: 11 March 2019

Accepted Date: 7 April 2019

Please cite this article as: Nasriani, H.R., Jamiolahmady, M., Flowback cleanup mechanisms of post-hydraulic fracturing in unconventional natural gas reservoirs, Journal of Natural Gas Science \& Engineering, https://doi.org/10.1016/j.jngse.2019.04.006.

This is a PDF file of an unedited manuscript that has been accepted for publication. As a service to our customers we are providing this early version of the manuscript. The manuscript will undergo copyediting, typesetting, and review of the resulting proof before it is published in its final form. Please note that during the production process errors may be discovered which could affect the content, and all legal disclaimers that apply to the journal pertain. 
$1 \quad$ Flowback cleanup mechanisms of post-hydraulic

2 fracturing in unconventional natural gas reservoirs

3

4

Hamid Reza Nasriani*1 ${ }^{1}$, Mahmoud Jamiolahmady ${ }^{2}$

${ }^{1}$ University of Central Lancashire, Faculty of Science and Technology, School of Engineering, Preston, United Kingdom

${ }^{2}$ Heriot-Watt University, Institute of Petroleum Engineering, Edinburgh, United Kingdom

\section{Abstract}

This work investigates the fracturing fluid cleanup mechanisms of post-hydraulic fracturing in unconventional gas formations by studying a large number of wide-ranging parameters simultaneously.

In this work, different scenarios of the cleanup operation of the hydraulic fracturing process are considered. This study consists of investigating the post-fracturing cleanup operation of hydraulically fractured vertical wells (VW) and multiple fractured horizontal wells (MFHWs). Additionally, the impact of soaking time, the range of the matrix permeability, applied drawdown pressure, injected fracturing fluid (FF) volume, fracture spacing and horizontal well length has been investigated by running different sets.

Results show that that the trend of the impact of relevant parameters for VWs and MFHWs are analogous excepting the matrix permeability, $\mathrm{k}_{\mathrm{m}}$. That is, in the MFHW base reference set, the effect of matrix permeability on capillary pressure is more significant than that on fluid flow while the reverse is observed for VW. The difference in the impact of $k_{m}$ in VWs and MFHWs is attributed to the geometry of the fluid flow towards the production well and different well completion scheme.

It is also concluded that the impact of parameters affecting the capillary pressure in the matrix is more significant for MFHWs whereas matrix and fracture mobility pertinent parameters are more important for VWs than MFHWs. As a result, larger matrix capillary pressure values are more vital in the cleanup of MFHWs because of more imbibition of FF into the matrix and subsequently lower conflict between the flow of gas and FF in the fracture.

The other part of this research concentrates on the impact of IFT reducing agents on the postfracturing production in different formations. In hydraulic fracturing operations, these agents 

65

are commonly used as an additive in fracturing fluid to facilitate its backflow by reducing Pc and subsequently enhancing gas production. The results of this work recommend that using such agents enhances the gas production rate for ultratight formations but not for tight formations (it reduces the gas production rate). Therefore it is not suggested to use such agents in tight formations.

The findings of this work improve the understanding of fracture cleanup leading to better design of hydraulic fracturing operations in unconventional formations.

Keywords: Hydraulic Fracturing; Fracking; Cleanup; unconventional fields; Flowback; fracturing fluid; Multiple Fractured Horizontal Well, Hydraulically Fractured Vertical Well

\section{Introduction \& Literature Review}

Natural gas is considered to be the cleanest fossil fuel with the least emissions. It is also considered to be one of the most substantial sources of energy in the future due to its abundance and environmental reliability. Natural gas plays a progressively important role in residential heating, industrial, commercial and electrical generation sectors across the world. Natural gas resources could be either conventional or unconventional. Unlike the conventional natural gas reserves that are considered to be one of the most economical and most accessible reserves to extract, unconventional natural gas resources are much more problematic and less economically viable to develop. Coalbed methane, tight and ultra-tight gas sands, gas shales and gas hydrates are considered as unconventional gas resources. Significant demand growth on natural gas has resulted in the development of natural gas resources from tight and ultra-tight gas sands, and shale gas plays. Tight and ultra-tight gas resources make up 57-59\% of the unconventional global resources with pronounced abundance in several parts of the world, i.e., Europe, Asia, North Africa, North America and the Middle East, (Dong et al., 2011).

Hydraulic fracturing is generally implemented for the productivity enhancement of the wells in the unconventional formations (Clark, 1949; Garrison, 1945; Height, 1944; Lee, 1939).

2 The initiation and propagation of fractures in unconventional reservoirs are achieved through 3 the injection of high volumes of fracturing fluid, FF (Holditch, 1979; Montgomery et al., 64 1990;). Initially, vertically drilled, hydraulically fractured wells in the tight oil and gas fields have been drilled in the North-eastern state of Pennsylvania in the United States. Several field 
experiences have shown that ineffective FF cleanup can significantly impair gas production.

There are several experimental, numerical and field studies investigating the impact of the cleanup efficiency of hydraulic fractures on gas production and FF flowback in unconventional tight/ultra-tight formations (e.g. Pope et al., 1996; Gdanski et al., 2005).

The volume of the flowback depends on the characteristic of the formation, FF physical property and the design of the hydraulic fracturing operation. The volume of the flowback that is recovered from the well at the surface could vary from $10 \%$ to $70 \%$ of the total volume of the FF that was initially injected. Usually, the existence of natural minor fractures in the formation and also having higher matrix capillary pressures could result in retaining more FF in the formation and consequently less flowback recovery at the surface. Nowadays, the optimisation of the fracturing fluid flowback is becoming increasingly important in the oil and gas industry for various reasons. Tech-Flo Consulting (2019) utilises a Tech-Flo hydraulic jet pump for FF flowback removal to optimise the load recovery. This technology could accelerate the safe recovery of a large volume of flowback with simultaneous separation of the hydrocarbon from the well stream. Halliburton (2018) has also introduced CALIBR engineered flowback service in MFHWs of unconventional fields to improve the well performance by mitigating the completion damage and optimising the longstanding production. CALIBR is an iterative procedure that optimises the well results by continually measuring, analysing and regulating the flowback in order to improve completion efficiency and enhance the well productivity. Using CALIBR could avoid destructive flowback approaches and mitigate the loss in fracture conductivity and impaired well performance by continuously measuring the bottom-hole pressure, analysing the well performance and real-time management of the choke.

Holditch (1979) conducted a study on the impact of damage to matrix grids in the surrounding area of the fracture, by examining the effect of FF (considered as water) saturation increase and permeability decrease in near fracture region, on the fractured wells' productivity. He conducted his study employing a finite difference numerical simulator. It was noted that the impact of capillary pressure, Pc, in tight formations (low permeability reservoirs) was evident in low-pressure drawdown (DP) cases in which DP was not significantly larger than the matrix Pc. He described that water blockage happens once the matrix permeability of fracture surrounding region decreases by $99.9 \%$ or DP does not become more than Pc in the region invaded by FF. He reported that the FF invasion depth in their matrix was up to 5 in, with uniform FF distribution in the matrix adjacent to the 
hydraulic fracture. He concluded that in low permeability formations, Pc and relative permeability in invaded zones are significantly important on cleanup efficiency but in his work, the impact of FF volume on the conductivity of the fracture was not investigated.

102 Pope et al. (1996) presented a positive relationship between load recovery and gas production

103 from field data. They explained that as FF is produced back to the surface from HF, an

104 equivalent space in the fracture becomes available to the flow of the gas toward the well.

105 Therefore, the higher the load recovery, the more the gas production. They presented a 106 correlation between FF flowback and gas production rates to support their theory. They also

107 highlighted more substantial initial flow rates would result in load FF recovery.

108 Gdanski et al., (2005) extended the study conducted by Holditch (1979) on cleanup to 109 further investigate the gas and FF two-phase flow and matrix permeability damage in the 110 invaded region. For this study, they developed a numerical model and discussed that the 111 damage in the fracture sand-face extensively reduced gas productivity if $\mathrm{k}_{\mathrm{m}}$ in the invaded 112 region is reduced to $1 \%$ of the initial permeability of the matrix. They also reported that the 113 larger the original matrix Pc, the more damage to the gas production. However, they did not 114 consider the fact that in the case of larger Pc, FF is imbibed more in the matrix, reducing the 115 FF saturation in the fracture grids, increased gas effective permeability inside the fracture and 116 consequently cleaner fractures.

117 Ghahri et al. (2009) studied the impact of various parameters affecting cleanup efficiency of 118 single fractured vertical wells, VW, of gas and gas-condensate fields. They also reproduced 119 the numerical model results mentioned by Holditch (1979) which has been referred to in 120 many cleanup simulation studies from then on. They reported that the existence of FF in the 121 invaded region affects the cumulative gas production by impairing the gas relative 122 permeability, i.e., it results in a gas production loss compared to a case when no FF was 123 injected. Decreasing the FF viscosity and consequently increasing FF mobility results in more 124 substantial FF recovery at the production stage.

125 They also highlighted that when Pc increases, the FF invades deeper into matrix resulting in 126 improved gas production less impeded by $\mathrm{FF}$

127 Ghahri et al. (2011) extended this work by conducting a wide-ranging analysis of 16 practical 128 parameters simultaneously employing experimental design together with the methodology of 129 response surface (RSM). They demonstrated that gas production loss, GPL, is significantly 130 affected by factors associated with the FF cleanup within the fracture mainly $\mathrm{k}_{\mathrm{f}}$. 
131 It should be highlighted that these two numerical studies, i.e., (Ghahri et al., 2011, 2009), the

132 required central processing unit (CPU) time was too long. Consequently, the authors were

133 able to study only two simulations' sets. To facilitate the studying of more different cleanup 134 scenarios, Jamiolahmady et al., (2014) further investigated the flowback cleanup 135 mechanisms, they decreased the number of parameters from 16 to just 12 parameters by 136 removing four parameters that had the slightest impacts on the cleanup performance. These 137 parameters were: the permeability in the matrix and the fracture, interfacial tension, pore size 138 index, and the exponents and endpoints of the Brooks Corey relative permeability correlation 139 for matrix and the fracture (Brooks and Corey, 1964). This work, which was also part of the 140 Heriot-Watt University Gas condensate recovery research was then extended to more 141 different cases of cleanup scenarios in tight and ultra-tight gas formations by conducting 84 142 different sets of simulations. Different factors that had a significant impact on the cleanup 143 efficiency, i.e., injected FF volumes, soaking time, bottom-hole flowing pressure, tightness of 144 the formation, were considered. It was noticed that if the formation becomes tighter (smaller $145 \mathrm{k}_{\mathrm{m}}$ ), it results in a more substantial loss in the gas production and consequently, the cleanup 146 procedure will become slower and vice versa. It was also concluded that if the pressure 147 drawdown is small, the impact of Pc on the clean-up performance was more significant, a 148 similar observation was noted once the soaking time was extended (Nasriani, 2017; Nasriani 149 et al., 2018, 2014b, 2014a, Nasriani and Jamiolahmady, 2018a, 2018b).

150 Nasriani et al. (2018) captured the impact of injected fracture fluid volume, length of the 151 fracture, pressure drawdown, hysteresis, layering, gravity segregation and mobility/immobility of the formation water on the post-fracturing cleanup performance. They reported that if a large volume of FF is injected into ultra-tight formations, it results in a substantial gas production loss and hinders the cleanup process intensely. In such a case, the impact of changing other parameters like soaking time extension or pressure drawdown 156 increase improved GPL insignificantly. They showed that hysteresis has an insignificant 157 impact on the cleanup efficiency. They also studied the impact of layered systems on the 158 cleanup performance; they identified that the fluid mobility coefficient within the fracture is meaningfully more significant in the top layer than those of the bottom layer while capillary

160 pressure becomes more significant in bottom layer in comparison with the top layers. They 161 also reported that in cases with high water saturation in the reservoir, the injection of IFT 162 reducing agent could alleviate the gas production loss corresponding to fracturing operation. 


\subsection{The purpose of this study}

165

166

167

168

169

170

171

172

173

174

175

176

177

178

179

180

181

182

183

184

185

186

187

188

189

190

191

192

193

194

195

Most of the previous studies considered the cleanup efficacy of hydraulically fractured vertical wells (VWs). The present study covers a broader area of investigations of the postfracturing cleanup operation in multiple fractured horizontal wells (MFHWs). More specifically, the impact of considering different fracture spacing and different horizontal lengths in MFHWs on the cleanup efficiency is discussed. It also presents a comparison between the post-fracturing cleanup operation in VWs and MFHWs. It should be noted that it took very long CPU time to conduct the numerical simulation for MFHW sets. Therefore a new sampling approach (Latin Hypercube Sampling (LHS) method) is introduced to reduce the long CPU time required for simulation runs based on full factorial sampling (FFS) experimental design that was implemented in some of the studies mentioned in the previous section.

It should be noted that some of the conclusions are due to assumptions or limitations in the model. Permeability and porosity were considered constant and uniform throughout the model to limit the number of variables and reduce the complexity of the model. Additionally, independent variations of the twelve parameters were considered without using dependency function between them.

\section{Methodology}

It is a challenging task to conduct and then analyse a large number of different simulation runs using statistical experimental designs methods and consequently a methodical approach is needed.

In this section, the adopted analysis methods and terminologies are explained using a flowchart. Figure 1 represents a Flowchart that explains the workflow of the study of the mechanisms of the cleanup after the fracturing stage. As it is shown, a vertical well (VW) model that was developed initially by Ghahri et al. (2009) was used for VW sets, the validation process of the modified VW model is described elsewhere (Nasriani and Jamiolahmady, 2018a).

In addition to the VW model, a new numerical model is developed for MFHW. As it is shown in Figure 1, once the two VW and MFHW models were validated, four scenarios are considered. It is worth mentioning that in each scenario, one or several simulation sets were conducted. The four different scenarios are: 
Scenario 1. VW Base reference set

Scenario 2. MFHW Base reference set

Scenario 3. MFHW sets with different shutin times, $\mathrm{k}_{\mathrm{m}}$, drawdown pressures and injected fracture fluid

Scenario 4. MFHW sets with different fracture spacing and horizontal length In the first two scenarios (i.e., VW base reference set and MFHW base reference set), the full factorial sampling (FFS) was adopted to conduct the required number of numerical simulations. Next, an accurate model, based on the mathematical surface methodology, was matched to the outputs of each set, and consequently, the outcomes of these sets were studied.

The FSS data sampling approach that was used to study the cleanup efficiency takes a long CPU (Central Processing Unit) time to conduct numerous runs (i.e. 4096 runs for each set). Introducing more complexity to the models, i.e., changing the numerical model from $\mathrm{VW}$ to MFHW, made the CPU time significantly longer. With the intention of decreasing the required number of runs and consequently reducing the CPU time, Latin Hypercube Sampling (LHS) method was used and verified. Consequently, LHS was applied to the MFHW scenarios to create the input to the simulation models. It is worth noting that several simulation sets were conducted in Scenario 3 and 4 for the MFHW case with Latin Hypercube Sampling (LHS) method.

\subsection{Construction, Modification and Validation of MFHW and VW Models}

In order to investigate the cleanup operation of vertical (VW) and multiple fractured horizontal wells (MFHW), six different models were set up using ECLIPSE 100 (Schlumberger, 2015). The six different models were: a pre-fractured single vertical well model and a new model with three, seven, nine and 13 fractures placed on the $600 \mathrm{~m}$ horizontal well length to capture the effect of fracture spacing on the cleanup performance. Additionally, a new MFHW model with ten fractures placed on the $900 \mathrm{~m}$ horizontal well length was set up to capture the impact of horizontal length on cleanup efficiency. The local grid refinement (LGR), rather than global refinement was used around fractures in the construction of MFHWs. The application of LGR enabled the authors to capture the impact of the variation of flow parameters in the stimulated reservoir volume while not increasing the CPU time significantly. 
The initial pressure of the model and the average matrix porosity are $7500 \mathrm{psi}$ and $15 \%$, correspondingly. The numerical models' dimensions are listed in Table 1. Figure 2 presents the section of VW model that is modelled. The set numbers refer to the order they were run as part of a much bigger set of simulations, not all of which are discussed here.

The fracking fluid (FF) is considered water. The corresponding viscosity and compressibility for FF were considered $0.5 \mathrm{cp}$ and 0.000005 (1/psia) respectively. For the duration of the hydraulic fracturing phase, the injected FF volume was considered as of twice the volume of the fracture in the sets that is assumed as the base reference sets for VW and MFHW cases. In the next stage of the numerical modelling (post-fracturing stage), gas and FF were produced under a controlled bottom-hole flowing pressure. It should be noted that just after the FF injection stage and before flowback production, a two-day well shut-in period was allowed.

It was mentioned previously that the validation process and the governing equations for the modified VW model are described elsewhere (Nasriani and Jamiolahmady, 2018a). The same validation technique was used for the MFHW model. Therefore, to authenticate the developed model for MFHW for the post-fracturing cleanup research, the well bottom-hole pressures versus production time that was predicted by numerical simulation of the MFHW model were compared with the same results from an analytical model for MFHW as that of previously used for VW model by Nasriani and Jamiolahmady (2018b).

Figure 3 displays the well bottom-hole pressure (Pwf) that is predicted by the simulation model and that forecasted by the analytical model versus production time. It is noted that the two curves are overlapping and laying on top of each other, which confirms the integrity of the simulation model.

It should be noted that twelve relevant parameters affecting the post-fracturing cleanup mechanisms are considered in this study. The first eight parameters out of the 12 are the exponents and endpoints of Brooks-Corey (for two different phases) relative permeability correlation.

Three parameters control capillary pressure in the matrix, i.e., matrix permeability $\left(\mathrm{k}_{\mathrm{m}}\right)$, interfacial tension (IFT) and distribution index of the pore size $(\lambda)$. The last parameter is fracture permeability, $\mathrm{k}_{\mathrm{f}}$.

The ranges of the variation of these parameters are presented in Table 2. It should be highlighted that there are six parameters listed in Table 2 that are considered constant 
throughout a simulation set, i.e., drawdown pressure, matrix porosity, the gas and water critical saturations in both fracture and matrix.

Equations $1 \& 2$ represent the threshold (entry) pressure and capillary pressure (Brooks and Corey, 1966; Thomas et al., 1968). The relative permeability correlation for water and gas are described by Equations $3 \& 4$ (Brooks and Corey, 1966).it should be noted that in each run of any simulation set, the data are taken within the ranges of the variation of the pertinent parameters that are listed in Table 2 based on a sampling technique, i.e., FFS or LHS.

$$
\frac{P d}{I F T}=0.0075 \times K^{-0.5}
$$

- Threshold pressure Pd, bar

- Surface tension IFT (dyne/cm)

- The permeability of the matrix $(\mathrm{K}(\mathrm{mD}))$

$$
\begin{aligned}
& \left(\frac{P d}{P c}\right)^{\lambda}=\frac{S w-S w r}{1-S w r} \\
& k_{r w}=K_{\max w} \times\left(\frac{S w-S w r}{1-S w r-S g r}\right)^{n w} \\
& k_{r g}=K_{\max g} \times\left(\frac{S g-S g r}{1-S w r-S g r}\right)^{n g}
\end{aligned}
$$

267

To capture the impact of pressure drop (DP) on the cleanup mechanisms, different sets of simulation sets are considered for each DP as noted in Table 3.a and b. It should be highlighted that in this study, the 12 pertinent parameters are scaled between zero and one, zero corresponds to the minimum, and one corresponds to the upper bound, this makes the analysis of the cleanup mechanisms more efficient by response surface methodology (RSM).

\subsection{Response Surface Methodology (RSM) and the main output}

In this study, Gas Production Loss (GPL, \%), which is used as the output, is expressed as the ratio of the difference between the cumulative fracture productions of the situation with an undamaged (totally clean from FF) fracture and damaged (unclean) fracture cumulative production to the undamaged (totally clean) fracture cumulative productions.

$$
\mathrm{GPL}=100 \times\left[\frac{\mathrm{FGPT}_{\text {clean }}-\mathrm{FGPT}_{\text {unclean }}}{\mathrm{FGPT}_{\text {clean }}}\right]
$$

FGPT: total gas cumulative production 
It is very difficult, or technically impossible, to have an entirely clean (undamaged) fracture after hydraulic fracturing operation. However, if the related parameters and their impact on post-fracturing operations are well understood then real field strategies regarding the fracturing operations could be further improved to attain a much cleaner fracture with enhanced productivity. It should be noted that this main response, i.e. GPL is a normalised parameter; making it easier to compare different scenarios. In the current study, the effect of the 12 parameters as mentioned earlier on gas production loss is captured using the tornado charts. In this approach, if a parameter has a positive influence on the cleanup efficiency, it reduces the gas production loss (GPL) or in other words more cumulative gas production when the value of the parameter is raised. Conversely, if a parameter has a negative influence on the cleanup efficiency, it increases the gas production loss (GPL) or in other words less cumulative gas production when the value of the parameter is raised.

In order to analyse that how sensitive some pertinent parameters are to a particular main output (main response), response surface methodology is widely used. In statistics and mathematics, response surface methodology finds an authentic relationship among several independent parameters, i.e., $\mathrm{x} 1, \mathrm{x} 2, \mathrm{x} 3 \ldots \mathrm{xn}$ and the main response variable (y or $\mathrm{f}(\mathrm{xi})$ ).

The RSM, i.e., the fitted polynomial function $\mathrm{f}(\mathrm{xi}), \mathrm{RSM}$ is defined by Equation 6.

$$
y=a_{0}+\sum_{k=1}^{n} a_{k} x_{k}+\sum_{i=1}^{n} \sum_{j=i+1}^{n} a_{i} a_{j} x_{i} x_{j}+\sum_{l=1}^{n} a_{l} x_{l}^{2}
$$

Equation 6 presents four different models of RSM:

- Linear Response Surface model (LRSM) that considers $\left(\mathrm{a}_{0}\right)$ and $\left(\mathrm{a}_{\mathrm{k}} \mathrm{x}_{\mathrm{k}}\right)$.

- Linear Response Surface Model with Interaction (ILRSM), if $\left(\mathrm{a}_{\mathrm{i}} \mathrm{a}_{\mathrm{j}} \mathrm{x}_{\mathrm{i}} \mathrm{x}_{\mathrm{j}}\right)$ are considered in addition to constant $\left(\mathrm{a}_{0}\right)$ and linear terms $\left(\mathrm{a}_{\mathrm{k}} \mathrm{x}_{\mathrm{k}}\right)$ terms.

- Pure Quadratic Response Surface model (PQRSM) that considers $\left(\mathrm{a}_{0}\right)$ and $\left(\mathrm{a}_{\mathrm{k}} \mathrm{x}_{\mathrm{k}}\right)$ and quadratic terms $\left(\mathrm{a}_{1}^{2} \mathrm{x}_{1}^{2}\right)$.

- Full Quadratic Response Surface model (FQRSM) which considers $\left(a_{0}\right),\left(a_{k} x_{k}\right)$ and

$$
\left(\mathrm{a}_{1}^{2} \mathrm{x}_{1}^{2}\right) \text {. }
$$

In this study, Interactive Linear Response Surface (ILRSM) and Full Quadratic Response

Surface (FQRSM) models were used to obtain GPL as a function of those 12 relevant parameters for two-level full factorial sampling (FFS), and Latin hypercube sampling (LHS) approaches respectively. Two different codes, i.e., a MATLAB code (The MathWorks, 2013) and a Python code, were developed to run all simulations of a simulation set including the pre and post-processing phases of the fracturing operation. 


\subsection{Analysis Methodology}

This work analyses a total of 31 different sets for fractured vertical wells (2 sets) and

314 Multiple fractured horizontal wells (29 sets). It should be noted that all sets use similar 315 reservoir dimensions, however, differ in pressure drawdown, horizontal length, number of 316 fractures (fracture spacing), matrix permeability, shut-in time and the volume of injected FF. 317 A full list of those different sets is shown in Table 3a and 3b. As it is shown in Table 3a and $3183 \mathrm{~b}$, there are two base reference sets for VW and MFHW respectively. The two base 319 reference sets consider the 12 relevant parameters with default ranges as shown in these two 320 tables. New sets are named according to the dissimilarities of the variation range of parameters compared to the base reference set. In Table $3 a \& b$, if a parameter is tick marked, the default variation range is considered for that particular parameter; otherwise, a new variation range is introduced.

\section{Results and Analyses}

\subsection{The Vertical Well Base Case Scenario}

Nasriani and Jamiolahmady (2018b) have comprehensively explained the vertical well base reference set, so in this study, a summary of the key findings are reported. For this set, the impact of pertinent parameters on GPL after 10, 30 and 375 days of production is displayed graphically in the form of a tornado chart, Figure 4.

Figure 4 shows that the permeability of the fracture, i.e., $\mathrm{k}_{\mathrm{f}}$, has a crucial role in fracture cleanup operation, it has the largest absolute coefficient value of one in the corresponding chart, i.e., the higher $\mathrm{k}_{\mathrm{f}}$ results in cleaner fracture and less gas production loss. It should be noted that a large absolute coefficient for the endpoint and exponent (nwf and $\mathrm{k}_{\operatorname{maxwf}}$ ) of Brooks and Corey's correlation (1966) is observed which is in line with having a large absolute value for the $\mathrm{k}_{\mathrm{f}}$ coefficient. These observations, i.e., having large absolute coefficient values for $\mathrm{k}_{\mathrm{f}}, \mathrm{n}_{\mathrm{wf}}$ and $\mathrm{k}_{\text {maxwf }}$, highlight that the efficiency of the post-fracturing cleanup could be improved if the FF mobility within the fracture is increased. From the data of Figure 4, it is also noted that an increase in the Corey exponents corresponding to gas in both matrix and fracture, i.e., $\mathrm{n}_{\mathrm{gf}} \& \mathrm{n}_{\mathrm{gm}}$, impairs the post-fracturing cleanup performance.

341 That means an increase in the mobility of gas within both matrix and fracture results in a decrease in GPL and vice versa. 
From the data of Figure 4, it is indicated that a decrease in IFT or an increase in $\lambda$ increases GPL. If Equations 1 and two are considered, a reduction in IFT or a rise in $\lambda$ reduce the capillary pressure $(\mathrm{Pc})$. Accordingly, it could be concluded that if $\mathrm{Pc}$ is increased, cleanup efficiency could improve, as higher Pc allows more FF to be imbibed further into the matrix which this leaves the fracture cleaner for gas to move through it. Notwithstanding the Pc also depends on $\mathrm{k}_{\mathrm{m}}$ in addition to IFT and $\lambda$, which is discussed next.

Figure 4 shows that $k_{m}$ has a negative coefficient; this suggests that larger $k_{m}$ results in smaller GPL values. However, it should be noted that $\mathrm{k}_{\mathrm{m}}$ has two diverse effects on GPL as follow:

(i) An increase in $\mathrm{k}_{\mathrm{m}}$ provides better fluid mobility throughout the injection and production stages.

(ii) An increase in $\mathrm{k}_{\mathrm{m}}$ decreases Pc, which leads to a rise in GPL.

It is worth mentioning that the impact of $\mathrm{k}_{\mathrm{m}}$ on the improvement of the mobility of the fluid is more dominant than that of the decreasing Pc for this set. Therefore, an increase in $\mathrm{k}_{\mathrm{m}}$ resulted in a better cleanup performance. These findings recommend that in the base reference set, the application of chemicals to decrease IFT and consequently to decrease Pc could rise GPL and harm cleanup efficacy and productivity.

\subsection{Multiple Fractured Horizontal Well set}

In this section, the clean-up efficiency of the MFHW set is discussed, and its results are compared with those of the corresponding VW set.

As mentioned before, for the case of MFHW, a new model was set-up with three fractures placed on the $600 \mathrm{~m}$ horizontal well length. Fracture half-length was $90 \mathrm{~m}$ rather than $400 \mathrm{~m}$ corresponding to the VW reference set.

It is interesting to note that the direction of the impact of parameters is similar except for $\mathrm{k}_{\mathrm{m}}$ if the tornado charts of the VW-Set and MFHW set 1 (Figure 4) are considered. That is; in the MFHW set the effect of $\mathrm{k}_{\mathrm{m}}$ on Pc is more dominant than that on fluid flow while the reverse is observed for the VW set. VW and MFHW are different in two ways. First the number and volume of fractures and second the position of a fracture concerning the well, resulting in different flow geometries.

In order to identify which of these two resulted in this trend change, a new vertical well model (with well competed in the Y-direction, referred to hereafter as Y-VW) was set-up. 
376

377

378

379

380

381

382

383

384

385

386

387

388

389

390

391

392

393

394

395

396

397

398

399

400

401

402

403

404

405

406

407

the original VW set up completed in the z-direction ( referred to, in this section, as Z-VW) but with the well completed in the Y-direction (rather than Z-direction used for the original VW set, (Figure 5).

Figure 9 represents the cumulative frequency of GPL runs of the VW and MFHW base reference set in a histogram chart. In the histogram chart for VW set, if GPL value of $20 \%$ is considered, it is noted that after ten days of production, $83 \%$ of the numerical simulations have GPL values higher than 20\% and 17\% less than 20\% GPL. At longer production times, i.e., 30 and 365 days, the GPL values decline noticeably, that means that the frequency of runs that have GPL values more than twenty per cent is around $68 \%$ and $28 \%$ respectively. Therefore it is concluded that as production time increases it results in a better cleanup.

Comparing tornado charts of the VW-Set 1 (Figure 4) and Y-VW set (Figure 6), it is noted that the $\mathrm{k}_{\mathrm{m}}$ trend in the Y-VW case is different from that of the Z-VW Set. This observation indicates that the trend change of $\mathrm{k}_{\mathrm{m}}$ is due to the change in the flow geometry and how the well is completed. It should be noted that in the $\mathrm{Y}-\mathrm{VW}$ set, the area perpendicular to flow at the wellbore is $2 \pi r_{w}{ }^{*} \mathrm{w}_{\mathrm{f}}$, which is much less than that, i.e. $\mathrm{H}^{*} \mathrm{w}_{\mathrm{f}}$, for the $\mathrm{Z}-\mathrm{VW}$ set, Figure 5. In other words, the connection area between fracture and well is significantly restricted in the Y-VW case. Hence, for the Y-VW set, the effect of flow from the matrix towards fracture during the backflow clean-up is less critical and rather imbibition of fracture fluid governed by matrix capillary pressure, which depends on $\mathrm{k}_{\mathrm{m}}$, is more important.

Economides and Martin (2010), reported a similar observation when they investigated the productivity index of different completions, i.e., horizontal transverse, horizontal longitudinal and vertically fractured completions. They referred to a near wellbore choking effect, which is caused by the minimal area of contact between fractures and wellbore and it can seriously affect the productivity of gas wells.

To further investigate this observation, Figure 7 and Figure 8 were prepared that show GPL and the gas to FF flow rate ratio vs numbers of runs for Z- and Y-VW cases. These results further confirm that due to a smaller flow area for the Y-VW set, there is more GPL while there is more gas production for the $\mathrm{Z}-\mathrm{VW}$ set at the same FF production rate. In other words, at the same FF flowback volumes, FF has a more detrimental impact on gas production in the $\mathrm{Y}-\mathrm{VW}$ case than the Z-VW case due to very restricted connection area between the well and the fracture in $\mathrm{Y}-\mathrm{VW}$ case. 
Based on these, it can be concluded that the $\mathrm{k}_{\mathrm{m}}$ trend change between VW and MFHWS sets is due to fracture-wellbore flow area connection between these two sets.

410 Figure 9 highlights how fast is the cleanup in MFHW-Sets 1 compared to VW-Set 1 using 411 a histogram chart. Faster clean-up is observed for the MFHW set compared to the VW set.

412 This observation is due to the higher production rate of the MFHW resulting in a faster and 413 more efficient clean-up.

414 In Figure 9, it is also noted that at GPL values larger than 60\%, the corresponding 415 cumulative frequencies are almost the same for both sets.

\subsection{New MFHW sets using a New Sampling approach, Latin hypercube sampling} (LHS)

In previous sets, the full factorial linear experimental design was used to study the cleanup efficiency. Using the FFS approach takes a relatively long CPU time to conduct a large number of simulation runs (i.e. 4096 runs for each set). Introducing more complexity to the models made the CPU time even longer. In order to decrease the required number of runs and reduce the CPU time, Latin Hypercube Sampling (LHS) method was adopted. It should be highlighted that the RSM fitted to results based on the FFS is linear whereas that fitted based on LHS could be either linear or quadratic, which increases the accuracy of the fitted RSMs. For these simulations, the Multiple Realization Optimizer (MEPO) software has been used to link different stages of the simulations conducted using ECLIPSE100 automatically and to perform pre and post-processing stages. MEPO (Schlumberger, 2013) is a software to design, perform and post-process many simulations' runs in different simulation engines. MEPO utilises powerful run management and provides faster results more efficiently. MEPO utilises Python script to perform the pre and post-processing stages. Hence a new computer code using the Python Programming Language (Python Software Foundation, 2013) was also developed. MFHW Nf7 L600m base reference sets with different run numbers were conducted and analysed to obtain the minimum (optimum) number of runs required for the LHS approach.

The results of this new approach with LHS MFHWs with the original MFHW base reference set were compared. The results indicated that using LHS, with fewer run numbers, retained the main trends in tornado charts whilst reducing CPU time. It also ensures achieving more accurate predictions for GPLs using both fitted linear and quadratic response 
methods as it will be shown in section 3.4.1. Finally, the different number of runs for LHS were compared to obtain the minimum number of runs with a reasonable error.

\subsubsection{Latin Hypercube Sampling (LHS)}

McKay et al. (1979) were the first to introduce Latin hypercube sampling (LHS). As a mathematical and statistical method, LHS creates a sample of possible groups of variable quantities. The LHS method is widely used to reduce the number of runs and CPU time. LHS is based on optional dimensions' numbers, by which each sample is unique in each axisaligned hyperplane.

In this approach and during the creation of a sample collection of a function of $n$ parameters, the variation range of each parameter is divided into $\mathrm{m}$ intervals in which their probability are equal. $\mathrm{M}$ sample points are then located in $\mathrm{m}$ intervals to satisfy the conditions of the Latin hypercube. This equally spaced interval sampling technique is the key advantage of LHS sampling compared to other sampling approaches. Another benefit of LHS is that random samples can be taken one at a time, while it remembers what samples have been taken up to now.

\subsubsection{MEPO Multiple Realization Optimizer}

MEPO (Schlumberger, 2013) was used in this study because this software enables the user to choose between different sampling approaches, i.e., Latin Hypercube, full factorial design, fractional factorial, Plackett-Burman and OVAT. On the other hand, In order to conduct the LHS approach, the MEPO software was used. MEPO is a suitable software to design, perform and post-process many simulation runs in different simulation engines. The MEPO multiple realisation optimiser utilises a robust run management arrangement and allows the user to attain faster results with relative ease.

In the previous MATLAB code, the results for each simulation run were read and exported to an excel file (or a text-file) for each run, i.e., in addition to the simulation run done by Eclipse, pre and post-processing were performed at the end of each run by MATLAB. However, in MEPO, the results are stored, and at the end, the results of all runs could be exported once into an excel-file. Additionally, the post-processing stage is faster using MEPO, and this also results in less CPU time compared to the previous MATLAB code. 


\subsubsection{Python Programming Code}

475

476

477

478

479

480

481

482

483

484

485

486

487

488

489

490

491

492

493

494

495

496

497

498

499

500

501

502

503

504

Python (Python Software Foundation, 2013) has been used in this study since MEPO performs pre- and post-processing using Python scripts. Hence, a new Python code has been developed to generate include-files for each run. Python is an excellent language for programming, which has effective complex data structures and a simple but efficient tactic to object-oriented programming. Python's stylish syntax and dynamic typing make it an impeccable language for scripting and swift application development in many subjects on most platforms. The Python interpreter also allows it to be implemented in $\mathrm{C}$ or $\mathrm{C}++$ or other languages callable from $\mathrm{C}$.

\subsection{New MFHW sets Using MEPO and LHS (MFHW-Sets 23 to 29 Nf7 L600m \& Base} Reference Set)

In this section, the results of MFHW Nf7L600m base reference set (i.e. MFHW-Set 8) rerun with different run numbers using the LHS approach are discussed. The first aim for running MFHW Nf7L600m base reference set using LHS was to conduct a sensitivity analysis on run numbers and to decrease the required number of runs and consequently to reduce the CPU time. The second aim was to increase the accuracy of the fitted response surface models. MFHW Nf7L600m base reference set was conducted with different run numbers of 4096, 3000, 2000, 1000, 500, 250 and 100 using the LHS approach. Here, the results of these sets and those of the original two-level full factorial MFHW Nf7L600m base reference set are analysed and compared with each other, and a comprehensive error analysis is conducted to obtain the optimum (minimum) required number of runs. Finally based on the error analysis, the most accurate response surface model (full quadratic surface model) is selected. For the new MFHW sets, which are based on the LHS experimental design approach, in order to have a consistent assessment with results reported previously, the impact of individual parameters in the tornado charts, are still studied based on the linear surface model without interaction.

Here the tornado chart of MFHW-set 23 Nf7 L600m Base Reference set using LHS with 4096 run numbers (Figure 11) with that of the two-level full factorial sampling (FFS) MFHW-Set 8 Nf7 L600m Base Reference set (Figure 10) with the only difference being different sampling approaches is compared. The same trend is observed in both tornado 
505

506

507

508

509

510

511

512

513

514

515

516

517

518

519

520

521

522

523

524

525

526

527

528

529

530

531 used to compare the results which are presented in Table 5.

$$
\text { RMSE }=\sqrt{\frac{\sum_{\mathrm{i}=1}^{\mathrm{n}}\left[G P L_{\text {predict }}-\mathrm{GPL}_{\text {sim }}\right]^{2}}{\mathrm{n}}}
$$

532

$$
\text { relative RMSE } \%=\frac{\text { RMSE }_{\mathrm{i}}-\mathrm{RMSE}_{\text {run number of } 4096}}{\mathrm{RMSE}_{\text {run number of } 4096}} * 100
$$


Table 6 list the RMSE and also relative RMSE\% for different run numbers using LHS and FFS. It is noted in Table 6 that IRSMs fitted to MFHW set using LHS approach with different run numbers predict GPL results more accurately than the relevant ILRSM using two-level FFS (except for LHS with run number 100). This observation suggests that generally, ILRSMs fitted to LHS runs predict GPLs better compared to those GPLs predicted by ILRSMs fitted to the data obtained using two-level FFS.

Figure 14 shows RMSE of ILRSMs versus run numbers for MFHW Nf7 L600m Base Reference sets with different sampling approaches, i.e., LHS, and two-level FFS. From Figure 14 in addition to the observation of having more accurate results for LHS runs, it is also noted that as the run numbers are decreased (below 1000), there is a significant increase in RMSE at all three production stages. This observation suggests that decreasing run numbers to values less than 500 (i.e., 250 and 100) result in less accurate ILRSMs and consequently higher RMSEs compared to larger run numbers. This finding is in agreement with what was formerly indicated in histogram charts, i.e., decreasing run numbers to the value of 250 and 100 resulted in less consistent charts than the ones for larger run numbers. Therefore, based on these results 1000 is considered the optimum number of runs.

\subsubsection{Error Analysis of Pure and Full Quadratic Response Surface Models}

The main reason to conduct this error analysis for different run numbers using LHS approach in addition to that presented in the previous section is to investigate the accuracy of pure quadratic response surface models (PQRSM), and full quadratic response surface models (FQRSM) fitted to LHS results.

In order to evaluate the reliability of these two models, the RMSE and relative RMSE of predicted GPL values of the MFHW set with different run numbers (run numbers of 4096, 3000, 2000, 1000, 500, 250 and 100) using fitted PQRSM and FQRSM have been calculated.

Table 6 and Table 7 show RMSE and relative RMSE\% of PQRSMs and FQRSMs fitted to the results of MFHW set using LHS approach with different run numbers. It is noted that the error of the predicted GPL values by FQRSM fitted to GPL values are less than the relevant ones for the predicted GPL values by PQRSM. In other words, the fitted FQRSMs predict the GPL values more accurately than the fitted PQRSMs except for the set with 100 run numbers.

563 For this latter case, more significant errors in predicted GPL values by FQRSMs compared to 564 the same GPL values predicted by PQRSMs is observed. That is because for FQRSMs, 91 surface model coefficients are calculated based on just 100 data points whereas, for 
PQRSMs, just 25 surface model coefficients are calculated based on the same 100 data points, therefore using 100 as the number of data points to fix a large number of the FQRSMs' coefficients is not desirable. These results confirm that FQRSM with a larger number of coefficients predict GPL more accurately if the number of data points is larger than 100 .

Figure 15 show RMSE of ILRSM, PQRSM and FQRSM models versus run numbers for MFHW Nf7 L600m Base Reference sets with different sampling approaches, i.e., LHS and two-level FFS. From Figure 15 it is noted that the two-level FFS design is the least accurate sampling design and FQRSM is the most accurate design. It also indicates that the accuracy of the models with interaction terms (i.e. ILRSMs and FQRSMs with 79 and 91 coefficients, respectively) decreases significantly in small run numbers (i.e., 100 and 250) due to very few data points.

These results suggest that generally, LHS approach is a more realistic and reliable approach compare to two-level FFS design. Using LHS with optimum run numbers compared to two-level FFS sets reduces the CPU time significantly. The response surface model which best-predicted GPL values was FQRSM; in other words, FQRSM best describes the real physics of clean-up performance. The optimum (minimum) required a number of MFHWNf7L600 runs for FQRSMs was 1000 run numbers. Consequently, in the following simulation sets, LHS approach was used to increase the accuracy of the simulation while decreasing the CPU time.

\subsection{Impact of Number of Hydraulic Fractures}

\subsubsection{Fixed horizontal well length}

In this section, the results of MFHW-Set 1, MFHW-Set 8, MFHW-Set 12 and MFHW-Set 13 with three, seven, nine and thirteen fractures placed on the same horizontal length of 600 $m$ respectively are discussed to evaluate the effect of fracture spacing. In these sets, the fracture spacing decreased from 300 in MFHW-Set 1 to 100, 75 and $50 \mathrm{~m}$ in MFHW-Set8 (MFHW Nf7 L600 set), MFHW-Set12 (MFHW Nf9 L600 set) and MFHW-Set13 (MFHW Nf13 L600 set) respectively. For these sets, new models were set-up, and the Python code was modified accordingly.

Comparing the tornado chart of MFHW-Set1 (Figure 4) and those of these new MFHW sets, i.e. MFHW Nf7 L600 set (Figure 11), MFHW Nf9 L600 sets (Figure 16) and MFHW 
parameters are almost alike indicating that fracture spacing does not affect the cleanup efficiency of MFHWs. This similarity is extended to the effect of $\mathrm{k}_{\mathrm{m}}$. That is, in all MFHW sets, with a different number of fractures (Nfs) and thereby different FF injected volume, the effect of $\mathrm{k}_{\mathrm{m}}$ on Pc is still more dominant than that on fluid flow.

Figure 18 shows the swiftness of cleanup operation for the following sets, MFHW-Set1 (MFHW Nf3 L600), MFHW-Set8 (MFHW Nf7 L600), MFHW-Set12 (MFHW Nf9 L600) and MFHW-Set13 (MFHW Nf13 L600). It is noted that generally minimal differences are observed when changing Nf from 3 to 13. This observation again reconfirms that the change in fracture spacing does not affect the cleanup efficiency of MFHWs.

608

\subsubsection{Fixed Fracture spacing}

A new model was set-up with ten $90 \mathrm{~m}$ fractures placed on the $900 \mathrm{~m}$ horizontal well length to capture the impact of horizontal well length on the cleanup efficiency of MFHWs when fracture spacing is the same. Here, the fracture spacing is the same as the one for MFHW-Set8 (MFHW Nf7 L600 set) but with longer horizontal length to accommodate ten fractures.

Comparing the tornado chart for MFHW-Set8, Figure 11, with that of MFHW-Set 14,

616 Figure 19, shows a similar trend and values for coefficients of different parameters for these 617 cases. Minimal differences are noted between MFHW-Set8 (MFHW Nf7 L600 and MFHW618 Set14 (MFHW Nf10 L900) in Figure 20. These results confirm that the impact of the number 619 of fractures on the cleanup efficiency, even when the fracture spacing is the same, is small. It 620 should be noted that for any of these sets the amount of gas production is different highlighting the impact of the number of fractures on production. However, the GPL ratio seems to be the same

\subsection{Increased FVR MFHW-Set 2}

In MFHW-Set 2, the fracture volume ratio has been raised from 2 in the MFHW-set1 to 5. Once the tornado chart of MFHW-Set 2, Figure 21a, is compared with that of MFHW-Set 1 $(\mathrm{FVR}=2)$ with the only difference being a higher FVR for MFHW-Set 2, Figure 4, It is observed that the trends are more or less the same.

The $\mathrm{k}_{\mathrm{f}}$ in both cases has the most substantial effect on GPL, and the sequences of the 630 significance of other parameters are reasonably similar. If the high FVR MFHW set is 
632 observed for all parameters except for $\mathrm{k}_{\mathrm{m}}$, which has been discussed earlier (Figure 21b). It is

633 also noted that Pc pertinent parameters are more critical in the MFHW set whilst endpoints

634 and exponents of Corey type relative permeability curves for gas and FF in both matrix and

635 frack are more critical in the VW set. These observations are due to the fact that FF

636 production has a more detrimental effect on gas production in the MFHW set due to smaller

637 area perpendicular to flow at the wellbore (also known as near wellbore choking effect).

638 Hence for the MFHW set the effect of flow from the matrix towards fracture during the

639 backflow clean-up is less important and rather imbibition of fracture fluid governed by matrix

640 capillary pressure, which depends on $\mathrm{k}_{\mathrm{m}}$ is more important. This trend was observed for all

641 MFHW sets presented in this exercise.

642 Similar to what was reported previously (Nasriani and Jamiolahmady, 2018a) for the VW 643 sets, faster clean-up is observed for the MFHW base reference set compared to the MFHW 644 FVR=5. This observation is due to less FF injected in the MFHW base reference set, which 645 requires less time to clean.

646

\subsection{Extended ST MFHW-Set 3}

648 In MFHW-Set 3, the soaking time (ST) has been extended from 2 days in the MFHW-set1 649 to 20 days. Considering the impact of the 12 parameters in two sets of MFHW-Set 3 (ST=20) 650 and MFHW-Set 1 (ST=2) with the only difference being a longer soaking time for MFHW651 Set 3), the same observation is noted as that of (Nasriani and Jamiolahmady, 2018a) for VW 652 sets, i.e., the observed magnitude and trends of all pertinent parameters are more or less the 653 same. However, the absolute value of Pc Pertinent parameters, i.e. IFT and $\lambda$, are larger than 654 those of MFHW-Set 1, confirming the observation reported for the VW sets that extending 655 soaking time makes the impact of Pc on production loss to be more significant (Nasriani and 656 Jamiolahmady, 2018a).

657 Faster clean-up was observed for the extended ST MFHW set compared to the MFHW 658 base reference set, but only at early production times, the same observation as the one 659 observed for VWs (Nasriani and Jamiolahmady, 2018a).

660 
In this section, the variation range corresponding to $\mathrm{k}_{\mathrm{m}}$ has been reduced from $1 \mu \mathrm{D}-100$ $\mu \mathrm{D}$ in the MFHW-set 1 to $0.1 \mu \mathrm{D}-10 \mu \mathrm{D}$ and $0.01 \mu \mathrm{D}-1 \mu \mathrm{D}$ in MFHW-Sets $4 \& 7$ respectively.

If the tornado charts of MFHW-Set $4(\mathrm{KMR}=10)$, Figure 22 , is compared with that of

666

667

668

669

670

671

672

673

674

675

676

677

678

679

680

681

682

683

684

685

686

687

688

689

690

691

692

693

694 MFHW-Set $1(\mathrm{KMR}=1)$ with ten times tighter formation for MFHW-Sets 4, Figure 4, it is noted that the observed trends are the same except for the $\mathrm{k}_{\mathrm{m}}$ coefficient. That is, in this MFHW-Set with the tighter formation, the first effect of $k_{m}$ on GPL (i.e. a rise in matrix permeability that advances fluid mobility and lessens GPL) is dominant whilst in MFHW-Set 1 the second effect (i.e. a rise in $\mathrm{k}_{\mathrm{m}}$ that decreases Pc and raises GPL) was dominant. Since in this tighter set, i.e., MFHW-Set 4 , the $\mathrm{k}_{\mathrm{m}}$ range has been reduced by a factor of 10 , Pc is already high enough, and hence the impact of $\mathrm{k}_{\mathrm{m}}$ on mobility is more significant.

If MFHW-Set 4 is compared with the corresponding VW set, VW-Set 4, the same observation as that highlighted in previous sets, is noted.

When the tornado chart of MFHW-Set $7(\mathrm{KMR}=100)$, Figure 23, is compared with that of MFHW-Set $1(\mathrm{KMR}=1)$, Figure 4, it is observed that the trends of impact pf all parameters are the same except for the $\mathrm{k}_{\mathrm{m}}$ and IFT coefficients. In this very tight formation, the first effect of $\mathrm{k}_{\mathrm{m}}$ on GPL (i.e. if $\mathrm{k}_{\mathrm{m}}$ increases that results in an improvement in the mobility of the fluid and consequently reduction in GPL) is dominant. Conversely, in MFHW-Set 1 the second effect (i.e. if $\mathrm{k}_{\mathrm{m}}$ increases that decreases Pc and accordingly an increase in GPL) is dominant. This is the same observation as that in MFHW-Set 4 with $\mathrm{k}_{\mathrm{m}}$ range decreased by a factor of 10. Since in the current MFHW-Set 7, the range of $k_{m}$ has been decreased 100 times smaller; now it is significantly more difficult for fluid to flow in the matrix; hence the effect of $\mathrm{k}_{\mathrm{m}}$ on mobility is more important. Figure 23 shows that the value of the $\mathrm{k}_{\mathrm{m}}$ coefficient is almost -1 at all production periods (in MFHW-Set 4, Figure 22, the value of $\mathrm{k}_{\mathrm{m}}$ was almost 0.1 ) indicating that as the formation gets tighter the first effect of $k_{m}$ on GPL is most pronounced.

It is noted that in MFHW-Sets 7, the IFT coefficient trend changes as production time increases. This highlights that using IFT reducing agent could improve the cleanup efficiency. This observation will be discussed in details in Section 3.8, 3.9 \& 3.10.

Slower clean-up was observed for the tighter formations MFHW-Set 4 \& 7 (MFHW with $\mathrm{KMR}=10$ \&100) compared to the MFHW-set1 using histogram charts. It shows the same observation similar to what was reported previously for the VW sets (Nasriani and Jamiolahmady, 2018a). 


\subsection{MFHW-Sets with different DP values}

697

698

In this section, DP has been changed from the default value in MFHW base reference set (1000 psi) to 100 and 4000 psi in MFHW-Sets 5 \& 6 respectively.

Considering the impact of the 12 parameters in two sets of MFHW-Set 5 (DP=100),

701

702

703

704

705

706

707

708

709

710

711

712

713

714

715

716

717

718

719

720

721

722

723

724

725

726

727

Figure 24, and that of MFHW-Set $1(\mathrm{DP}=1000)$ with the only difference being a lower DP by a factor of 10 for MFHW-Set 5, Figure 4, it is interesting to note that the observed trends of pertinent parameters are the same with the exception of an increase in the absolute value of Pc pertinent parameters. This observation is in line with what was reported previously for low DP VW sets, i.e., in low DP sets the influence of Pc on GPL is more pronounced (Nasriani and Jamiolahmady, 2018a).

In MFHW-Set 5, the impact of the endpoints and exponents of Corey type relative permeability curves for the fluid in the porous medium of the rock is more important than that of these parameters in MFHW-Set 1 confirming the observation noted in the corresponding VW sets. That is, in low DP sets, it is more important how fluid (Gas and FF) flows from the matrix to fracture than how it flows from fracture to the wellbore. Figure 24 shows a small negative value for the $\mathrm{k}_{\mathrm{m}}$ coefficient after ten days indicating that at this period the effect of $\mathrm{k}_{\mathrm{m}}$ on GPL is minimal, but due to its negative sign, it could be concluded that the first influence of $\mathrm{k}_{\mathrm{m}}$ on production loss is more dominant.

In MFHW-Set 6, DP was increased 4 times larger (4000psi) than its base value (1000pasi). When the results of these two sets were compared it was observed that the trends of pertinent parameters are more or less similar except for a drop in the magnitude of Pc pertinent parameters. This observation is in line with what was reported previously for high DP VW sets, i.e., in high DP sets the weight of Pc on production improvement was less pronounced (Nasriani and Jamiolahmady, 2018b; Nasriani et al., 2018).

The impact of the endpoints and exponents of Corey type relative permeability curves for fluid in the matrix was also less distinct than that of these parameters in MFHW-Set 1, this confirms the observation noted in the VW sets, that is, in high DP sets it is less important how fluid (Gas and FF) flows from the matrix to fracture than how it flows from fracture to the wellbore. This follows the same trend as what was observed above for the low DP set, MFHW DP=100 (MFHW-Set 5). Slower/faster clean-up was observed for this lower/higher DP set compared to the MFHW base reference set. 


\subsection{MFHW-Sets with $\mathrm{Nf7}$ and $\mathrm{L600m}$ with different $\mathrm{k}_{\mathrm{m}}$ ranges}

Following the IFT trend change which was observed in Section 3.8 for MFHW-Set 7 with three fractures, three different MFHW-Sets (with $\mathrm{Nf}=7$ rather than sets with $\mathrm{Nf}=3$ discussed in section 3.8) with different $\mathrm{k}_{\mathrm{m}}$ ranges were studied. For this purpose, the range of $\mathrm{k}_{\mathrm{m}}$ was dropped from $1 \mu \mathrm{D}-100 \mu \mathrm{D}$ in the MFHW-Set8 Nf7 L600 base reference set to $0.1 \mu \mathrm{D}-10 \mu \mathrm{D}$ and $0.01 \mu \mathrm{D}-1 \mu \mathrm{D}$ in MFHW-Set9 and MFHW-Set10, respectively.

Analysis of the impact of the 12 parameters in three sets of MFHW-Set $8(\mathrm{KMR}=1)$, Figure 11, MFHW-Set9 (KMR=10), Figure 26, and MFHW-Set10 (KMR=100), Figure 27 , shows that the trends of most of the parameters are more or less the same, including the trend of the $\mathrm{k}_{\mathrm{m}}$ coefficient. However, in MFHW-Set10, $\mathrm{k}_{\mathrm{m}}$ is the most critical parameter at 30 and 370 days and the second most crucial parameter after $\mathrm{k}_{\mathrm{f}}$ at ten days. That is because, in the current set, MFHW-Set10, $\mathrm{k}_{\mathrm{m}}$ range has been reduced by a factor of 100 , the mobility of different fluids in the matrix becomes very vital. If one compares the fluid mobility pertinent parameters in MFHW-Set8, MFHW-Set9 and MFHW-Set10, it is noted that fluid mobility within the matrix of the rock is more/most significant in tighter/tightest formations $(\mathrm{KMR}=10 / \mathrm{KMR}=100)$, i.e., the tighter the formation, the more important the effect of fluid mobility on clean-up efficiency.

From the data of Figure 27, it is also observed that the trend of IFT coefficient has changed from negative in MFHW-Set $8(\mathrm{KMR}=1)$ and MFHW-Set9 $(\mathrm{KMR}=10)$ to positive in the tightest set (MFHW-Set10 $(\mathrm{KMR}=100))$. Since this trend change of IFT could have an impact on Pc, therefore it is essential to study the impact of Pc on the cleanup performance in this section for these three MFHW-Sets. Capillary pressure of these three MFHW-Sets was calculated by choosing the corresponding values of IFT, $\mathrm{k}_{\mathrm{m}}$ and $\lambda$ for the worst (maximum GPL) and best (Minimum GPL) case scenarios from the corresponding tornado charts in addition to Equations 1 and 2. The calculated Pc data for these three MFHW-Sets shows that in this set, MFHW-Set10, the magnitude of the Pc value for the worst case is considerably larger than that of the best case whereas, in MFHW-Set8 and MFHW-Set9, the Pc value of the best case is higher than that of the worst case. This observation highlights that in MFHWset 8 and MFHW-set-9, it is recommended to retain the FF within the matrix employing higher capillary pressure, however in the tightest formation set, MFHW-Set10, it is recommended to flowback the FF as much as possible and minimise the FF saturation in the matrix. This is attributed to very tight nature of the formation (in MFHW-Set10) in which 
760

761

762

763

764

765

766

767

768

769

770

771

772

773

774

775

776

777

778

779

780

781

782

783

784

785

786

787

788

789

790

791

792

keeping the FF in the matrix has a more harmful impact on production than its adverse effect once it is produced through the fracture.

Figure 28 shows Pc versus water saturation, Sw, for those sets above (MFHW-Set8, MFHW-Set9 and MFHW-Set10). It is demonstrated that higher Pc values were observed for the best case than the worst case at all water saturation values in Sets MFHW-Set8 and MFHW-Set9 (indicating that keeping FF in the matrix is better and results in less GPL). Conversely, higher Pc values were observed in MFHW-Set10 for the worst case than the best case at all water saturation values (it is best to reproduce the injected FF from the matrix). In other words, in MFHW-Set 10, contrasting the previous two sets, using chemicals agents to reduce IFT and consequently decreasing Pc could lessen GPL.

According to the results of these three sets (MFHW-Set 8, MFHW-Set 9 and MFHW-Set 10), matrix permeability plays a vital role in hydraulic fracturing design. For those sets with $\mathrm{k}_{\mathrm{m}}$ variation $1 \mu \mathrm{D}-100 \mu \mathrm{D}$ and $0.1 \mu \mathrm{D}-10 \mu \mathrm{D}$, using IFT reducing agents will have a detrimental impact on the production and consequently increases GPL. Conversely, in very tight sets with matrix permeability variation $0.01 \mu \mathrm{D}-1 \mu \mathrm{D}$, it is recommended to use IFT reducing agents in order to decrease Pc and consequently reduce GPL.

All these runs were at moderate DP of 1000 psi. In order to confirm that this observation is also valid at low and high DP values, six new MFHW-Sets were conducted.

Three new sets (MFHW-Set15 Nf7-L600m DP4000, MFHW-Set17 Nf7-L600m KMR10 DP4000 and MFHW-Set19 Nf7-L600m KMR100 DP4000) were conducted to capture the effect of $k_{m}$ at high DP=4000 psi. The $k_{m}$ range is $1 \mu \mathrm{D}-100 \mu \mathrm{D}$ in MFHW-Set15, $0.1 \mu \mathrm{D}-10$ $\mu \mathrm{D}$ in MFHW-Set17 and $0.01 \mu \mathrm{D}-1 \mu \mathrm{D}$ MFHW-Set19 with DP=4000 psi in all of these sets.

A comparison of the tornado charts of these sets, Figure 29, Figure 30 and Figure 31, shows that $\mathrm{k}_{\mathrm{f}}$ is the most important parameter affecting GPL for all three sets at all production periods. Other fluid mobility parameters in the fracture $\left(\mathrm{k}_{\operatorname{maxwf}}, \mathrm{k}_{\operatorname{maxwf}}, \mathrm{n}_{\mathrm{wf}}\right.$ and $\left.\mathrm{n}_{\mathrm{gf}}\right)$ are the second most important set of parameters affecting GPL for MFHW-set15 and MFHW-set17 at all production periods and the third most important parameter for MFHW-set19. As the $\mathrm{k}_{\mathrm{m}}$ variation range is 10 and 100 time reduced in MFHW-set17 and MFHW-set19, the impact of $\mathrm{k}_{\mathrm{m}}$ and fluid mobility in the matrix become progressively more important. This is because, in tighter (tightest) formation, the fluid flow through the matrix becomes more (most) challenging.

Figure 31 shows that the trend of IFT has changed in MFHW-set19 compared to the other two sets. In order to fully understand the effect of Pc in these sets, the same approach as the 
one conducted for the three previous sets, i.e., MFHW-set8, $9 \& 10$, was followed by preparing the corresponding Pc values versus $\mathrm{Sw}$ for the best/worst scenarios, Figure 32.

Data in this Figure confirms that for those sets with KMR of 1 and 10, having higher Pc, corresponding to the best case scenario, is more favourable and application of IFT reducing agents will increase GPL. Contrariwise, whilst in the very tight set $(\mathrm{KMR}=100)$ with higher $\mathrm{Pc}$ for the best case scenario, it is recommended to use such chemicals in order to diminish Pc and consequently minimise GPL.

Following the results of the previous sets with moderate and high DP, here in MFHW-Sets with $\mathrm{DP}=100$ psi in all of these sets.

The tornado charts of these three low DP sets, i.e., Figure 33, Figure 34 and Figure 35, and their Pc plots versus Sw for the best/worst cases of these sets (Figure 36) show the same results as the ones observed in high and moderate DP.

Comparing the results of all 9 sets (with different DPs and $\mathrm{K}_{\mathrm{m}}$ ranges) confirms that regardless of DP, for those MFHW sets with $k_{m}$ ranges of $1 \mu \mathrm{D}-100 \mu \mathrm{D}$ and $0.1 \mu \mathrm{D}-10 \mu \mathrm{D}$, the application of IFT reducing agents will raise GPL whilst in very tight sets with the $\mathrm{k}_{\mathrm{m}}$ range of $0.01 \mu \mathrm{D}-1 \mu \mathrm{D}$ it is recommended to use such additives to diminish Pc and consequently minimize GPL. Specifically, it is best to retain FF in the matrix in sets with $\mathrm{k}_{\mathrm{m}}$ ranges of $1 \mu \mathrm{D}-100 \mu \mathrm{D}$ and $0.1 \mu \mathrm{D}-10 \mu \mathrm{D}$. However, the positive effect of retaining FF in the matrix weakens in sets with the $\mathrm{k}_{\mathrm{m}}$ range of $0.1 \mu \mathrm{D}-10 \mu \mathrm{D}$ compared to the sets with the $\mathrm{k}_{\mathrm{m}}$ 814 range of $1 \mu \mathrm{D}-100 \mu \mathrm{D}$. In fact, in sets with the tightest formations, i.e., $\mathrm{k}_{\mathrm{m}}$ range of $0.01 \mu \mathrm{D}-1$ $\mu \mathrm{D}$, this trend becomes opposite, i.e., it is best to backflow the FF. In other words, it is observed that using IFT reducing agents as an additive in fracturing fluid is not recommended for tight formations (it reduces the gas production rate) whilst it is highly recommended to use such agents for ultratight formations (it enhances the gas production rate).

819 If the tornado charts of the three low DP sets (Figure 33, Figure 34 and Figure 35) are 820 compared with the relevant high DP sets (Figure 29, Figure 30 and Figure 31), it is noted that 821 fluid mobility pertinent parameters $\left(\mathrm{k}_{\operatorname{maxgm}}, \mathrm{n}_{\mathrm{gm}}, \mathrm{k}_{\operatorname{maxwm}}\right.$ and $\left.\mathrm{n}_{\mathrm{wm}}\right)$ in the matrix are more 822 important at low DP sets compared to the relevant ones in high DP sets. This is because as 823 DP decreases, fluid mobility within the matrix becomes more critical and consequently have a more significant impact on the GPL reduction. 


\section{Conclusions}

827 Following the extensive investigation on clean-up efficiency of VWs, this study has 828 extended the previous work (Nasriani et al., 2018; Nasriani and Jamiolahmady, 2018a) to MFHWs systems.

830 A summary of the main conclusions is given below:

831 1. The results of VW and MFHW base reference sets which had similar properties were compared.

a. The $\mathrm{k}_{\mathrm{m}}$ trend in the MFHW base reference set was different from that in the VW Set. It was shown that this $\mathrm{k}_{\mathrm{m}}$ trend change (from having a negative to a positive coefficient value) in the MFHW set was due to the flow geometry change and how the well was completed.

b. It was noted that Pc pertinent parameters were more important in the MFHW sets whilst endpoints and exponents of Corey type relative permeability curves for gas and FF in both matrix and the fracture were more important in the VW sets.

i. This observation suggests that FF production had a more detrimental effect on gas production in the MFHW set. In other words, having a higher Pc that results in more FF to be further imbibed into the matrix and less resistance to the gas flow, is more important in MFHWs.

c. Faster clean-up was observed for MFHW compared to VW. This was due to having a higher production rate in MFHW sets.

d. In Reduced (increased) DP MFHW sets, slower (faster) clean-up was observed; this is similar to what was previously reported for the corresponding VW sets

2. In the reduced matrix permeability range MFHW sets, the first effect of $k_{m}$ on GPL (i.e. a rise in $\mathrm{k}_{\mathrm{m}}$ increasing the fluid mobility and diminishing GPL) was dominant (i.e. $\mathrm{k}_{\mathrm{m}}$ coefficient was negative). Conversely, in MFHW-Set 1 (MFHW base reference set) the second effect (i.e. a rise in $\mathrm{k}_{\mathrm{m}}$ value, diminishing Pc and escalate GPL) was dominant (i.e. positive $\mathrm{k}_{\mathrm{m}}$ coefficient).

3. In low (high) DP MFHW sets, Pc has a stronger (weaker) impact on GPL. This trend is similar to what was previously reported for the corresponding low (high) DP VW sets. 
4. .Increasing horizontal well length while the fracture spacing was fixed did not change the fracture clean-up efficiency at all.

5. Slower clean-up is observed for the tight and ultratight formations compared to the base reference set due to a lower production rate of the tightest (and tighter) formation resulting in a slower and less efficient clean-up.

6. Regardless of pressure drop, for the MFHW sets with matrix permeability variation ranges of $1 \mu \mathrm{D}-100 \mu \mathrm{D}$ and $0.1 \mu \mathrm{D}-10 \mu \mathrm{D}$, the application of the IFT reducing agents will intensify GPL whilst in ultratight sets (i.e., $\mathrm{k}_{\mathrm{m}}$ range of $0.01 \mu \mathrm{D}-1 \mu \mathrm{D}$ ), it is recommended to use such chemicals to weaken Pc and consequently diminish GPL.

a. In other words, it is concluded that using IFT reducing agents as an additive in fracturing fluid is not recommended for tight formations (it reduces the gas production rate) whilst it is highly recommended for ultratight formations (it enhances the gas production rate).

7. Although the impact of fracture interference/fracture spacing on flow is significant, its impact on clean-up performance is minimal in MFHWs systems with different fracture spacing.

8. In this study, a new sampling approach (Latin Hypercube Sampling (LHS) method) is introduced and the results were compared with the full factorial sampling approach.

a. The results of MFHW sets with LHS suggest that generally, LHS approach is a more realistic and reliable sampling approach compared to the two-level FFS experimental design.

b. Using LHS with an optimum run number (1000 run numbers) reduces the CPU time significantly compared to two-level FFS sets.

c. The response surface model, which best-predicted GPL values was FQRSM. In other words, FQRSM describes the real physics of clean-up performance better. 


\section{Acknowledgements}

886 The above study was conducted as a part of the Gas-condensate Recovery Project at Heriot-

887 Watt University. This research project is sponsored by Daikin, DongEnergy,

888 Ecopetrol/Equion, ExxonMobil, GDF, INPEX, JX-Nippon, Petrobras, RWE, Saudi-Aramco and TOTAL, whose contribution is gratefully acknowledged.

890

\section{Nomenclature}

892 k absolute reservoir permeability

$893 \mathrm{k}_{\max }$ end point of the Corey relative permeability formula

$894 \mathrm{P} \quad$ pressure

895 Pc capillary pressure

896 S saturation

$897 \mathrm{n} \quad$ exponent of the Corey relative permeability formula

$898 \quad \mathrm{x} \quad \mathrm{x}$-direction

899 y $\quad$ y-direction

$900 \quad \mathrm{z} \quad$ z-direction

901

\section{Subscript}

$903 \mathrm{~g}$ gas

904 w water

$905 \mathrm{r} \quad$ residual

$906 \mathrm{f} \quad$ fracture

907 m matrix

\section{Abbreviations}

909 CPU Central Processing Unit

910 DP Pressure drawdown

911 FF fracture fluid

912 FFS full factorial sampling

913 FGPT total gas cumulative production

914 FVR the ratio of injected fracture fluid to fracture volume

915 FQRSM Full Quadratic Response Surface model

916 GPL gas production loss

917 HF Hydraulic Fracturing

918 ILRSM linear response surface model with interaction

919 IFT interfacial tension

920 KMR Matrix Permeability Ratio, i.e., if $\mathrm{KMR}=10$ mean the $\mathrm{k}_{\mathrm{m}}$ variation range is reduced by factor

921 of 10

922 LHS Latin Hypercube Sampling

923 LRSM linear response surface model

924 MEPO Multiple Realization Optimizer

925 MFHW Multiple Fractured Horizontal Well

926 PQRSM Pure Quadratic Response Surface model

927 RMSE The root means square error

928 RSM Response Surface Methodology

929 ST Shut-in/Soaking time

930 VW Vertical Well

931 
932

933

934

935

936

937

938

939

940

941

942

943

944

945

946

947

948

949

950

951

952

953

954

955

956

957

958

959

960

961

962

963

964

\section{References}

Brooks, R.H., Corey, A.T., 1966. Properties of porous media affecting fluid flow. J. Irrig. Drain. Div. 92, 61-90.

Brooks, R.H., Corey, A.T., 1964. Hydraulic properties of porous media.

Clark, J.B., 1949. A Hydraulic Process for Increasing the Productivity of Wells. J. Pet. Technol. 1, 1-8. https://doi.org/10.2118/949001-G

Dong, Z., Holditch, S.A., McVay, D., Ayers, W.B., 2011. Global Unconventional Gas Resource Assessments. https://doi.org/10.2118/148365-MS

Economides, M.J., Martin, A.N., 2010. How to decide between horizontal transverse, horizontal longitudinal and vertical fractured completion, in: Proceedings - SPE Annual Technical Conference and Exhibition. pp. 2474-2491.

Garrison, A.D., 1945. Treatment of wells.

Gdanski, R.D., Weaver, J., Slabaugh, B., Walters, H., Parker, M., 2005. SPE 94649 Fracture Face Damage - It Matters. Water.

Ghahri, P., Jamiolahmady, M., Sohrabi, M., 2011. SPE 144114 A Thorough Investigation Of Cleanup Efficiency Of Hydraulic Fractured Wells Using Response Surface Methodology. https://doi.org/10.2118/144114-MS

Ghahri, P., Jamiolahmady, M., Sohrabi, M., 2009. Investigation of cleanup efficiency of hydraulically fractured wells in gas condensate reservoirs, in: 8th European Formation Damage Conference 2009 - New Technologies for Conventional and Unconventional Reservoirs. pp. 537-551.

Halliburton [WWW Document], 2018. . 125 W Missouri Midland, TX 79701. URL https://www.halliburton.com/en-US/ps/testing-subsea/reservoir-testinganalysis/calibr.html?node-id=i4msmulo

Height, B.C., 1944. Process of increasing permeability of sands and strata.

Holditch, S.A., 1979. Factors Affecting Water Blocking and Gas Flow From Hydraulically Fractured Gas Wells. https://doi.org/10.2118/7561-PA

Jamiolahmady, M., Alajmi, E., Nasriani, H.R., Ghahri, P., Pichestapong, K., 2014. A Thorough Investigation of Clean-up Efficiency of Hydraulic Fractured Wells Using Statistical Approaches. SPE Annu. Tech. Conf. Exhib. 27-29 October,. https://doi.org/10.2118/170862-MS

Jamiolahmady, M., Sohrabi, M., Ghahri, P., 2009. Investigation of Cleanup Efficiency of Hydraulically Fractured Wells in Gas Condensate Reservoirs. 
965

966

967

968

969

970

971

972

973

974

975

976

977

978

979

980

981

982

983

984

985

986

987

988

989

990

991

992

993

994

995

996

997

https://doi.org/10.2118/121916-MS

Lee, R.E., 1939. Method of treating a producing formation.

McKay, M.D., Beckman, R.J., Conover, W.J., 1979. A Comparison of Three Methods for Selecting Values of Input Variables in the Analysis of Output from a Computer Code. Technometrics 21, 239-245. https://doi.org/10.2307/1268522

Montgomery, K.T., Holditch, S.A., Berthelot, J.M., 1990. Effects of fracture fluid invasion on cleanup behavior and pressure buildup analysis, in: Proceedings - SPE Annual Technical Conference and Exhibition. pp. 279-290.

Nasriani, H.R., 2017. Cleanup efficiency of hydraulically fractured vertical and multiple fractured horizontal wells. Heriot-Watt University.

Nasriani, H.R., Jamiolahmady, M., 2018a. Maximizing fracture productivity in unconventional fields; analysis of post hydraulic fracturing flowback cleanup. J. Nat. Gas Sci. Eng. 52. https://doi.org/https://doi.org/10.1016/j.jngse.2018.01.045

Nasriani, H.R., Jamiolahmady, M., 2018b. A Comparison of Clean-Up Efficiency of Multiple Fractured Horizontal Wells and Hydraulically Fractured Vertical Wells in Tight Gas Reservoirs, in: SPE Europec Featured at 80th EAGE Conference and Exhibition. Society of Petroleum Engineers. https://doi.org/10.2118/190862-MS

Nasriani, H.R., Jamiolahmady, M., Alajmi, E., 2014a. An Integrated Study of Cleanup Efficiency of Short Hydraulic Fractured Vertical Wells Using Response Surface Methodology, in: 76th EAGE Conference and Exhibition 2014. https://doi.org/10.3997/2214-4609.20141380

Nasriani, H.R., Jamiolahmady, M., Alajmi, E., Ghahri, P., 2014b. A Study of Hydraulic Fracturing Clean-up Efficiency in Unconventional Gas Reservoirs Using Statistical Approaches, in: ECMOR XIV-14th European Conference on the Mathematics of Oil Recovery.

Nasriani, H.R., Jamiolahmady, M., Saif, T., Sánchez, J., 2018. A systematic investigation into the flowback cleanup of hydraulic-fractured wells in unconventional gas plays. Int. J. Coal Geol. 193. https://doi.org/10.1016/j.coal.2018.04.012

Pope, D., Britt, L.K., Constien, V., Anderson, A., Leung, L., 1996. Field Study of Guar Removal from Hydraulic Fractures. SPE Int. Symp. Form. Damage Control 1-7. https://doi.org/10.2118/31094-MS

Python Software Foundation, 2013. Python Programming Language, Python v2.7.6. Python Softw. Found. 
998 Schlumberger, 2013. MEPO Multiple Realization Optimizer; MEPO4.2.0; Build:2617;

999 Date:2013-Apr-25_15-59. SPT Group; A Schlumberger Co.

1000 Tech-Flo Consulting [WWW Document], 2019. . Tech-Flo Consult. | 9701 Pozos Ln, 1001 Conroe, TX 77303 | 494-4330. URL http://www.tech-flo.net/frac-flowback.html

1002 The MathWorks, 2013. MATLAB and Statistics Toolbox Release 2014b (8.4.0.150421).

$1003 \quad$ Natick Inc.

1004 Thomas, L.K., Katz, D.L., Tek, M.R., 1968. Threshold pressure phenomena in porous media. $1005 \quad$ Soc. Pet. Eng. J. 8, 174-184.

1006

1007

1008 
1009

\section{Tables}

1010

Table 1 VW model

1011

\begin{tabular}{|c|c|c|c|c|}
\hline $\mathbf{X}_{\mathbf{f}}(\mathbf{m})$ & $\mathbf{w}_{\mathbf{f}}(\mathbf{m})$ & $\mathbf{X r e s}(\mathbf{m})$ & $\mathbf{Y r e s}(\mathbf{m})$ & $\operatorname{Zres}(\mathbf{m})$ \\
\hline 100 or 400 & 0.004 & 2000 & 2000 & 40 \\
\hline
\end{tabular}

1012

1013

1014

1015

Table 2 The parameters' variation range

\begin{tabular}{|c|c|c|}
\hline Parameter & Min & Max \\
\hline $\mathrm{k}_{\mathrm{f}}(\mathrm{D})$ & 1 & 30 \\
\hline $\mathrm{k}_{\mathrm{m}}$ & $1 \mu \mathrm{D}$ & $100 \mu \mathrm{D}$ \\
\hline$\lambda$ & 1 & 4 \\
\hline $\mathrm{IFT}(\mathrm{mNm} / \mathrm{m})$ & 2 & 50 \\
\hline $\mathrm{n}_{\mathrm{gm}}$ & 1.5 & 5 \\
\hline $\mathrm{n}_{\mathrm{wm}}$ & 1.2 & 4 \\
\hline $\mathrm{k}_{\operatorname{maxg}}$ & 0.5 & 1.0 \\
\hline $\mathrm{k}_{\operatorname{maxw}}$ & 0.05 & 0.6 \\
\hline $\mathrm{n}_{\mathrm{gf}}$ & 1.5 & 5 \\
\hline $\mathrm{n}_{\mathrm{wf}}$ & 1.2 & 4 \\
\hline $\mathrm{k}_{\operatorname{maxg}}$ & 0.5 & 1.0 \\
\hline $\mathrm{k}_{\operatorname{maxw}}$ & 0.1 & 0.75 \\
\hline
\end{tabular}

1016 
1017 Table 3a VW Set analysed

\begin{tabular}{|c|c|c|c|c|c|c|c|c|c|c|c|c|c|c|c|c|}
\hline $\begin{array}{l}\stackrel{\mathscr{D}}{\&} \\
\underset{Z}{Z} \\
\stackrel{0}{0}\end{array}$ & 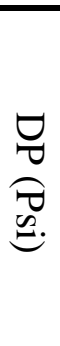 & $\sum_{\lambda}^{T}$ & 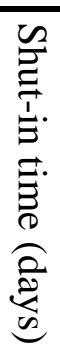 & 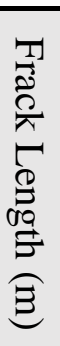 & 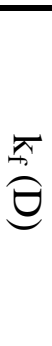 & $\overbrace{\tilde{\Xi}}^{\pi}$ & $\overrightarrow{\tilde{B}}$ & 雬 & $\underset{g}{\sigma a g}$ & है & $\begin{array}{c}\text { त्र̃ } \\
\text { 啇 } \\
\text { og }\end{array}$ & 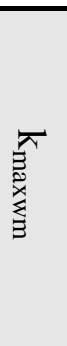 & 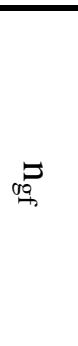 & 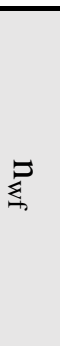 & 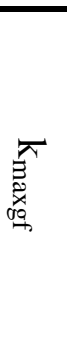 & 压 \\
\hline $\begin{array}{l}\text { Default } \\
\text { Values }\end{array}$ & 8 & $N$ & $N$ & 8 & ث̈ & $\frac{5}{8}$ & $\ddot{p}$ & $\stackrel{N}{\mathfrak{y}_{0}}$ & ú & $\stackrel{\vec{N}}{+}$ & í & $\begin{array}{l}0 \\
\dot{\gamma} \\
\text { bo } \\
0\end{array}$ & ü & $\stackrel{i}{\dot{1}}$ & $\stackrel{0}{\stackrel{0}{i}}$ & $\begin{array}{l}0 \\
\dot{1} \\
\dot{0} \\
\dot{u}\end{array}$ \\
\hline $\begin{array}{c}\text { VW-Set } \\
\text { base } \\
\text { reference set }\end{array}$ & $\checkmark$ & $\checkmark$ & $\checkmark$ & $\checkmark$ & $\checkmark$ & $\checkmark$ & $\checkmark$ & $\checkmark$ & $\checkmark$ & $\checkmark$ & $\checkmark$ & $\checkmark$ & $\checkmark$ & $\checkmark$ & $\checkmark$ & $\checkmark$ \\
\hline VW-Set 9 & $\checkmark$ & 5 & $\checkmark$ & $\checkmark$ & $\checkmark$ & $\checkmark$ & $\checkmark$ & $\checkmark$ & $\checkmark$ & $\checkmark$ & $\checkmark$ & $\checkmark$ & $\checkmark$ & $\checkmark$ & $\checkmark$ & $\checkmark$ \\
\hline $\begin{array}{l}\text { Y direction } \\
\text { VW-Set }\end{array}$ & $\checkmark$ & $\checkmark$ & $\checkmark$ & $\checkmark$ & $\checkmark$ & $\checkmark$ & $\checkmark$ & $\checkmark$ & $\checkmark$ & $\checkmark$ & $\checkmark$ & $\checkmark$ & $\checkmark$ & $\checkmark$ & $\checkmark$ & $\checkmark$ \\
\hline
\end{tabular}

1018

1019

1020

1021 
1022 Table 3b MFHW Set analysed

\begin{tabular}{|c|c|c|c|c|c|c|c|c|c|c|}
\hline Set Name & 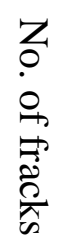 & 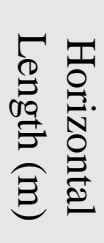 & $\begin{array}{l}\underset{\vartheta}{\vartheta} \\
\underset{\theta}{\theta} \\
.\end{array}$ & $\underset{D}{\frac{\pi}{2}}$ & 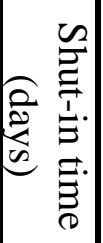 & 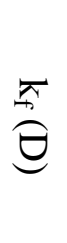 & $\stackrel{\pi}{\Xi}$ & $\overrightarrow{\hat{\Xi}}$ & 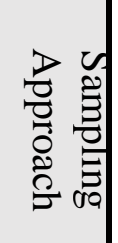 & 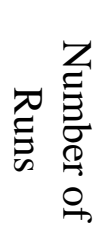 \\
\hline Default Values & $\omega$ & 8 & $\overline{8}$ & N & $N$ & $\stackrel{\vec{\omega}}{0}$ & $\frac{1}{8}$ & $\vec{p}$ & $\begin{array}{l}T \\
T \\
\text { T }\end{array}$ & 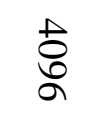 \\
\hline $\begin{array}{c}\text { MFHW-Set } 1 \\
\text { (base reference } \\
\text { set) }\end{array}$ & $\checkmark$ & $\checkmark$ & $\sqrt{ }$ & $\checkmark$ & $\checkmark$ & $\checkmark$ & $\checkmark$ & $\checkmark$ & $\checkmark$ & $\checkmark$ \\
\hline MFHW-Set 2 & $\checkmark$ & $\checkmark$ & $\checkmark$ & 5 & $\checkmark$ & $\checkmark$ & $\checkmark$ & $\checkmark$ & $\checkmark$ & $\checkmark$ \\
\hline MFHW-Set 3 & $\checkmark$ & $\checkmark$ & $\checkmark$ & $\checkmark$ & 20 & $\checkmark$ & $\checkmark$ & $\checkmark$ & $\checkmark$ & $\checkmark$ \\
\hline MFHW-Set 4 & $\checkmark$ & $\checkmark$ & $\checkmark$ & $\checkmark$ & $\checkmark$ & $\checkmark$ & $0.1-10$ & $\checkmark$ & $\checkmark$ & $\checkmark$ \\
\hline MFHW-Set 5 & $\checkmark$ & $\checkmark$ & 100 & $\checkmark$ & $\checkmark$ & $\checkmark$ & $\checkmark$ & $\checkmark$ & $\checkmark$ & $\checkmark$ \\
\hline MFHW-Set 6 & $\checkmark$ & $\checkmark$ & 4000 & $\checkmark$ & $\checkmark$ & $\checkmark$ & $\checkmark$ & $\checkmark$ & $\checkmark$ & $\checkmark$ \\
\hline MFHW-Set 7 & $\checkmark$ & $\checkmark$ & $\checkmark$ & $\checkmark$ & $\checkmark$ & $\checkmark$ & $0.01-1$ & $\checkmark$ & $\checkmark$ & $\checkmark$ \\
\hline MFHW-Set 8 & 7 & $\checkmark$ & $\checkmark$ & $\checkmark$ & $\checkmark$ & $\checkmark$ & $\checkmark$ & $\checkmark$ & $\checkmark$ & $\checkmark$ \\
\hline MFHW-Set 9 & 7 & $\checkmark$ & $\checkmark$ & $\checkmark$ & $\checkmark$ & $\checkmark$ & $0.1-10$ & $\checkmark$ & $\checkmark$ & $\checkmark$ \\
\hline MFHW-Set 10 & 7 & $\checkmark$ & $\checkmark$ & $\checkmark$ & $\checkmark$ & $\checkmark$ & $0.01-1$ & $\checkmark$ & $\checkmark$ & $\checkmark$ \\
\hline MFHW-Set 11 & 7 & $\checkmark$ & 100 & $\checkmark$ & $\checkmark$ & $\checkmark$ & $\checkmark$ & $\checkmark$ & $\checkmark$ & $\checkmark$ \\
\hline MFHW-Set 12 & 9 & $\checkmark$ & 100 & $\checkmark$ & $\checkmark$ & $\checkmark$ & $\checkmark$ & $\checkmark$ & $\checkmark$ & $\checkmark$ \\
\hline MFHW-Set 13 & 13 & $\checkmark$ & 100 & $\checkmark$ & $\checkmark$ & $\checkmark$ & $\checkmark$ & $\checkmark$ & $\checkmark$ & $\checkmark$ \\
\hline MFHW-Set 14 & 10 & 900 & 100 & $\checkmark$ & $\checkmark$ & $\checkmark$ & $\checkmark$ & $\checkmark$ & $\checkmark$ & $\checkmark$ \\
\hline MFHW-Set 15 & 7 & $\checkmark$ & 4000 & $\checkmark$ & $\checkmark$ & $\checkmark$ & $\checkmark$ & $\checkmark$ & $\checkmark$ & $\checkmark$ \\
\hline MFHW-Set 16 & 7 & $\checkmark$ & 100 & $\checkmark$ & $\checkmark$ & $\checkmark$ & $0.1-10$ & $\checkmark$ & $\checkmark$ & $\checkmark$ \\
\hline MFHW-Set 17 & 7 & $\checkmark$ & 4000 & $\checkmark$ & $\checkmark$ & $\checkmark$ & $0.1-10$ & $\checkmark$ & $\checkmark$ & $\checkmark$ \\
\hline MFHW-Set 18 & 7 & $\checkmark$ & 100 & $\checkmark$ & $\checkmark$ & $\checkmark$ & $0.01-1$ & $\checkmark$ & $\checkmark$ & $\checkmark$ \\
\hline MFHW-Set 19 & 7 & $\checkmark$ & 4000 & $\checkmark$ & $\checkmark$ & $\checkmark$ & $0.01-1$ & $\checkmark$ & $\checkmark$ & $\checkmark$ \\
\hline MFHW-Set 20 & 7 & $\checkmark$ & $\checkmark$ & $\checkmark$ & $\checkmark$ & $\checkmark$ & $100-10000$ & $\checkmark$ & $\checkmark$ & $\checkmark$ \\
\hline MFHW-Set 21 & 9 & $\checkmark$ & $\checkmark$ & $\checkmark$ & $\checkmark$ & $\checkmark$ & $100-10000$ & $\checkmark$ & $\checkmark$ & $\checkmark$ \\
\hline MFHW-Set 22 & 13 & $\checkmark$ & $\checkmark$ & $\checkmark$ & $\checkmark$ & $\checkmark$ & $100-10000$ & $\checkmark$ & $\checkmark$ & $\checkmark$ \\
\hline MFHW-Set 23 & 7 & $\checkmark$ & $\checkmark$ & $\checkmark$ & $\checkmark$ & $\checkmark$ & $\checkmark$ & $\checkmark$ & LHS & $\checkmark$ \\
\hline MFHW-Set 24 & 7 & $\checkmark$ & $\checkmark$ & $\checkmark$ & $\checkmark$ & $\checkmark$ & $\checkmark$ & $\checkmark$ & LHS & 3000 \\
\hline MFHW-Set 25 & 7 & $\checkmark$ & $\checkmark$ & $\checkmark$ & $\checkmark$ & $\checkmark$ & $\checkmark$ & $\checkmark$ & LHS & 2000 \\
\hline MFHW-Set 26 & 7 & $\checkmark$ & $\checkmark$ & $\checkmark$ & $\checkmark$ & $\checkmark$ & $\checkmark$ & $\checkmark$ & LHS & 1000 \\
\hline MFHW-Set 27 & 7 & $\checkmark$ & $\checkmark$ & $\checkmark$ & $\checkmark$ & $\checkmark$ & $\checkmark$ & $\checkmark$ & LHS & 500 \\
\hline MFHW-Set 28 & 7 & $\checkmark$ & $\checkmark$ & $\checkmark$ & $\checkmark$ & $\checkmark$ & $\checkmark$ & $\checkmark$ & LHS & 250 \\
\hline MFHW-Set 29 & 7 & $\checkmark$ & $\checkmark$ & $\checkmark$ & $\checkmark$ & $\checkmark$ & $\checkmark$ & $\checkmark$ & LHS & 100 \\
\hline
\end{tabular}




\section{ACCEPTED MANUSCRIPT}

Table 4 Parameters of the worst / best scenarios for the Base Reference Set

\begin{tabular}{|l|l|l|l|}
\hline \multirow{2}{*}{ No. } & \multirow{2}{*}{ Parameter } & Case & \\
\cline { 3 - 4 } & & Worst & Best \\
\hline 1 & $\mathrm{k}_{\mathrm{f}}(\mathrm{D})$ & 1 & 30 \\
\hline 2 & $\mathrm{k}_{\mathrm{m}}(\mu \mathrm{D})$ & 1 & 100 \\
\hline 3 & $\lambda$ & 4 & 1 \\
\hline 4 & $\mathrm{IFT}(\mathrm{mNm} / \mathrm{m})$ & 2 & 50 \\
\hline 5 & $\mathrm{n}_{\mathrm{gm}}$ & 5 & 1.5 \\
\hline 6 & $\mathrm{n}_{\mathrm{wm}}$ & 4 & 1.2 \\
\hline 7 & $\mathrm{k}_{\operatorname{maxgm}}$ & 0.5 & 1.0 \\
\hline 8 & $\mathrm{k}_{\operatorname{maxwm}}$ & 0.05 & 0.6 \\
\hline 9 & $\mathrm{n}_{\mathrm{gf}}$ & 5 & 1.5 \\
\hline 10 & $\mathrm{n}_{\mathrm{wf}}$ & 4 & 1.2 \\
\hline 11 & $\mathrm{k}_{\operatorname{maxgf}}$ & 0.5 & 1.0 \\
\hline 12 & $\mathrm{k}_{\operatorname{maxwf}}$ & 0.1 & 0.75 \\
\hline 13 & $\phi$ & 0.15 & \\
\hline 14 & $\mathrm{~S}_{\mathrm{wrf}}$ & 0.15 & \\
\hline 15 & $\mathrm{~S}_{\mathrm{wrm}}$ & 0.15 & \\
\hline 16 & $\mathrm{~S}_{\mathrm{grf}}$ & 0.1 & \\
\hline 17 & $\mathrm{~S}_{\mathrm{grm}}$ & 0.1 & \\
\hline & & & \\
\hline
\end{tabular}


1027 Table 5 RMSE and relative RMSE of interactive linear surface models (ILRSM) at three 1028 production stages for various MFHW Nf7 L600m Base Reference sets with different run 1029 numbers and sampling approaches, i.e., Latin Hypercube, LHS, and two-level Full Factorial 1030 Sampling, FFS.

\begin{tabular}{|c|c|c|c|c|c|c|c|}
\hline & 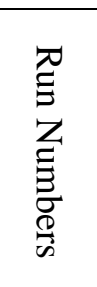 & 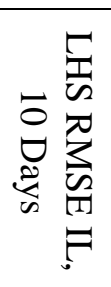 & 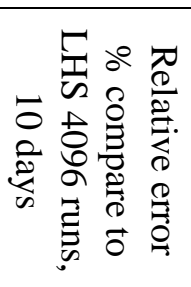 & 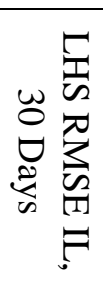 & 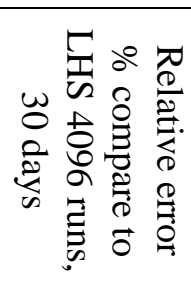 & 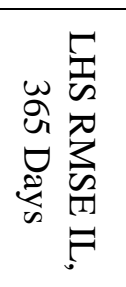 & 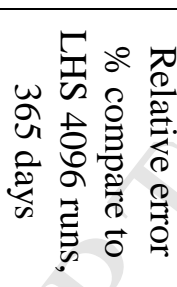 \\
\hline $\begin{array}{l}\text { LHS } 4096 \\
\text { Runs }\end{array}$ & 4096 & 6.88 & 0.00 & 7.17 & 0.00 & 4.72 & 0.00 \\
\hline $\begin{array}{l}\text { LHS } 3000 \\
\text { Runs }\end{array}$ & 3000 & 7.02 & 1.93 & 7.30 & 1.83 & 4.74 & 0.39 \\
\hline $\begin{array}{c}\text { LHS } 2000 \\
\text { Runs }\end{array}$ & 2000 & 7.14 & 3.72 & 7.45 & 3.99 & 4.77 & 1.02 \\
\hline $\begin{array}{l}\text { LHS } 1000 \\
\text { Runs }\end{array}$ & 1000 & 7.40 & 7.51 & 7.53 & 5.13 & 4.72 & -0.04 \\
\hline LHS 500 Runs & 500 & 7.87 & 14.27 & 7.78 & 8.64 & 4.69 & -0.68 \\
\hline LHS 250 Runs & 250 & 8.62 & 25.30 & 8.59 & 19.87 & 4.91 & 4.07 \\
\hline \multirow[t]{2}{*}{ LHS 100 Runs } & 100 & 15.79 & 129.43 & 15.17 & 111.68 & 7.39 & 56.64 \\
\hline & 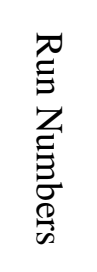 & 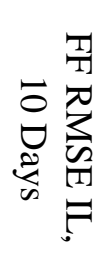 & 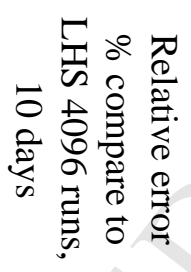 & 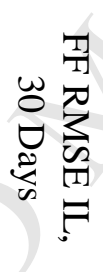 & 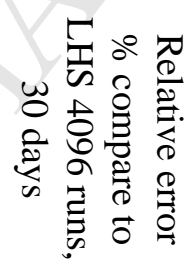 & 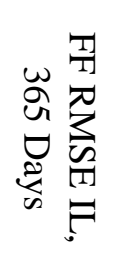 & 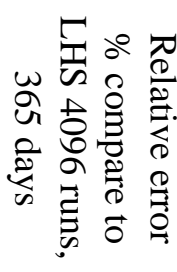 \\
\hline $\begin{array}{c}\text { Full Factorial } \\
\text { (4096 Runs) }\end{array}$ & 4096 & 13.56 & 97.02 & 15.15 & 111.41 & 9.15 & 93.80 \\
\hline
\end{tabular}

1031

1032 1033

1034
Table 6 RMSE and relative RMSE of the pure quadratic (PQ) model in run numbers for MFHW Nf7 L600m Base Reference sets with LHS approach.

\begin{tabular}{|c|c|c|c|c|c|c|c|}
\hline & 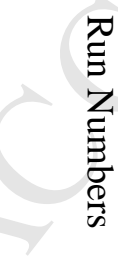 & 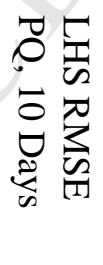 & 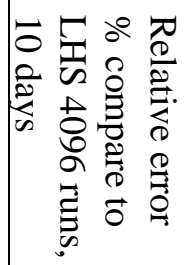 & 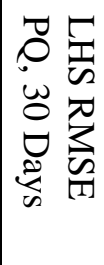 & 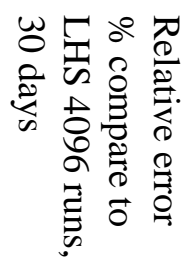 & 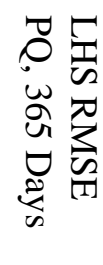 & 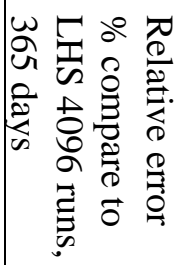 \\
\hline LHS 4096 Runs & 4096 & 5.63 & 0.00 & 5.38 & 0.00 & 4.28 & 0.00 \\
\hline LHS 3000 Runs & 3000 & 5.68 & 0.93 & 5.47 & 1.73 & 4.28 & -0.07 \\
\hline LHS 2000 Runs & 2000 & 5.68 & 0.93 & 5.46 & 1.48 & 4.27 & -0.14 \\
\hline LHS 1000 Runs & 1000 & 5.76 & 2.29 & 5.44 & 1.23 & 4.25 & -0.76 \\
\hline LHS 500 Runs & 500 & 5.75 & 2.09 & 5.45 & 1.35 & 4.28 & 0.00 \\
\hline LHS 250 Runs & 250 & 5.94 & 5.47 & 5.58 & 3.71 & 4.30 & 0.57 \\
\hline LHS 100 Runs & 100 & 6.03 & 7.02 & 5.95 & 10.69 & 4.33 & 1.08 \\
\hline
\end{tabular}


1035

1036 Table 7 RMSE and relative RMSE of the full quadratic (FQ) model in run numbers for 1037 MFHW Nf7 L600m Base Reference sets with LHS approach.

\begin{tabular}{|c|c|c|c|c|c|c|c|}
\hline & 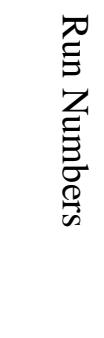 & 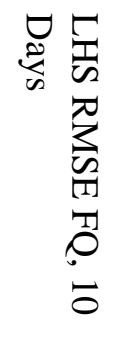 & 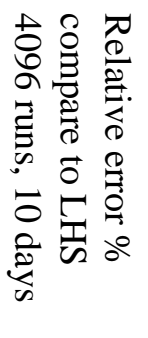 & 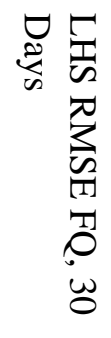 & 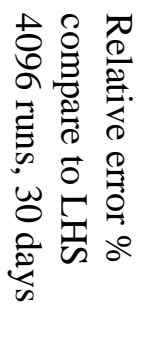 & 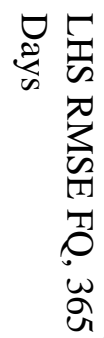 & 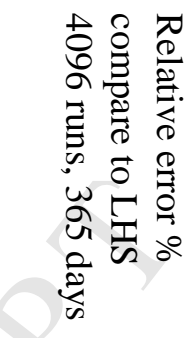 \\
\hline LHS 4096 Runs & 4096 & 4.13 & 0.00 & 4.49 & 0.00 & 4.26 & 0.00 \\
\hline LHS 3000 Runs & 3000 & 4.22 & 2.27 & 4.59 & 2.22 & 4.26 & 0.02 \\
\hline LHS 2000 Runs & 2000 & 4.35 & 5.44 & 4.67 & 3.92 & 4.27 & 0.20 \\
\hline LHS 1000 Runs & 1000 & 4.41 & 6.80 & 4.74 & 5.45 & 4.20 & -1.42 \\
\hline LHS 500 Runs & 500 & 4.58 & 10.95 & 4.85 & 7.84 & 4.24 & -0.42 \\
\hline LHS 250 Runs & 250 & 5.74 & 38.94 & 5.52 & 22.84 & 4.39 & 3.04 \\
\hline LHS 100 Runs & 100 & 13.32 & 222.62 & 10.88 & 142.17 & 4.33 & 1.62 \\
\hline
\end{tabular}




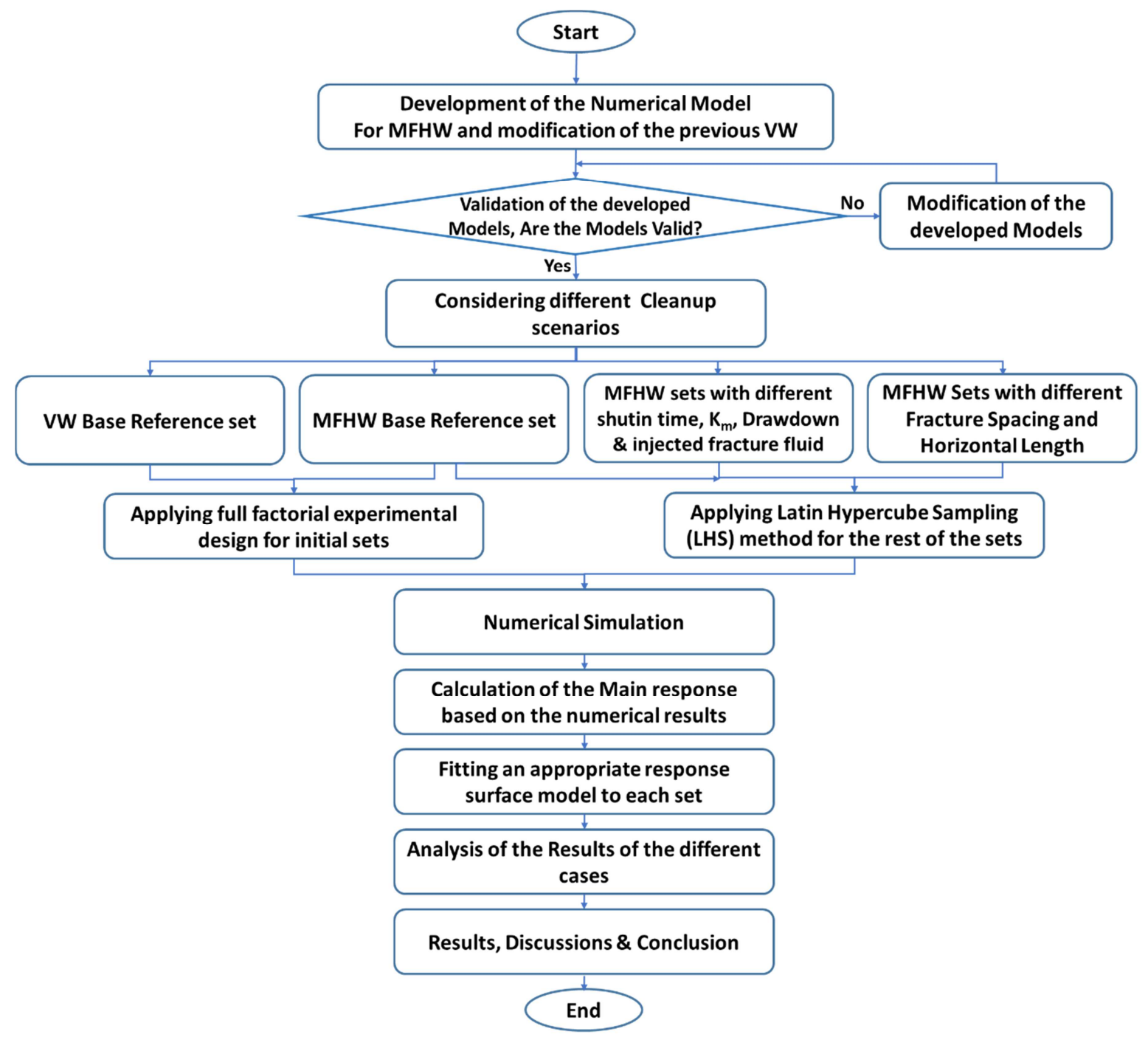

Figure 1 the workflow of the study

Fracture width, $W_{f}=0.004 m$

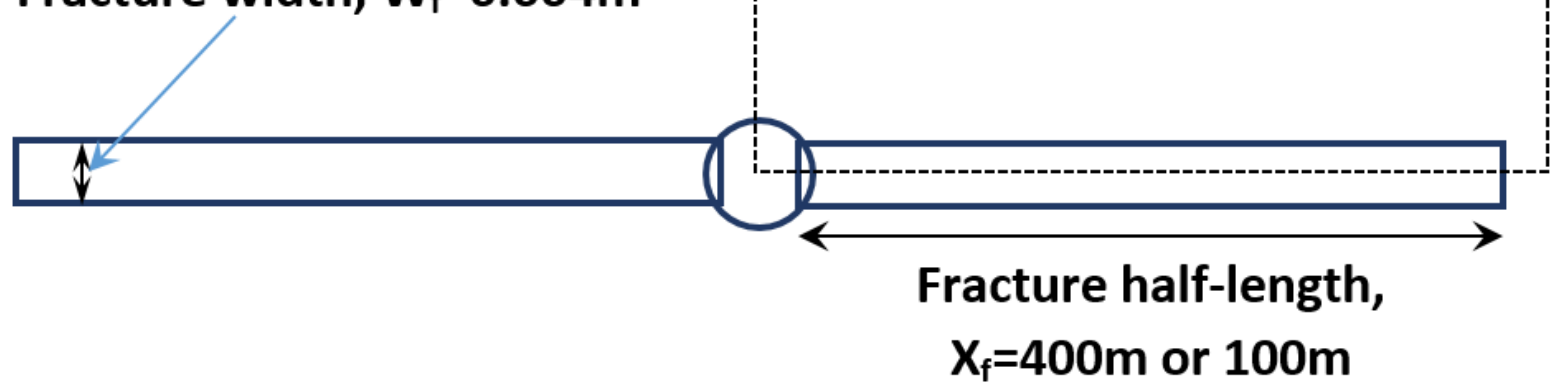

Figure 2 The modelled section 


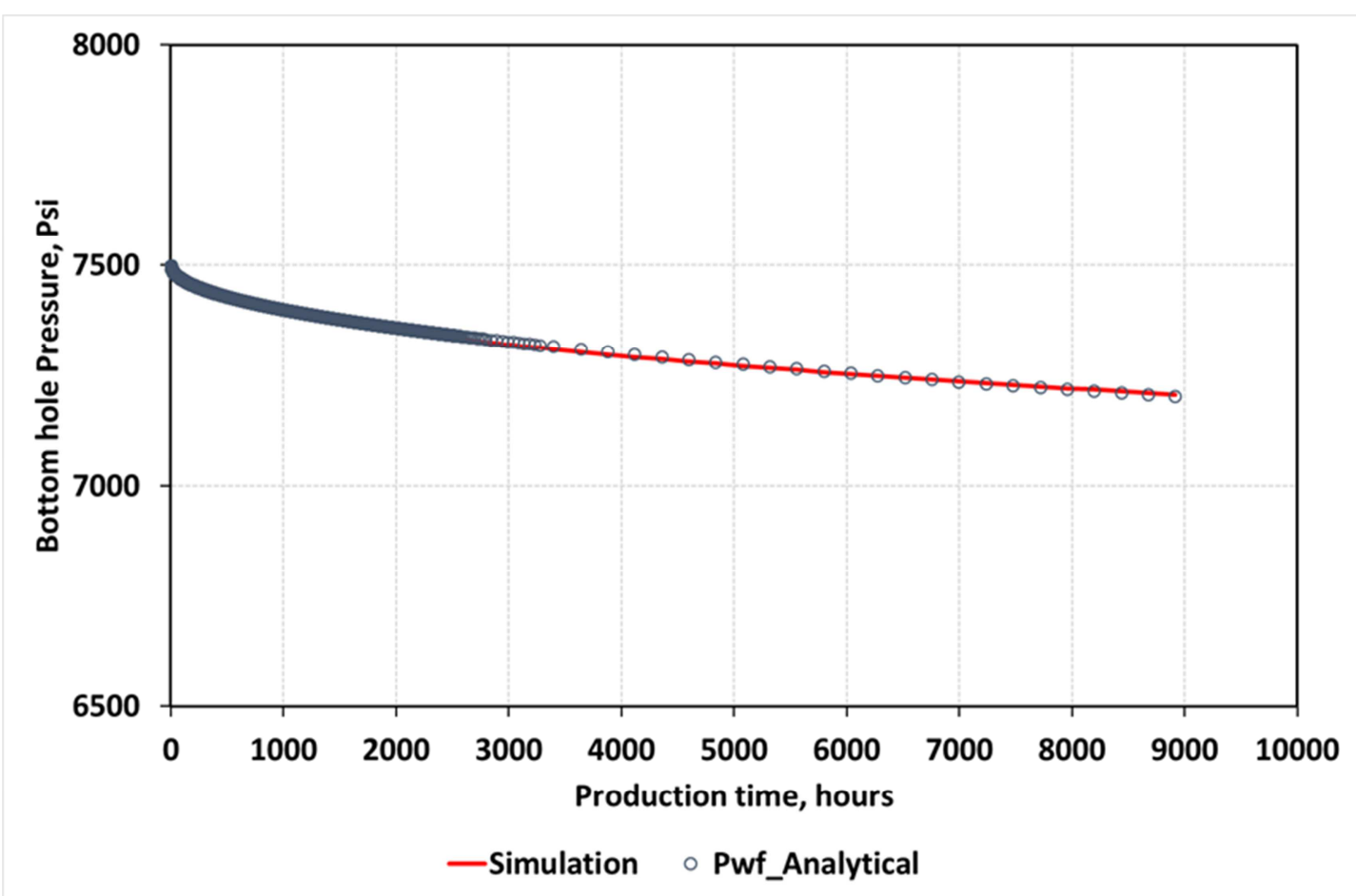

Figure 3 Predicated Pwf by numerical and analytical models versus time.

1041

1042

1043 
VW and MFHW Base Reference Set, GPL - LRSM

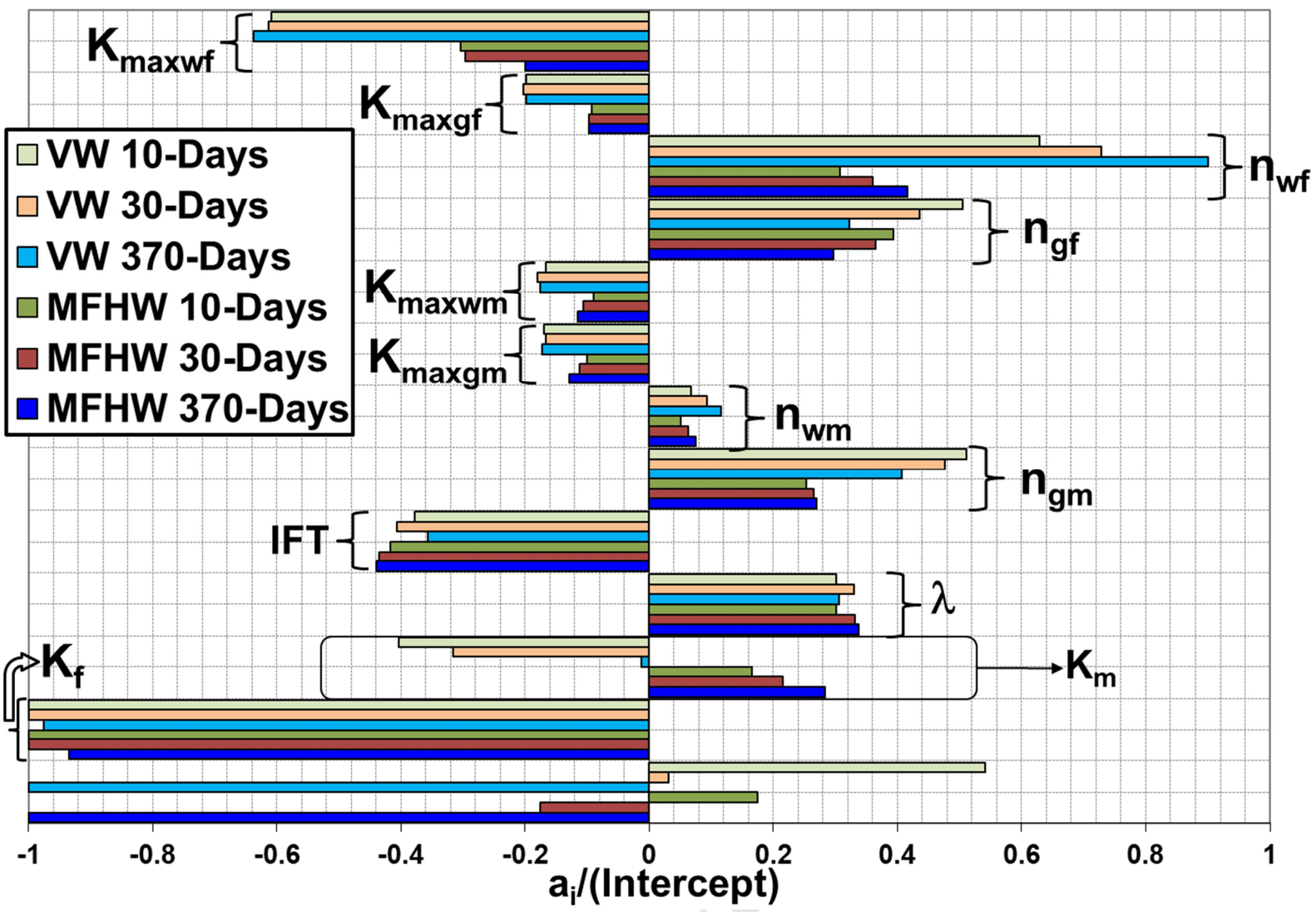

Figure 4 LRSM coefficients, VW and MFHW Base Reference Sets (FVR=2, DP=1000 psi, ST=2 days and $\mathrm{KMR}=1)$. 


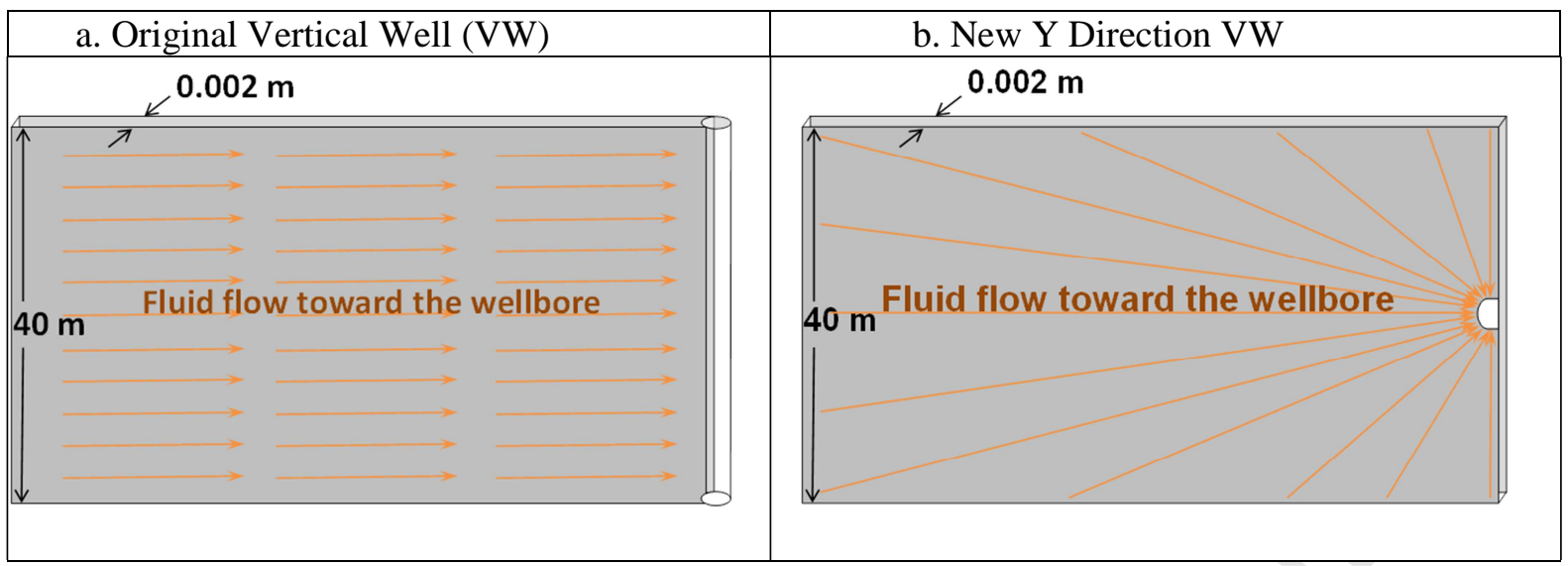

Figure 5 Well trajectory and flow geometry of Single Fracture (a) original Vertical Well (Z-VW) completed in the Z-direction, and (b) New VW completed in the Y-Direction (Y-VW).

1047

SFVW Base Reference Set, Y-Direction, Long Fracture, GPL- LRSM

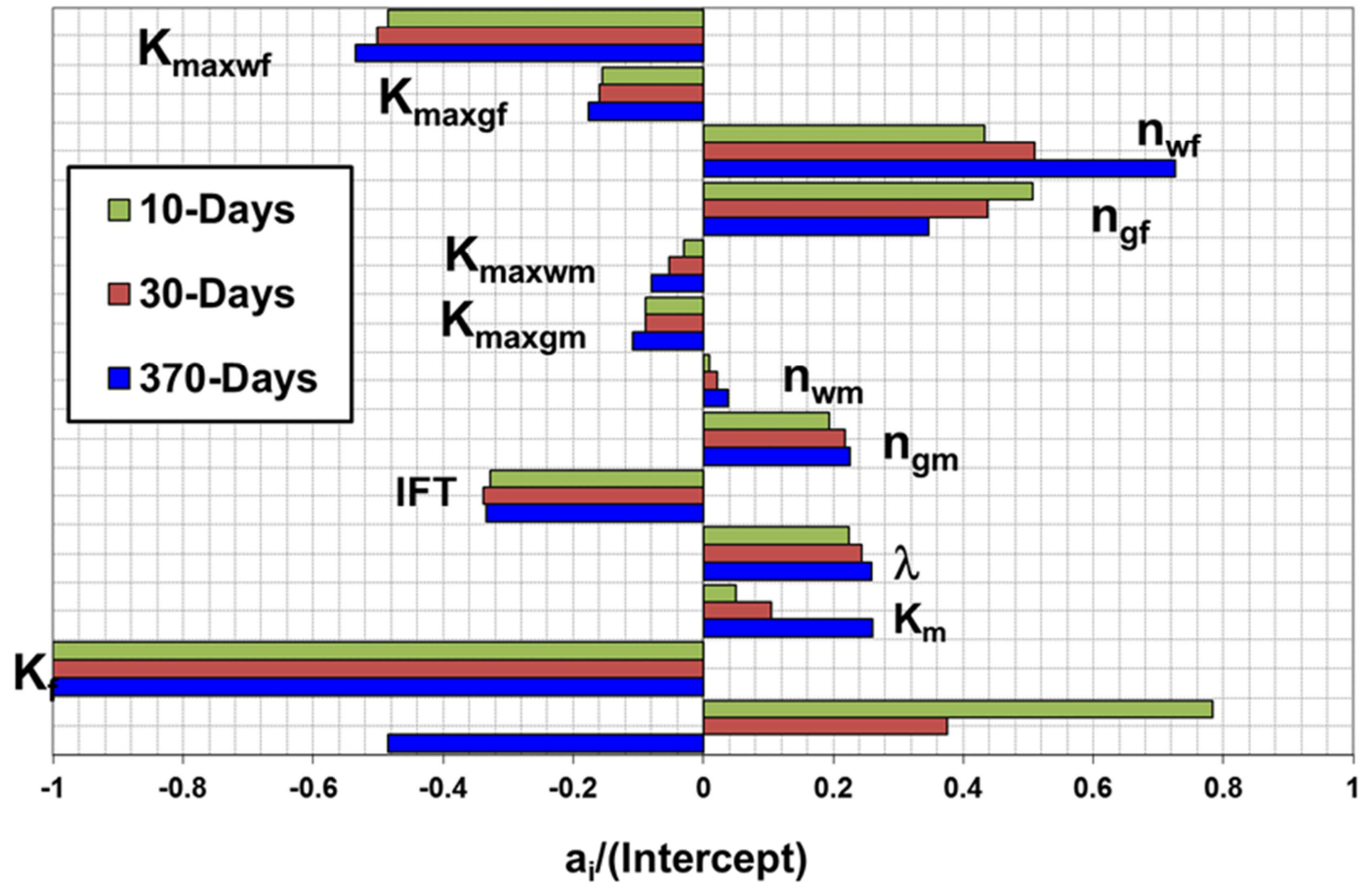

Figure 6 LRSM coefficients, at three production stages for the New Y-VW set. 


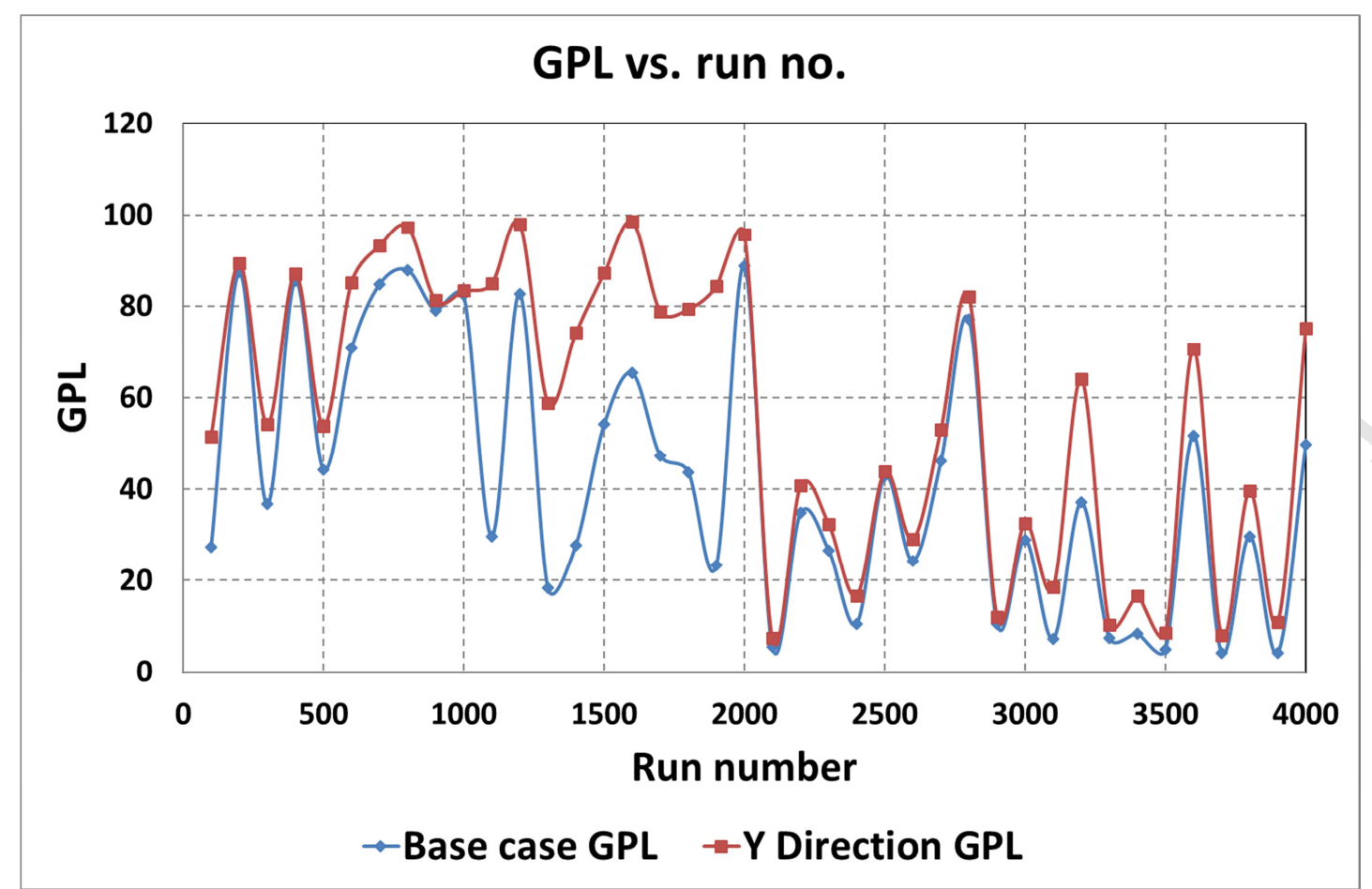

1049

Figure 7 GPL vs Run Number for Z-VW and Y-VW sets,

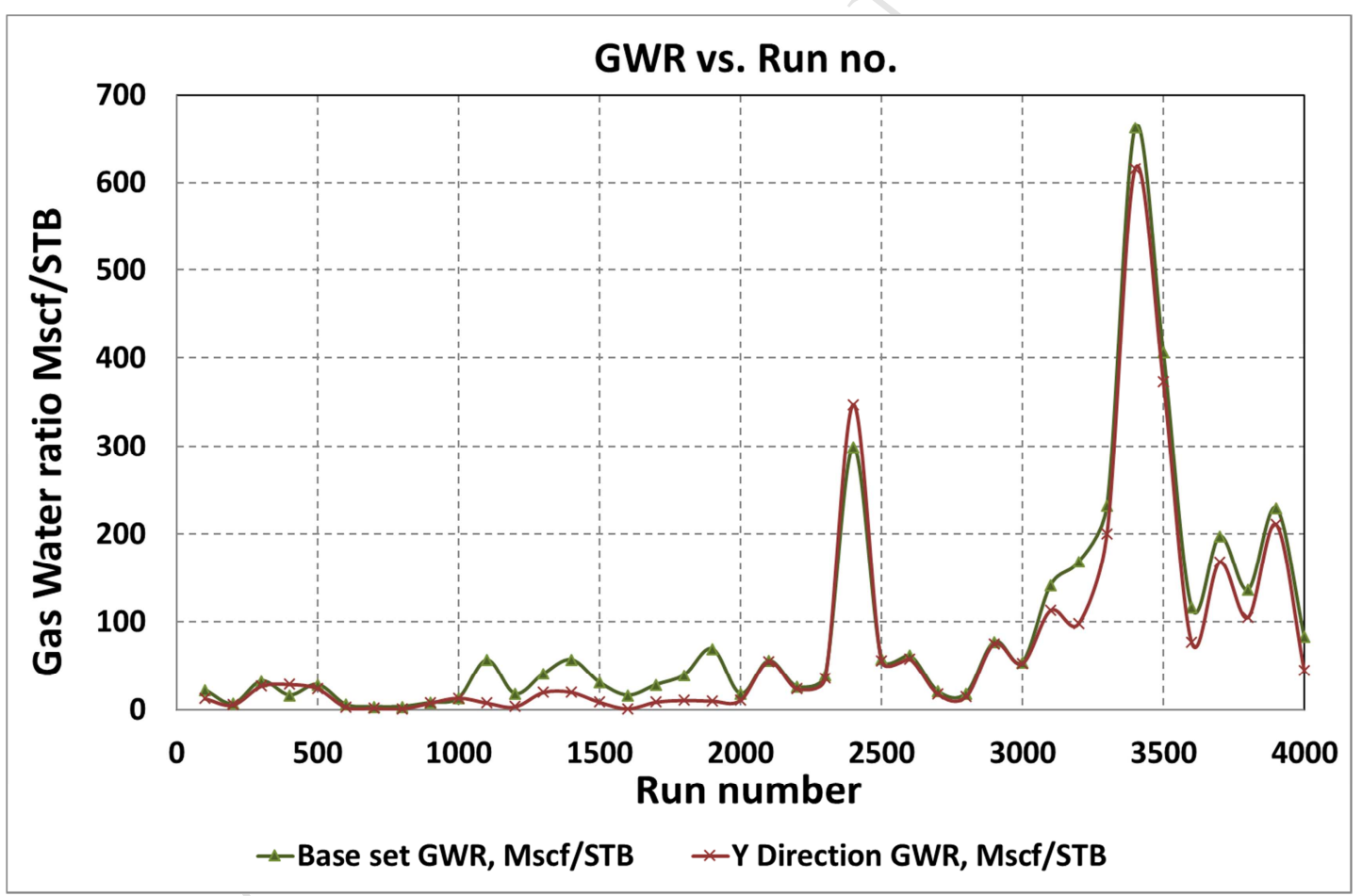

Figure 8 Gas Water Ratio vs Run Number for Z-VW and Y-VW sets, 


\section{ACCEPTED MANUSCRIPT}

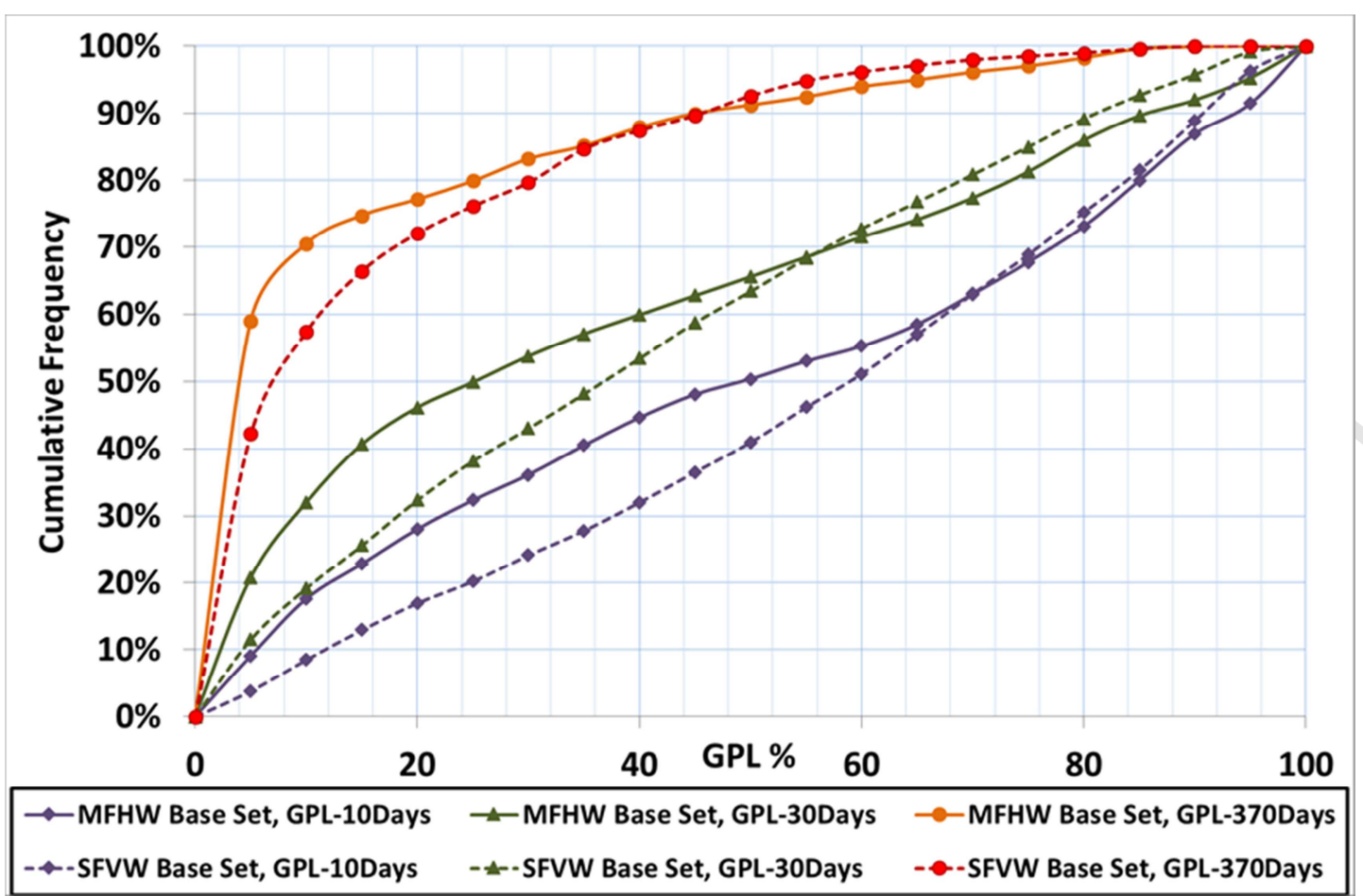

Figure 9 The GPL cumulative frequency of the MFHW set and VW Set at three production 1051 stages.

\section{MFHW-Set8 NF7-L600, Full Factorial Sampling, GPL-LRSM}

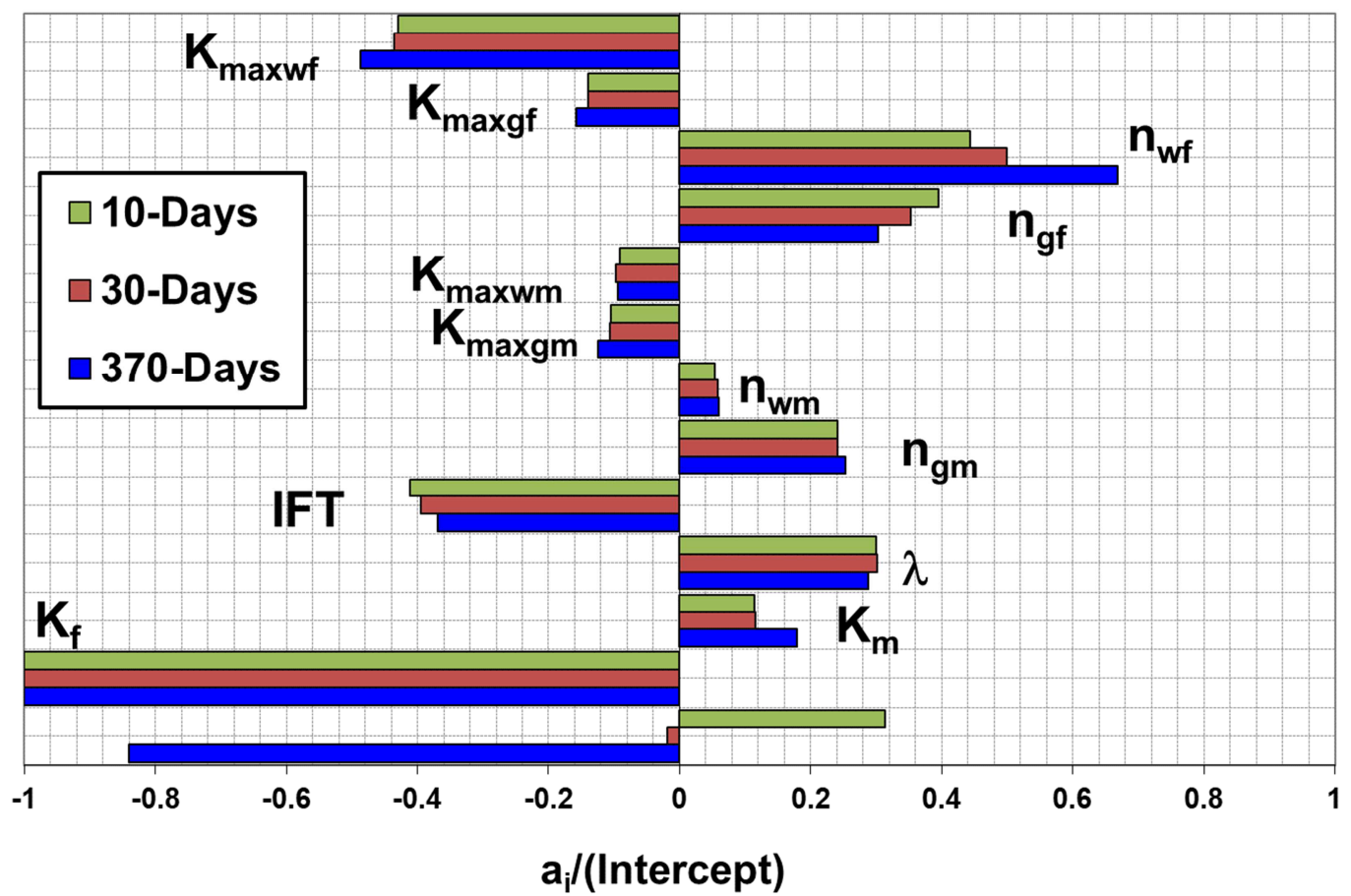

Figure 10 LRSM coefficients, MFHW-Set8 Nf7 L600, Using FFS ,Base Reference Set, 
MFHW-Set23 NF7-L600, 4096 runs, Latin Hypercube , GPL- LRSM

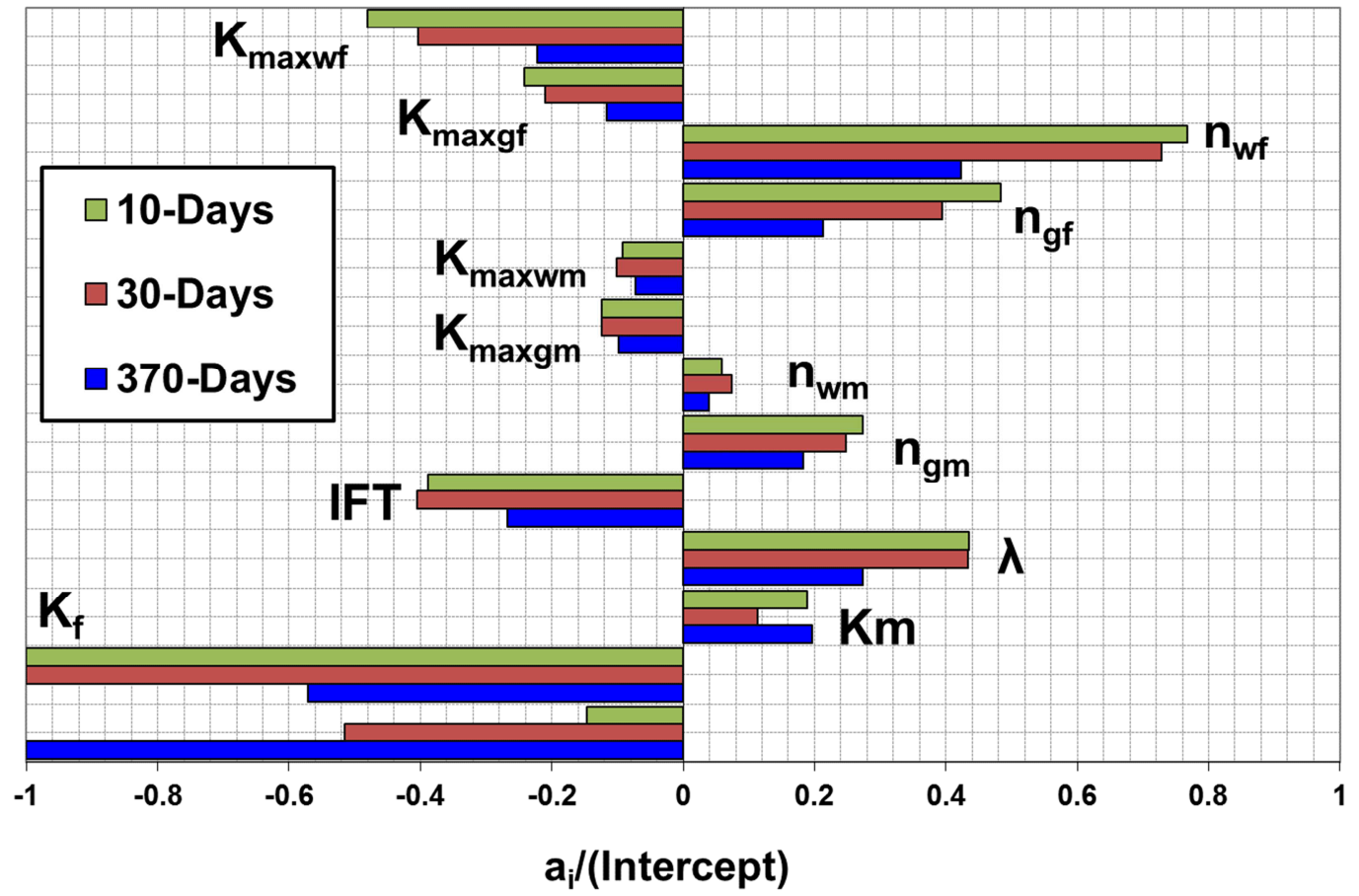

Figure 11 LRSM coefficients, MFHW-Set23 Nf7 L600m Base Reference sets with LHS with 4096 Runs

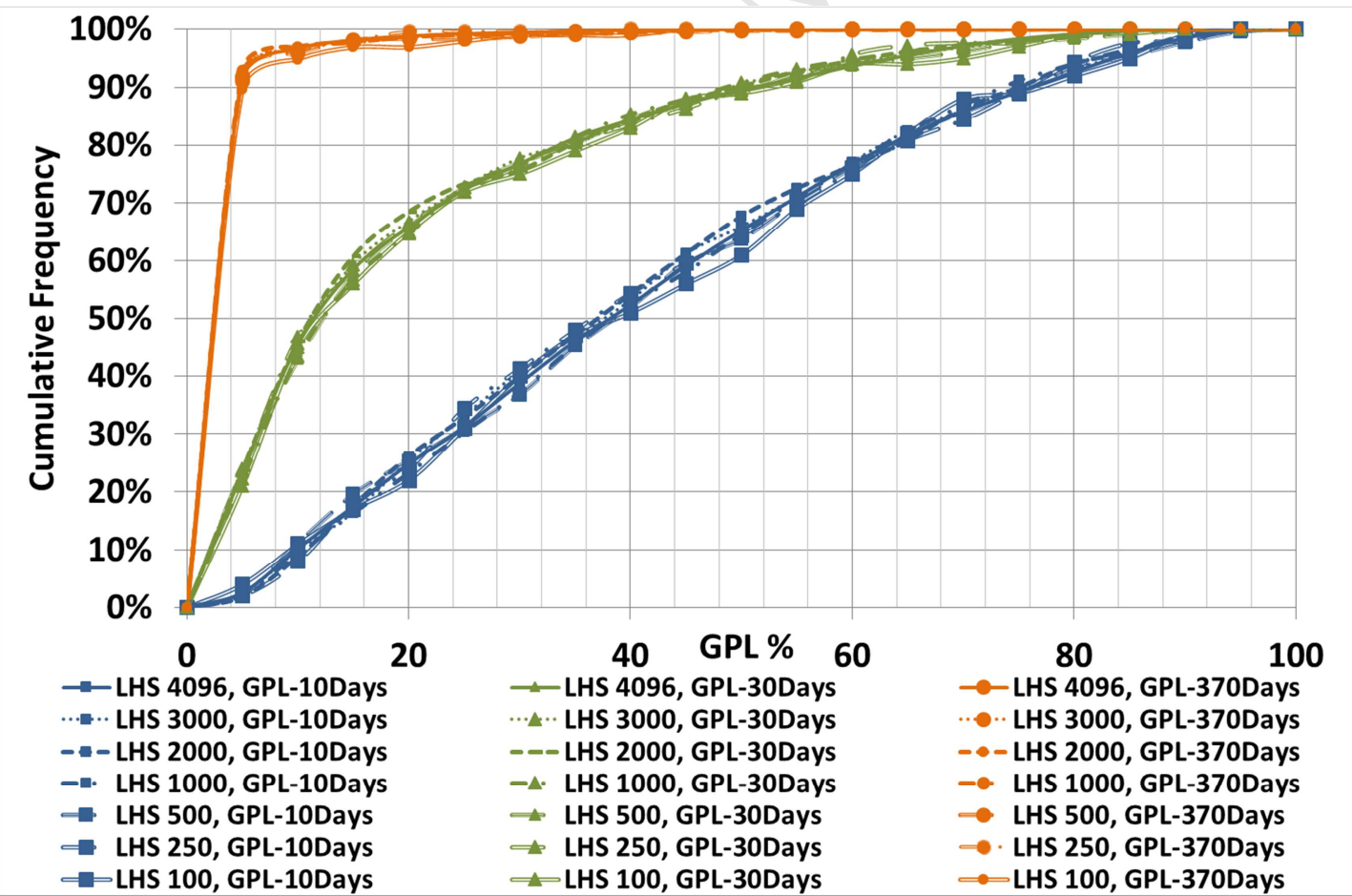

Figure 12 The GPL cumulative frequency of MFHW Base reference sets using LHS with different run numbers, (a) LHS with 4096 Runs, (b) LHS with 3000 Runs, (c) LHS with 2000 Runs, (d) LHS with 1000 Runs, (e) LHS with 500 Runs, (f) LHS with 250 Runs, (g) LHS with 100 Runs, 


\section{ACCEPTED MANUSCRIPT}

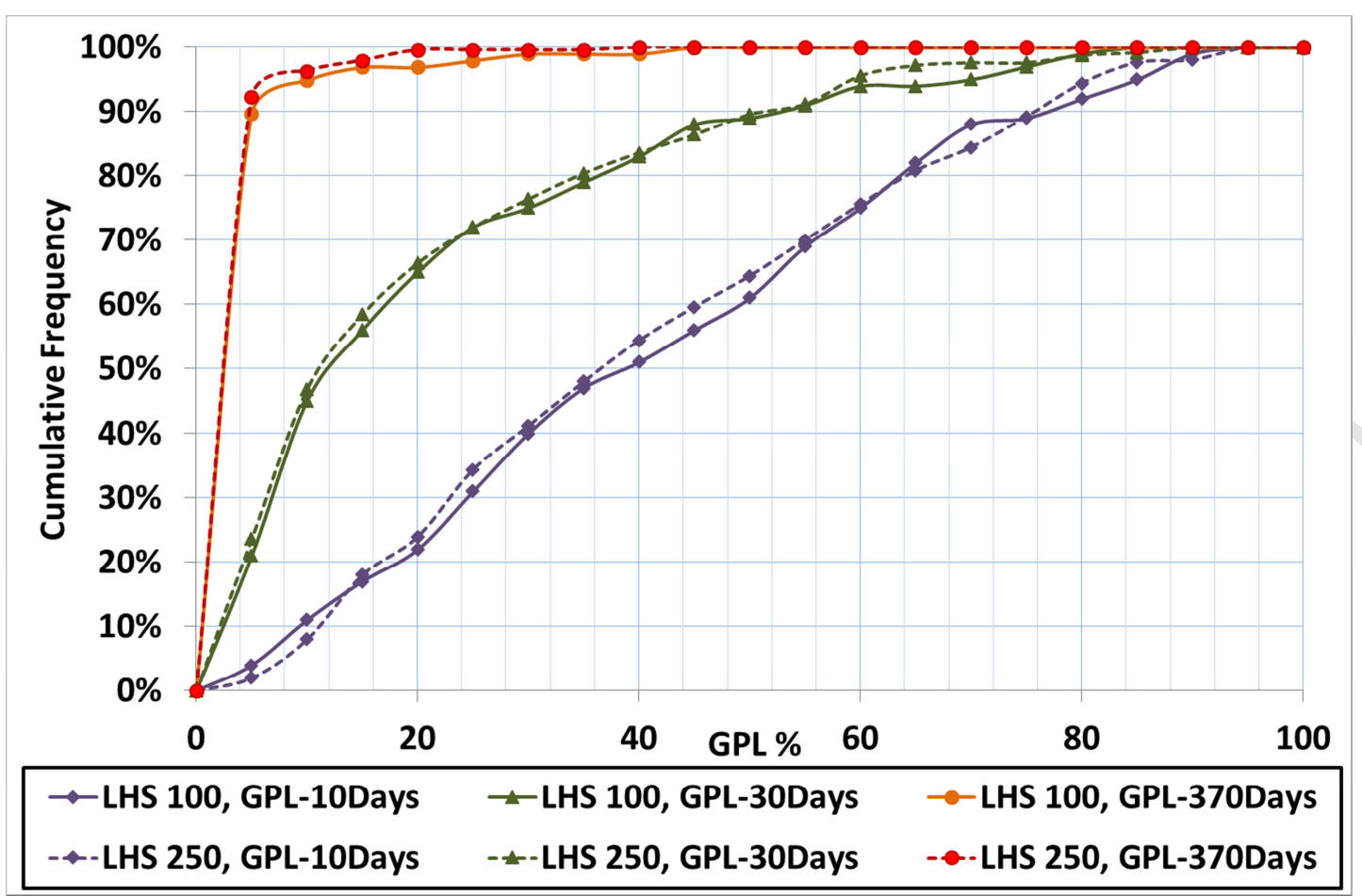

Figure 13 The GPL cumulative frequency of MFHW Base reference sets using LHS with 250 and 100 run numbers.

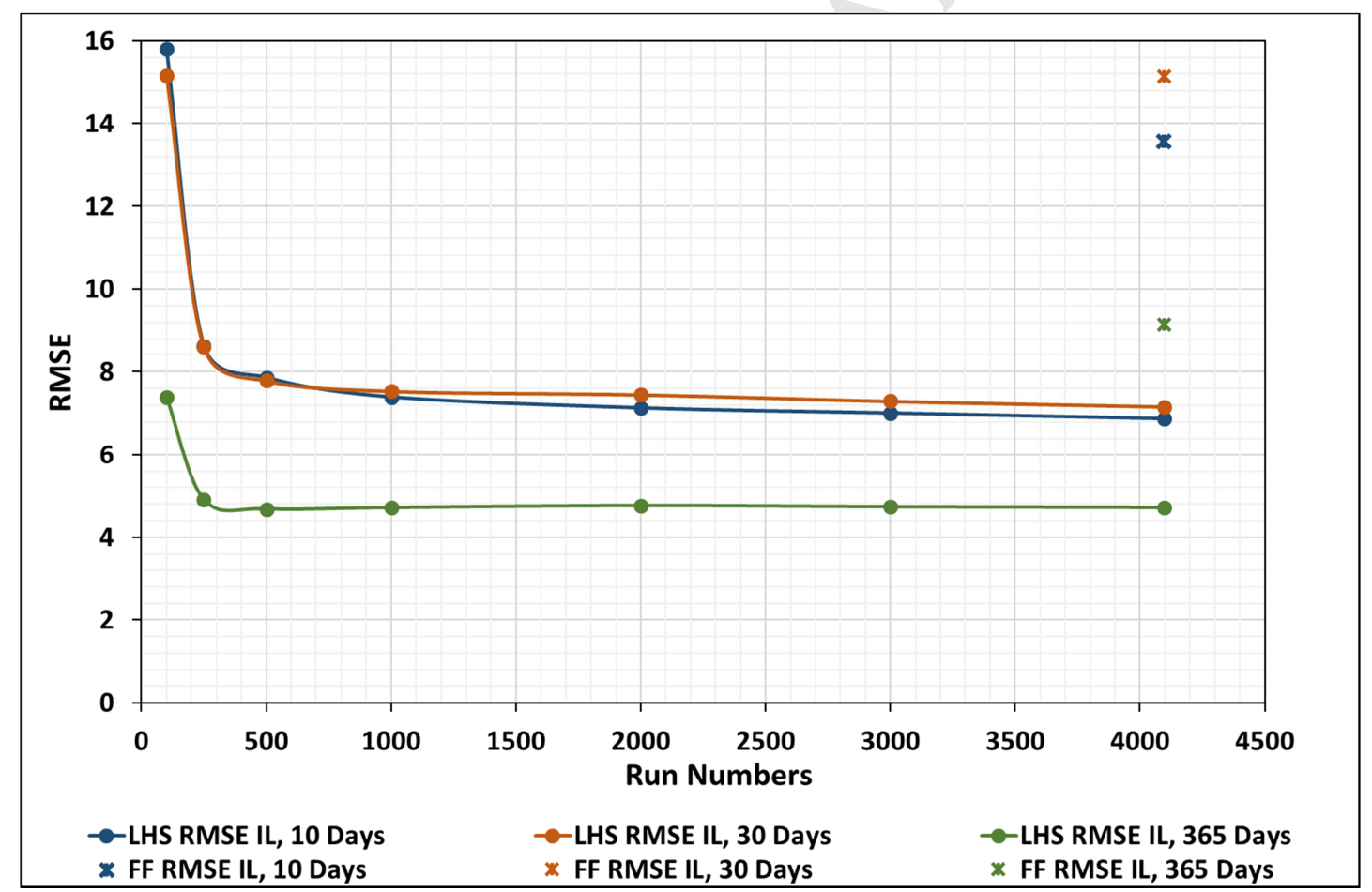

Figure 14 RMSE of interactive linear surface models (ILRSM) versus run numbers at three production stages for MFHW Nf7 L600m Base Reference sets with different sampling approaches, i.e., Latin Hyper Cube Sampling, LHS, and two level Full Factorial sampling (FFS) 


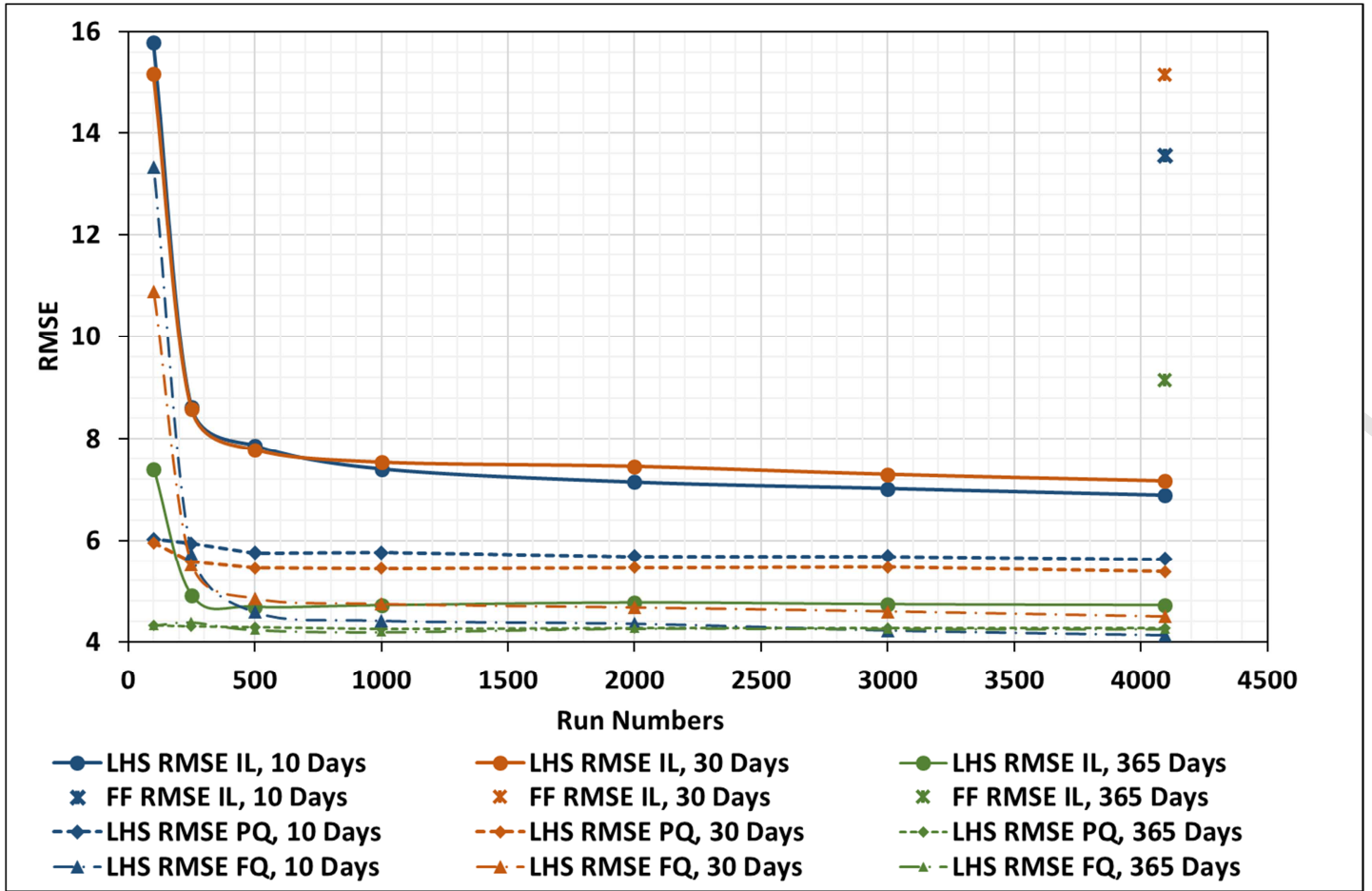

Figure 15 RMSE of ILRSM, pure quadratic (PQ) and full quadratic (FQ) models versus run numbers at three production stages for MFHW Nf7 L600m Base Reference sets with different sampling approaches, i.e., Latin HyperCube, LHS, and two level Full Factorial sampling (FFS)

\section{MFHW-Set 12 NF9 L600 Base Reference Set, GPL - LRSM}

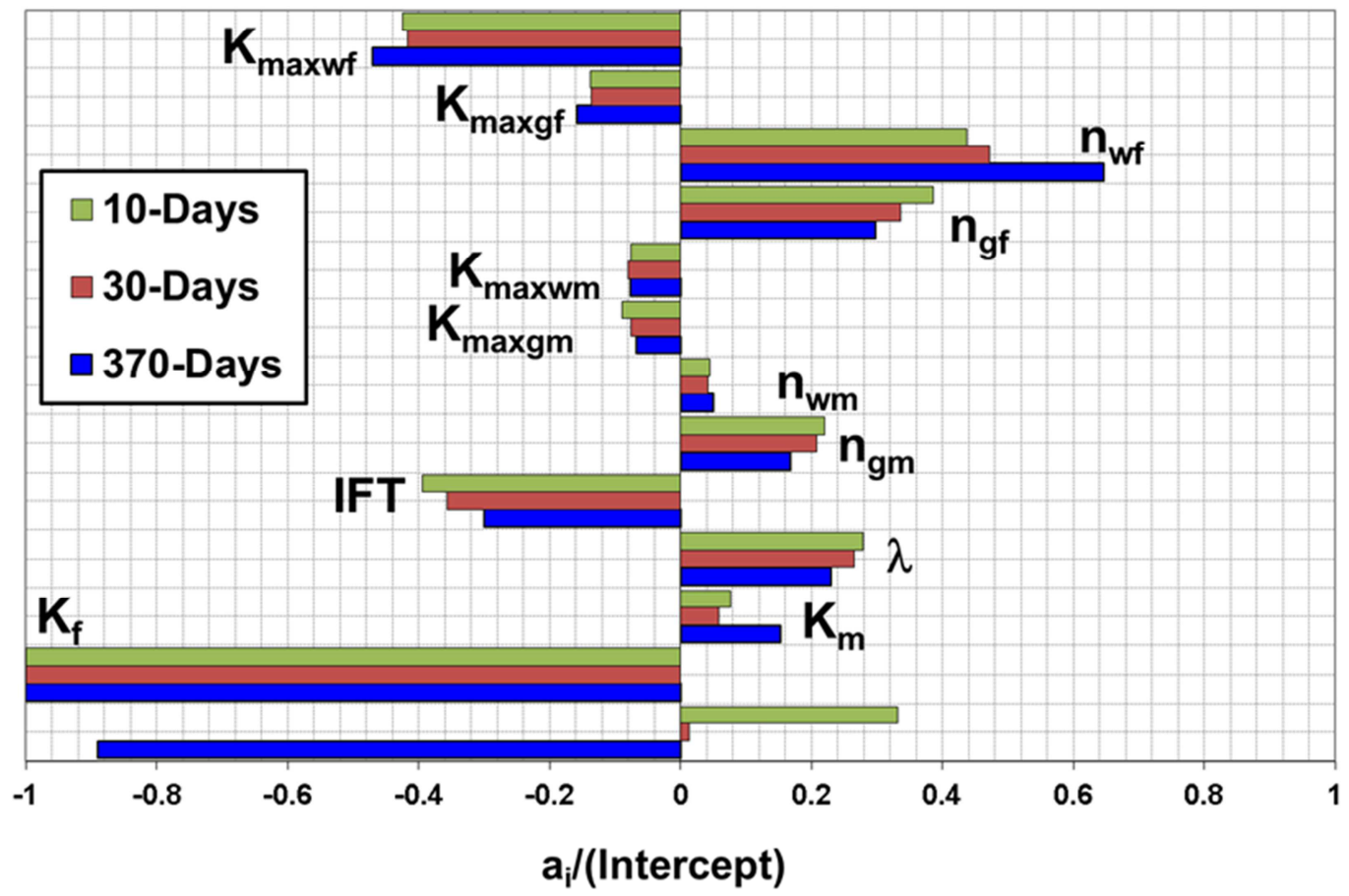

Figure 16 LRSM coefficients, MFHW-Set12 Nf9 L600 
MFHW-Set 13 NF13 L600 Base Reference Set, GPL - LRSM

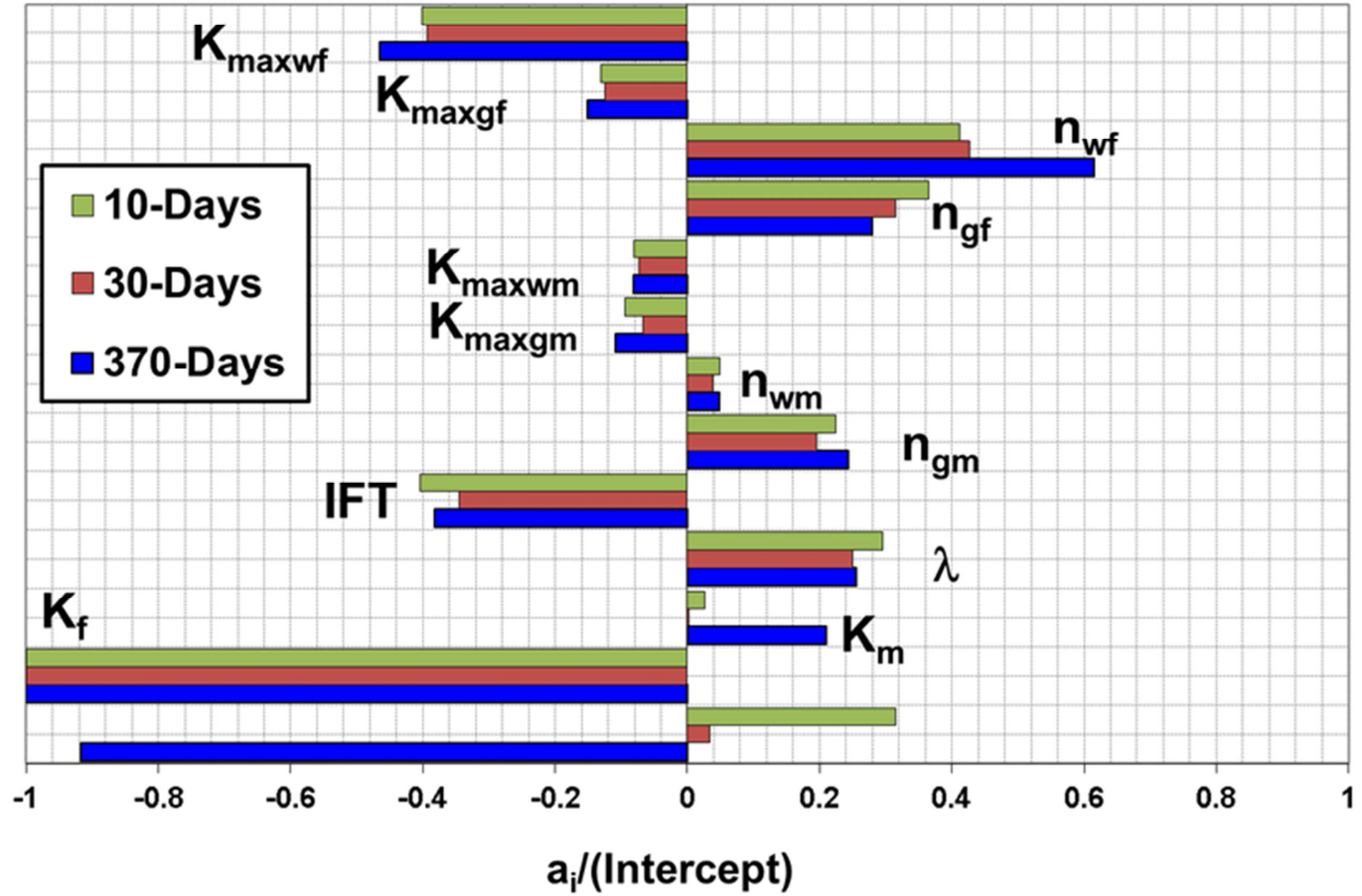

Figure 17 LRSM coefficients, MFHW-Set13 Nf13 L600

1060

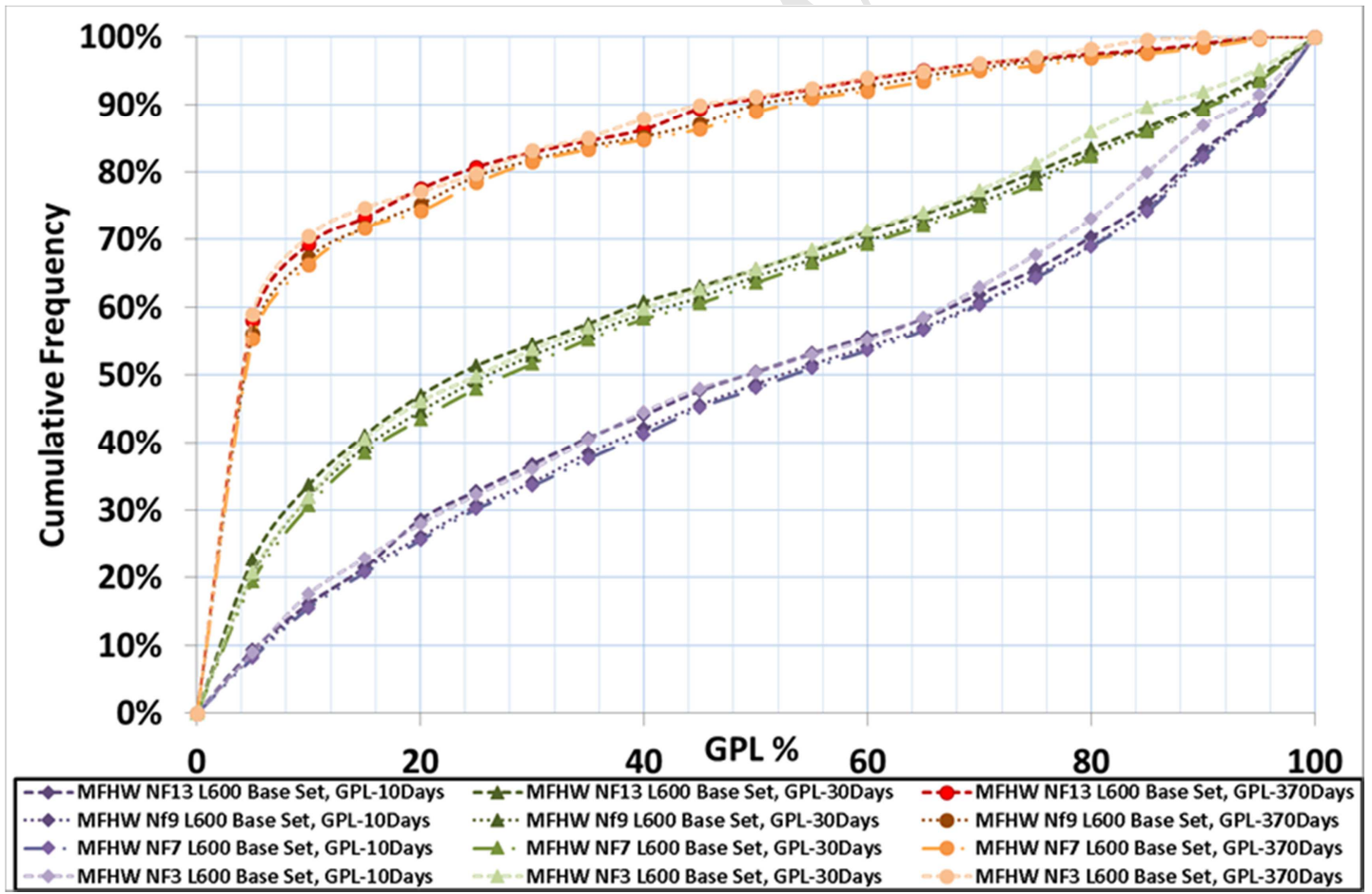

Figure 18 Histogram chart, GPL cumulative frequency of MFHW-Set $1 \mathrm{Nf}=3 \&$ MFHW-Set 8 with $\mathrm{Nf}=7$, MFHW-Set 12 with $\mathrm{Nf}=9$ and $\mathrm{MFHW}$-Set 13 with $\mathrm{Nf}=13$ at three production stages. 
MFHW-Set14 NF10 L900 Base Reference Set, GPL - LRSM

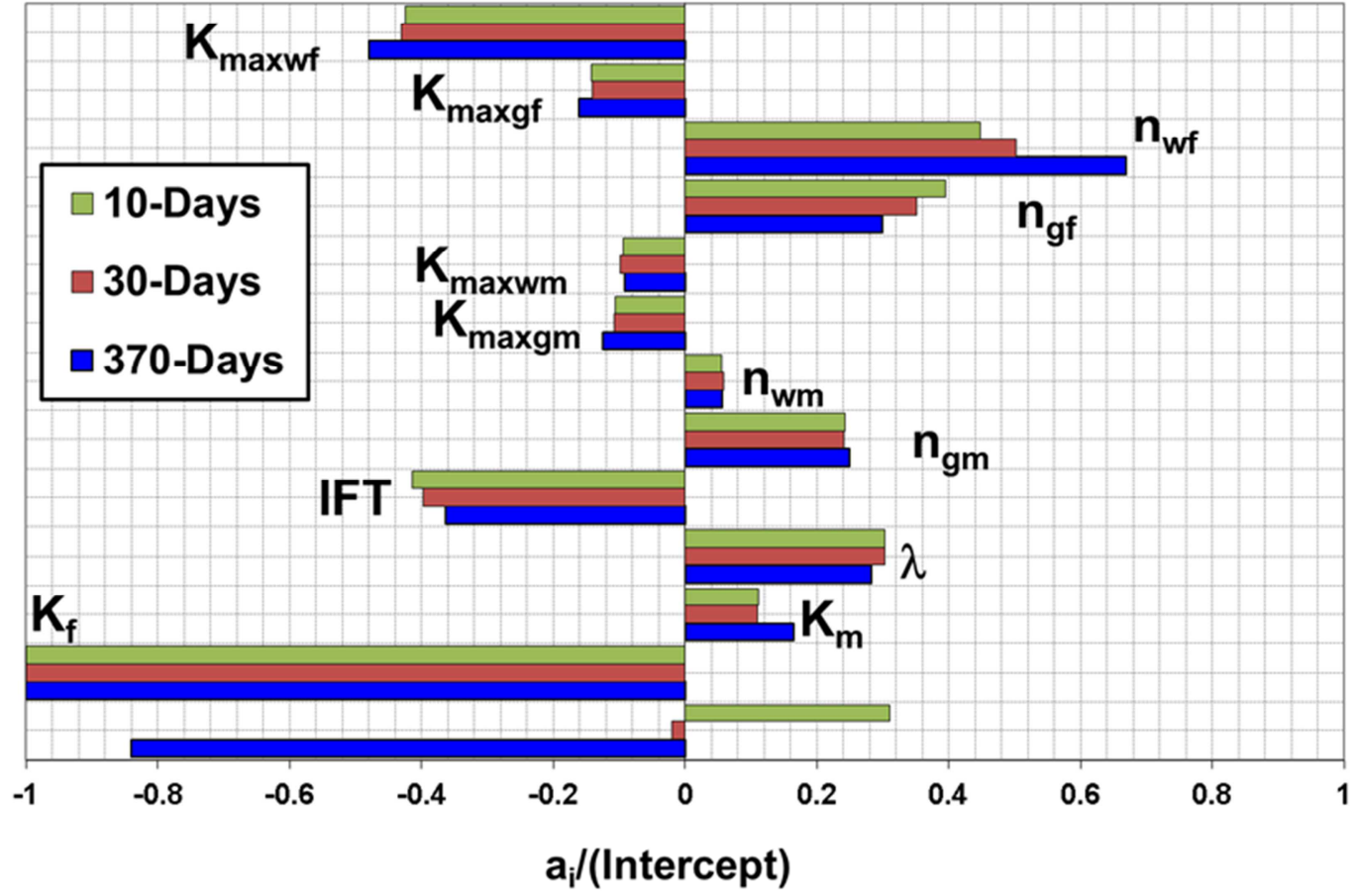

Figure 19 LRSM coefficients, MFHW-Set14 Nf10 L600

1062

1063

1064

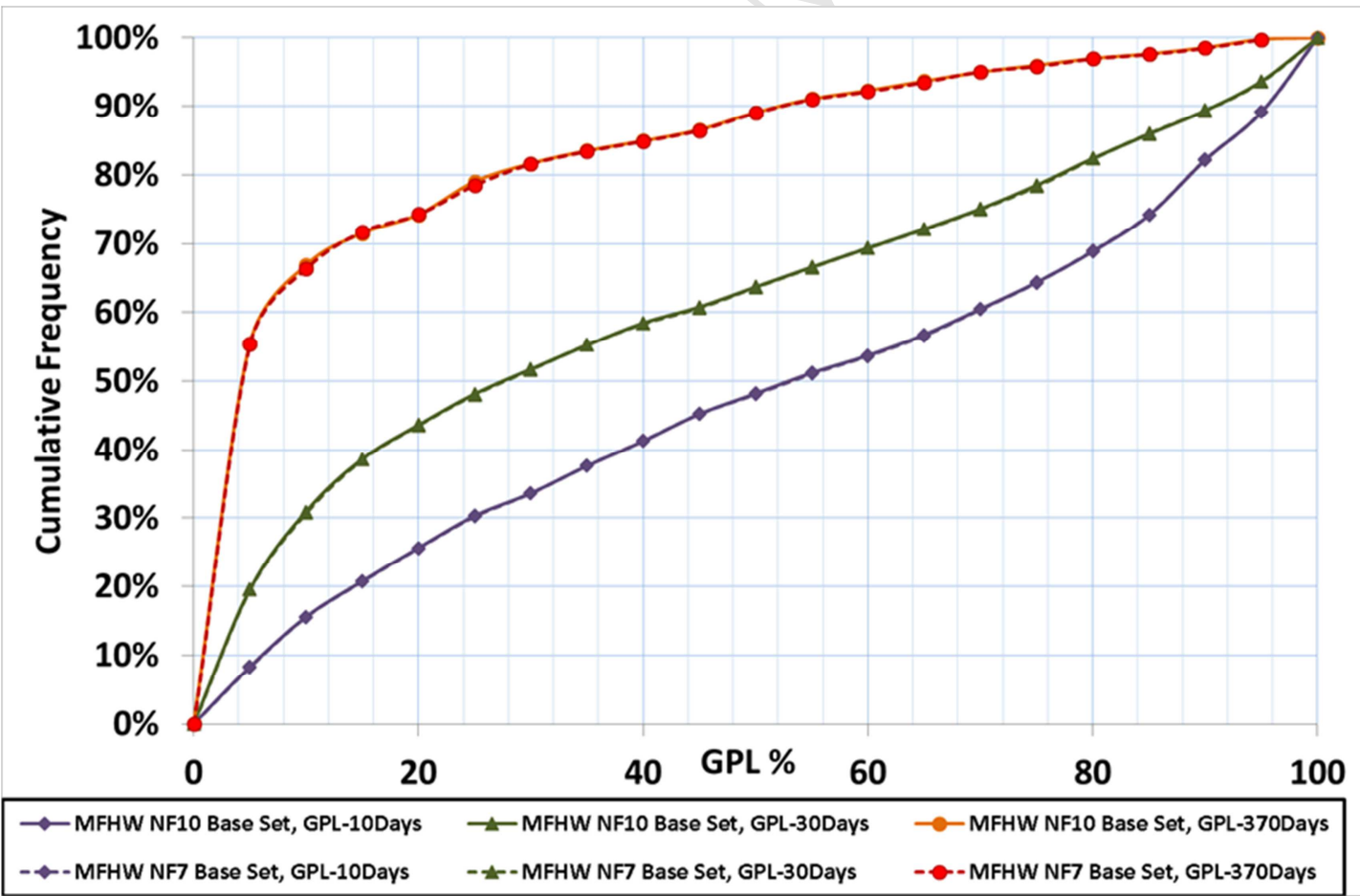

Figure 20 The GPL cumulative frequency of MFHW-Set 8 and Nf=7 \& MFHW-Set 14 with $\mathrm{Nf}=10$ at three production stages. 
a. MFHW-Set2 FVR=5

MFHW-Set 2, MFHW FVR=5, Gas Production Loss (GPL) - LRSM

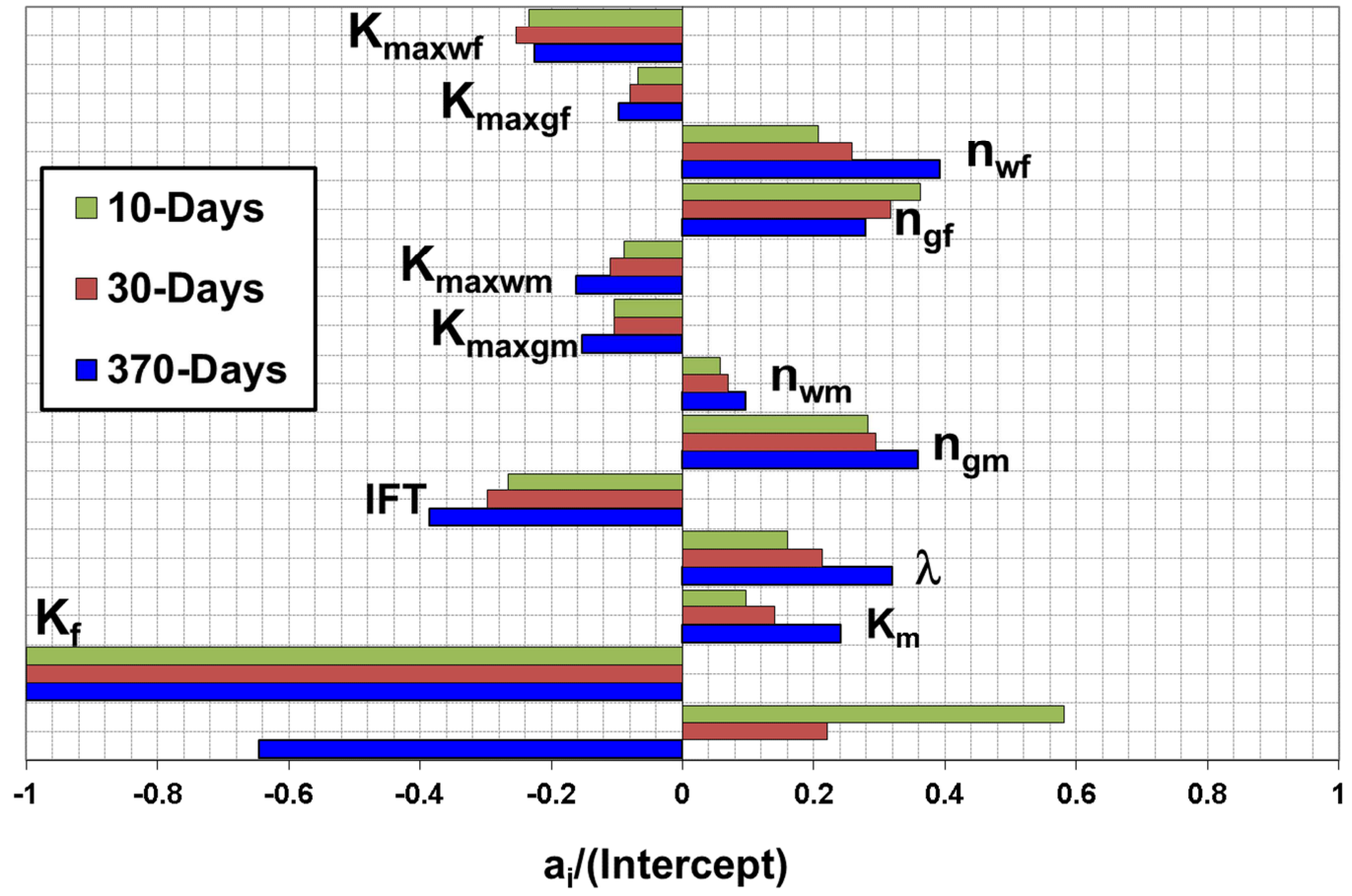

b. SFVW-Set 9 FVR=5

SFVW-Set 9, FVR=5, Gas Production Loss (GPL) - LRSM

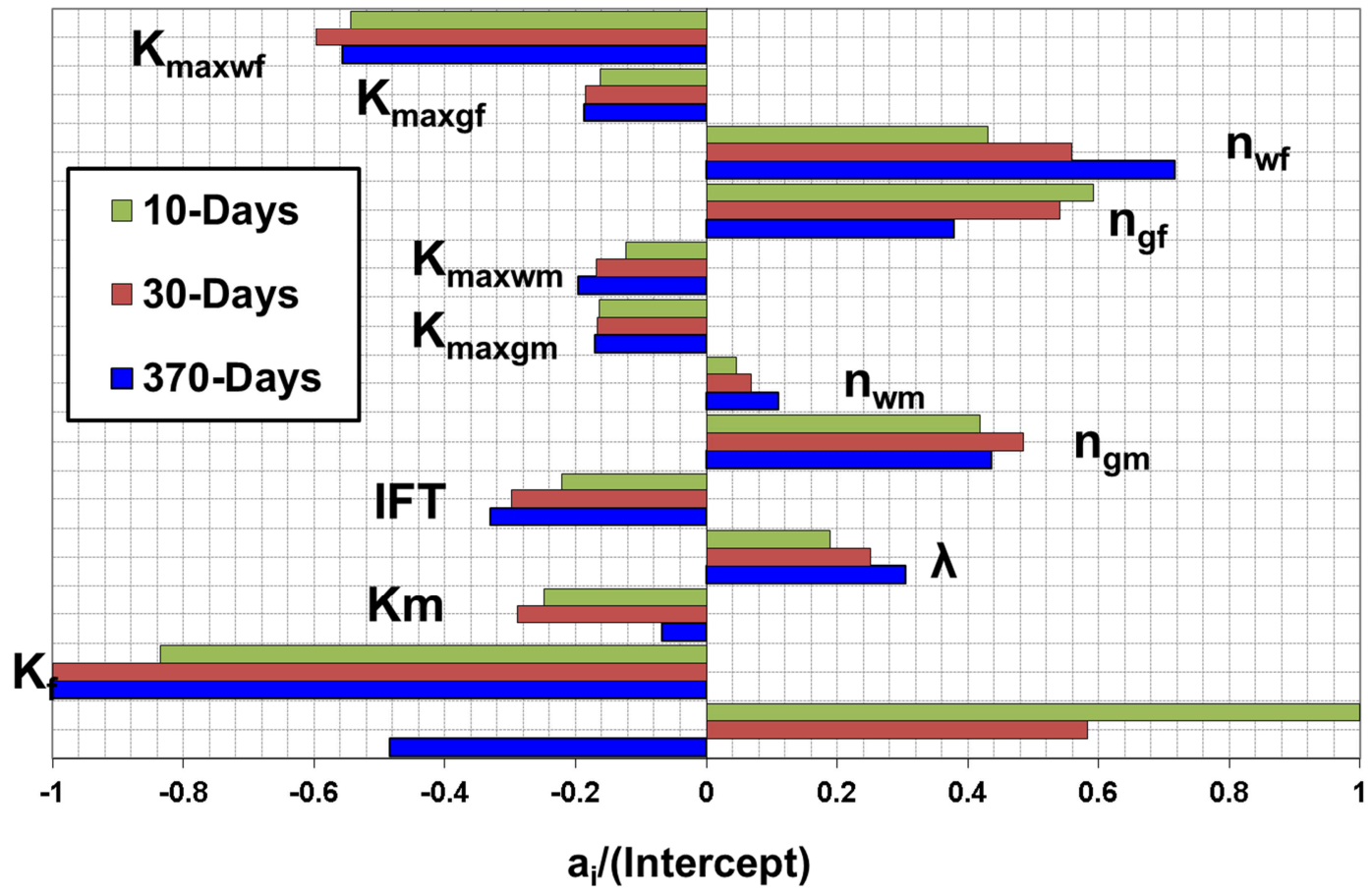

Figure 21 LRSM coefficients, (a)MFHW- Set 50 FVR=5 \& (b) SFVW-Set9 FVR=5 
MFHW-Set 4, MFHW Kmr=10, Gas Production Loss (GPL) - LRSM

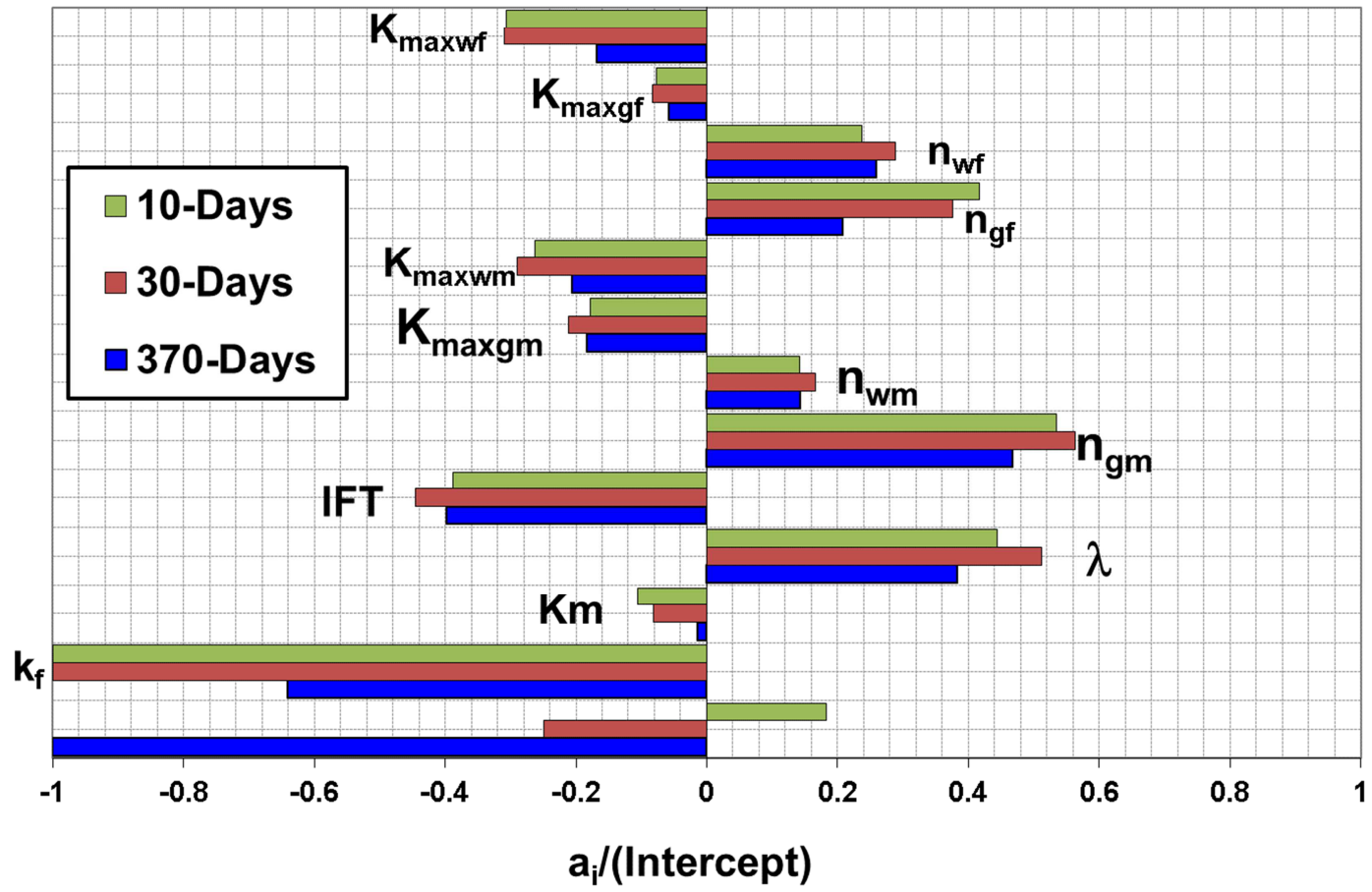

Figure 22 LRSM coefficients, MFHW KMR=10, MFHW-Set 4 1071 
MFHW-Set 7, MFHW Kmr=100, Gas Production Loss (GPL) - LRSM

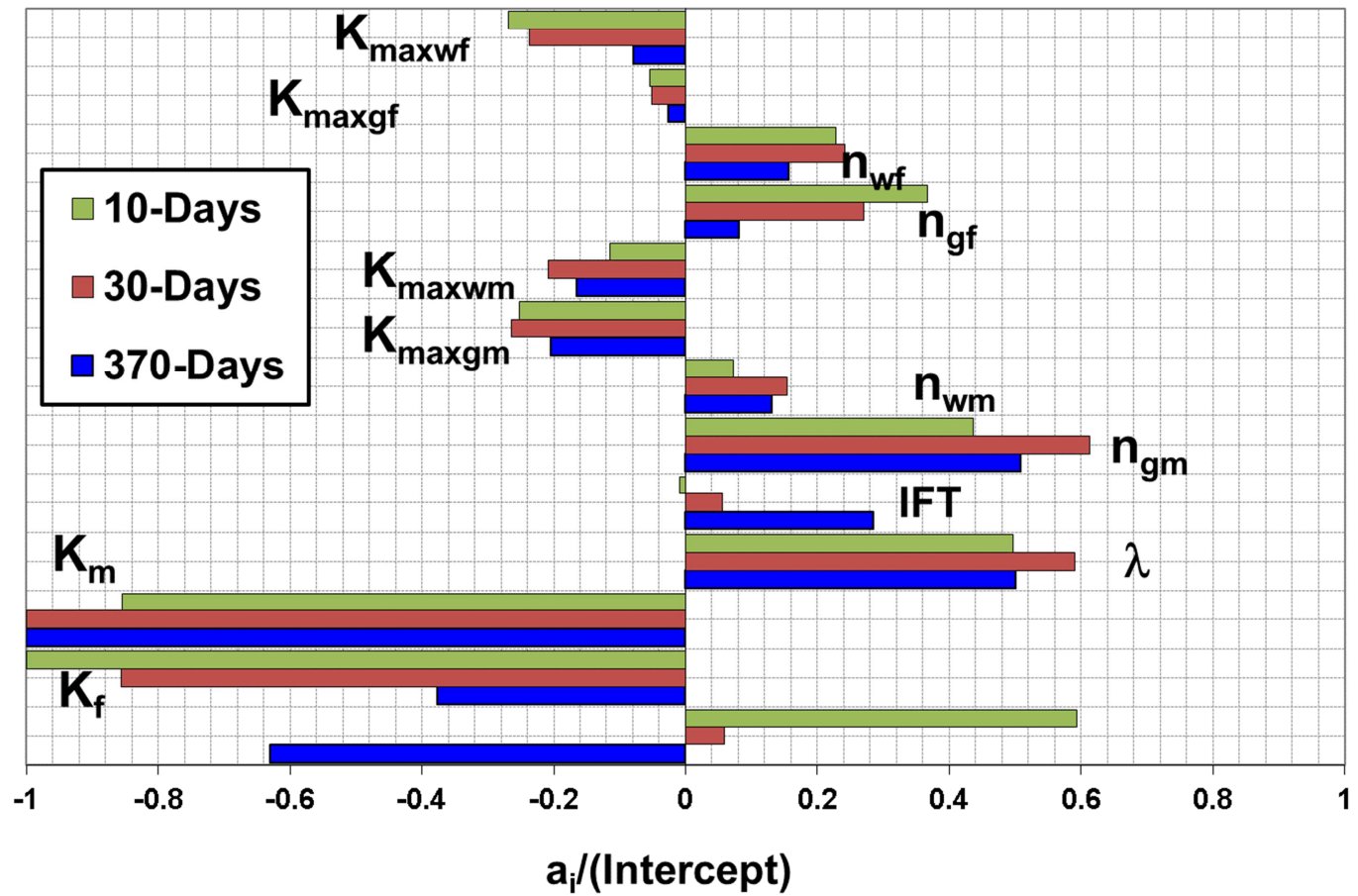

Figure 23 LRSM coefficients, MFHW KMR=100, MFHW-Set 7

1073

MFHW-Set 5, MFHW DP=100, Gas Production Loss (GPL) - LRSM

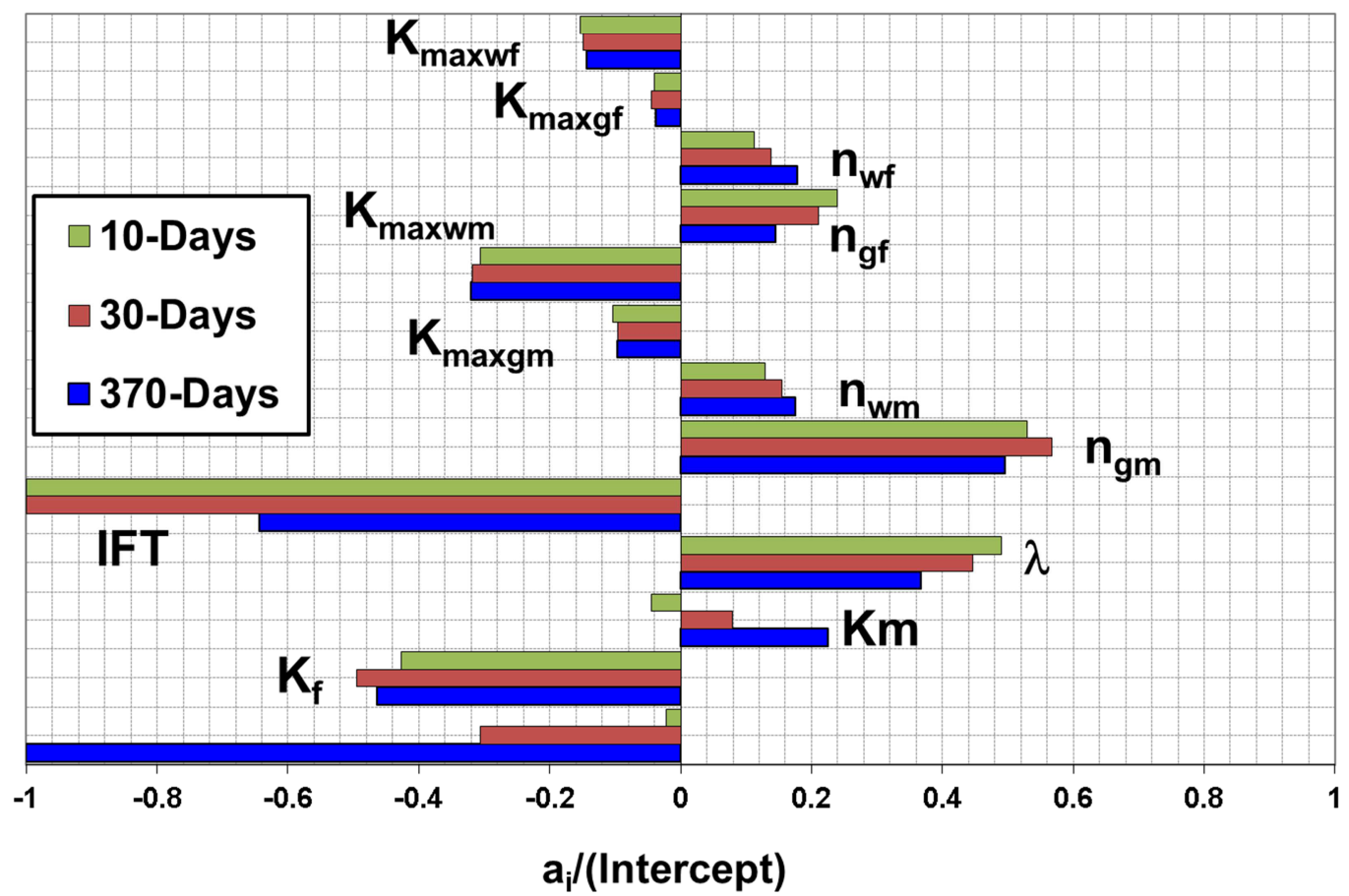

Figure 24 LRSM coefficients, MFHW DP=100, MFHW-Set 5 


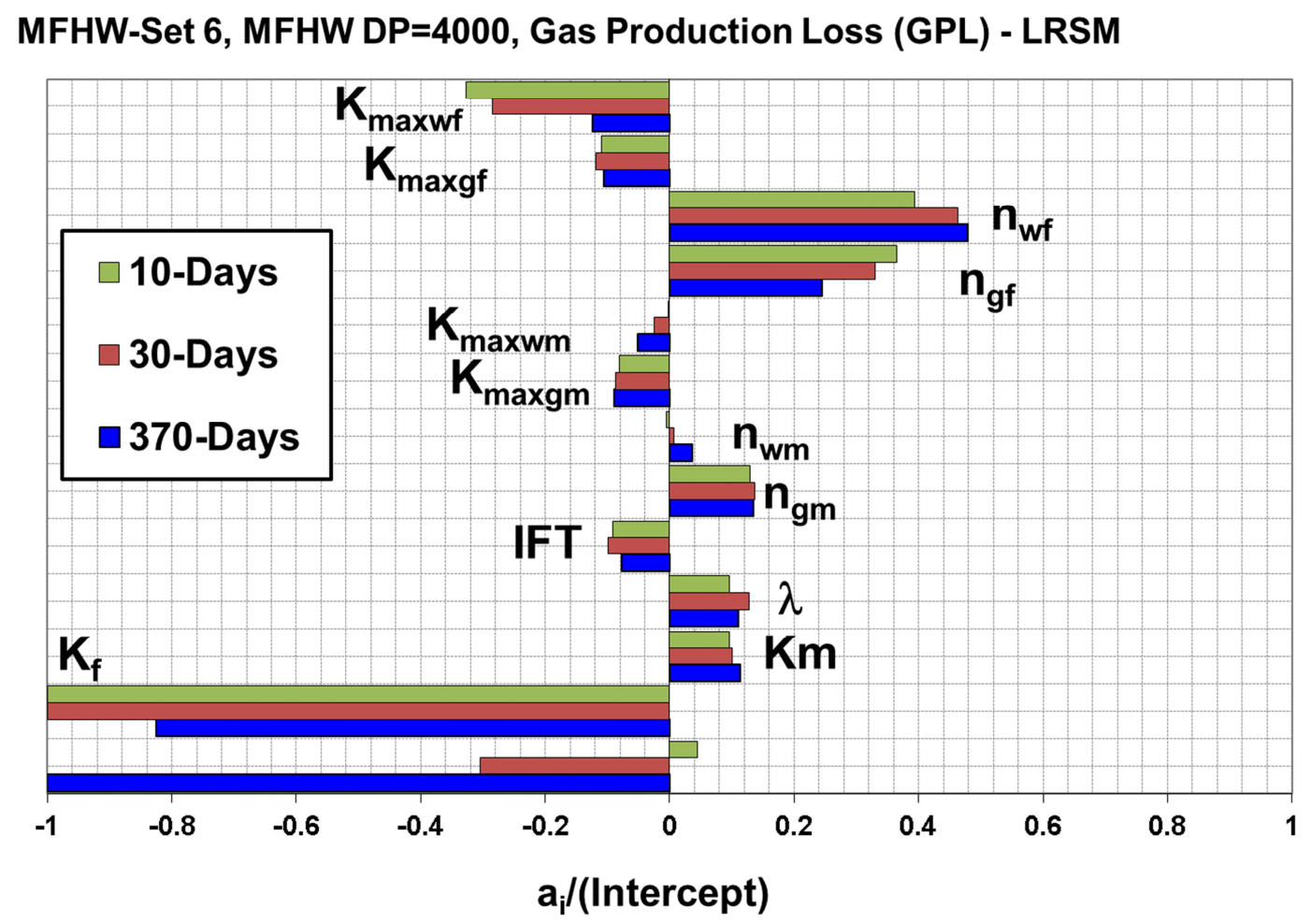

Figure 25 LRSM coefficients, MFHW DP=4000, MFHW-Set 6 
MFHW-Set9 Nf7 L600 Kmr=10, Gas Production Loss (GPL) - LRSM

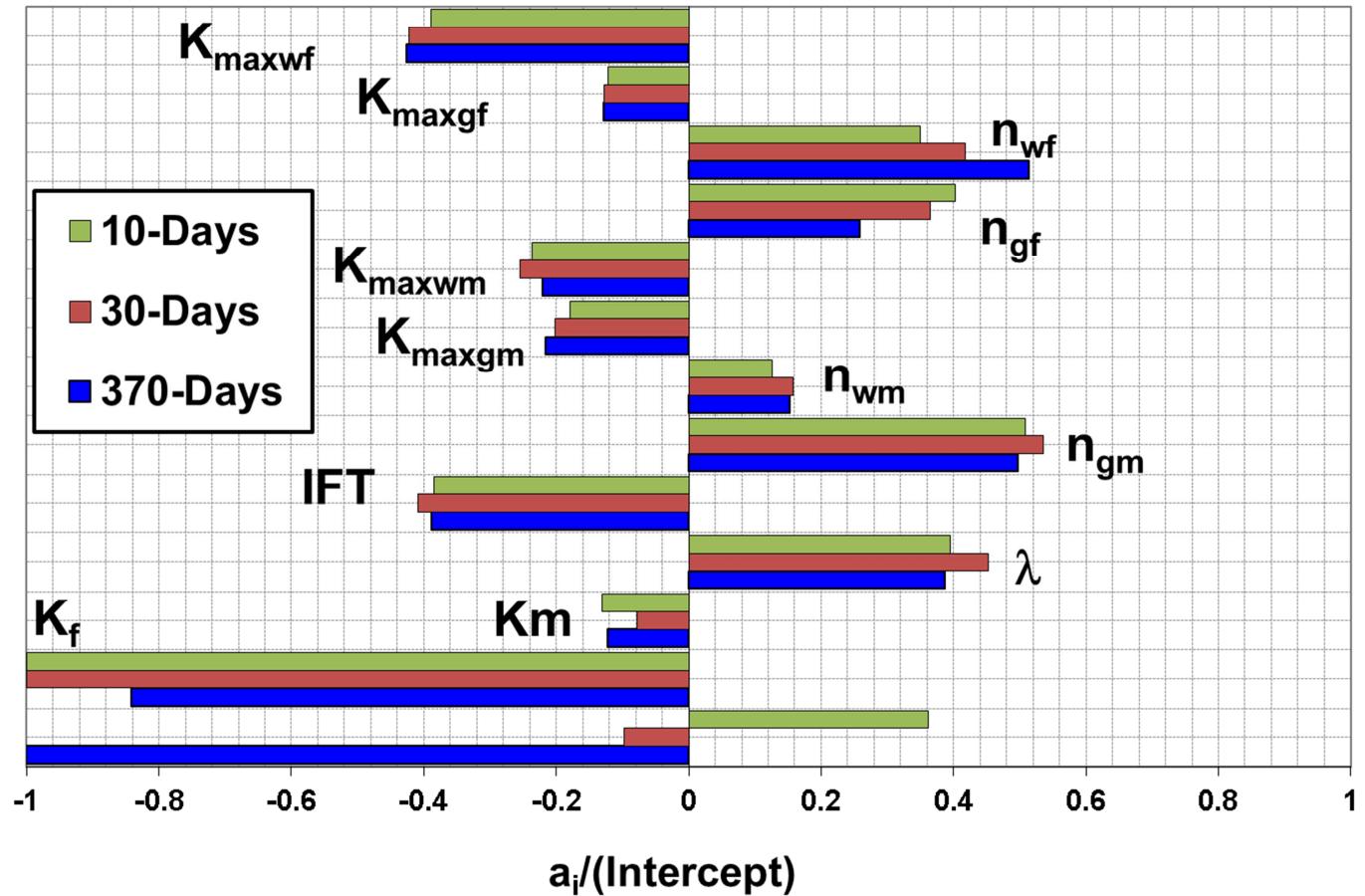

Figure 26 LRSM coefficients, MFHW-Set9 Nf7 L600 KMR=10, Base Reference Set 1080

\section{MFHW-Set10 Nf7 L600 Kmr=100, Gas Production Loss (GPL) - LRSM}

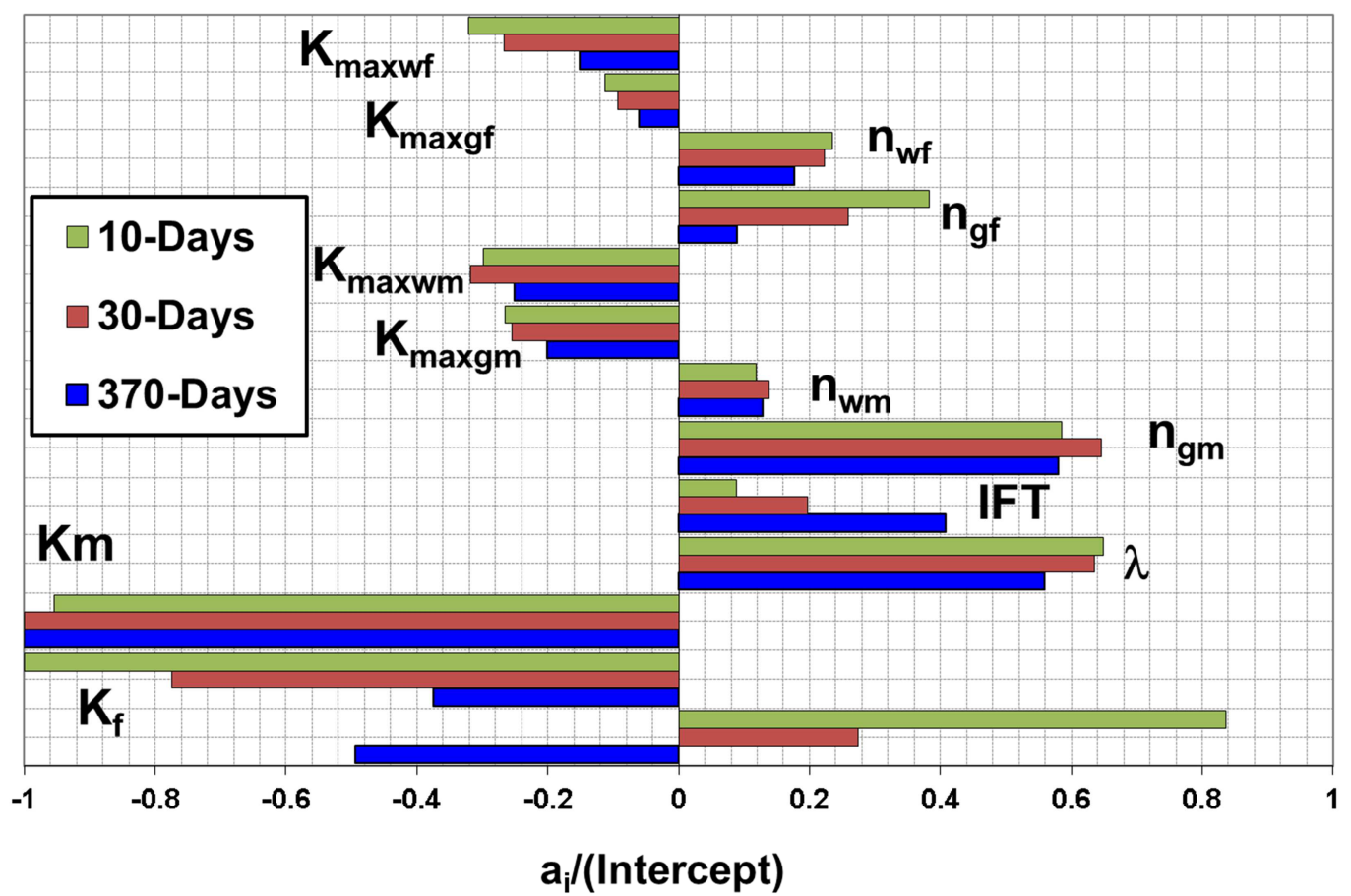

Figure 27 LRSM coefficients, MFHW-Set10 Nf7 L600 KMR=100, Base Reference Set 


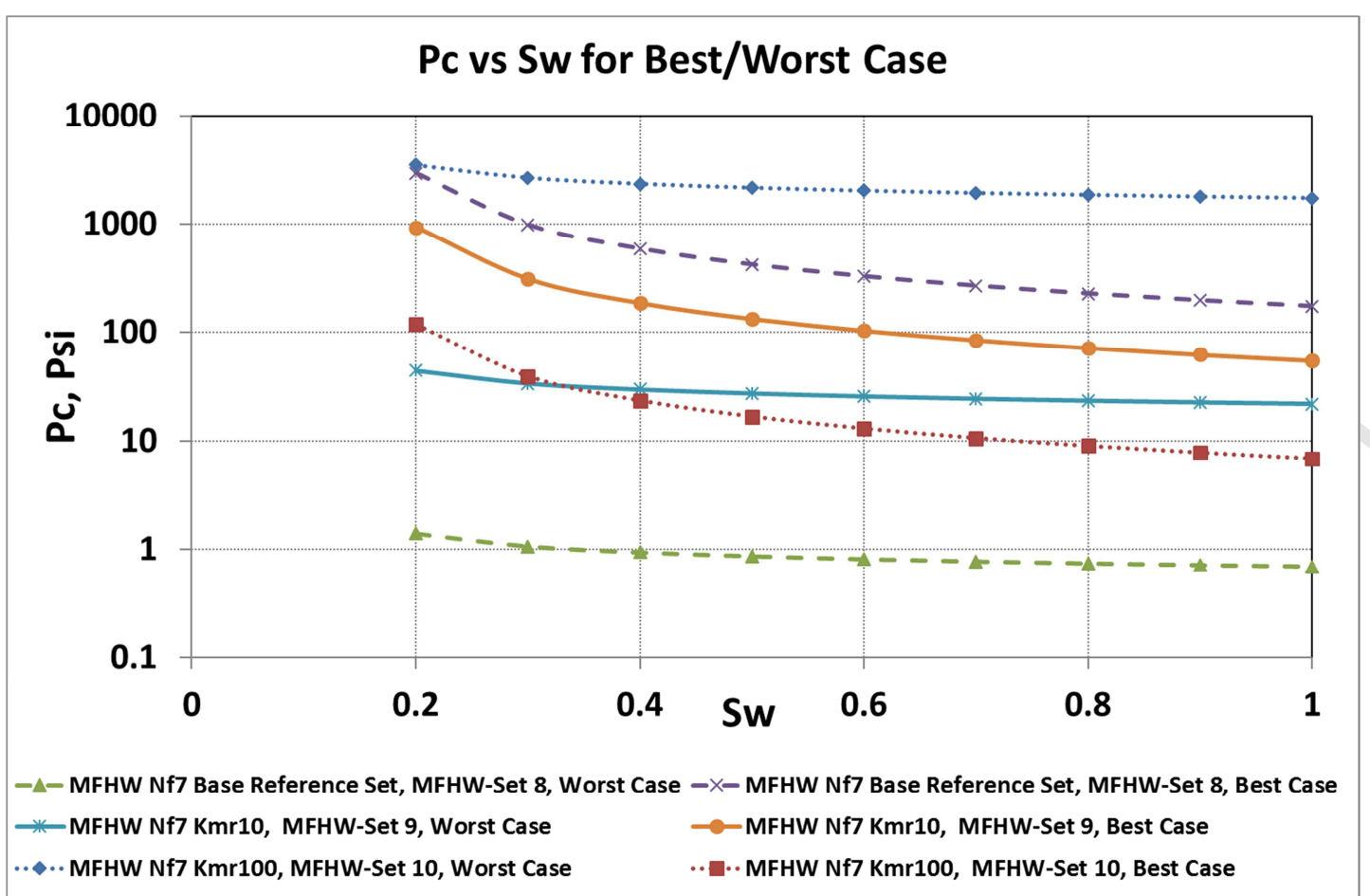

Figure 28 Pc vs. Sw for best/Worst Case of Sets MFHW-Set8, MFHW-Set9 and MFHWSet 10 .

1082

MFHW-set15 Nf7-L600 DP4000, Gas Production Loss (GPL) - LRSM

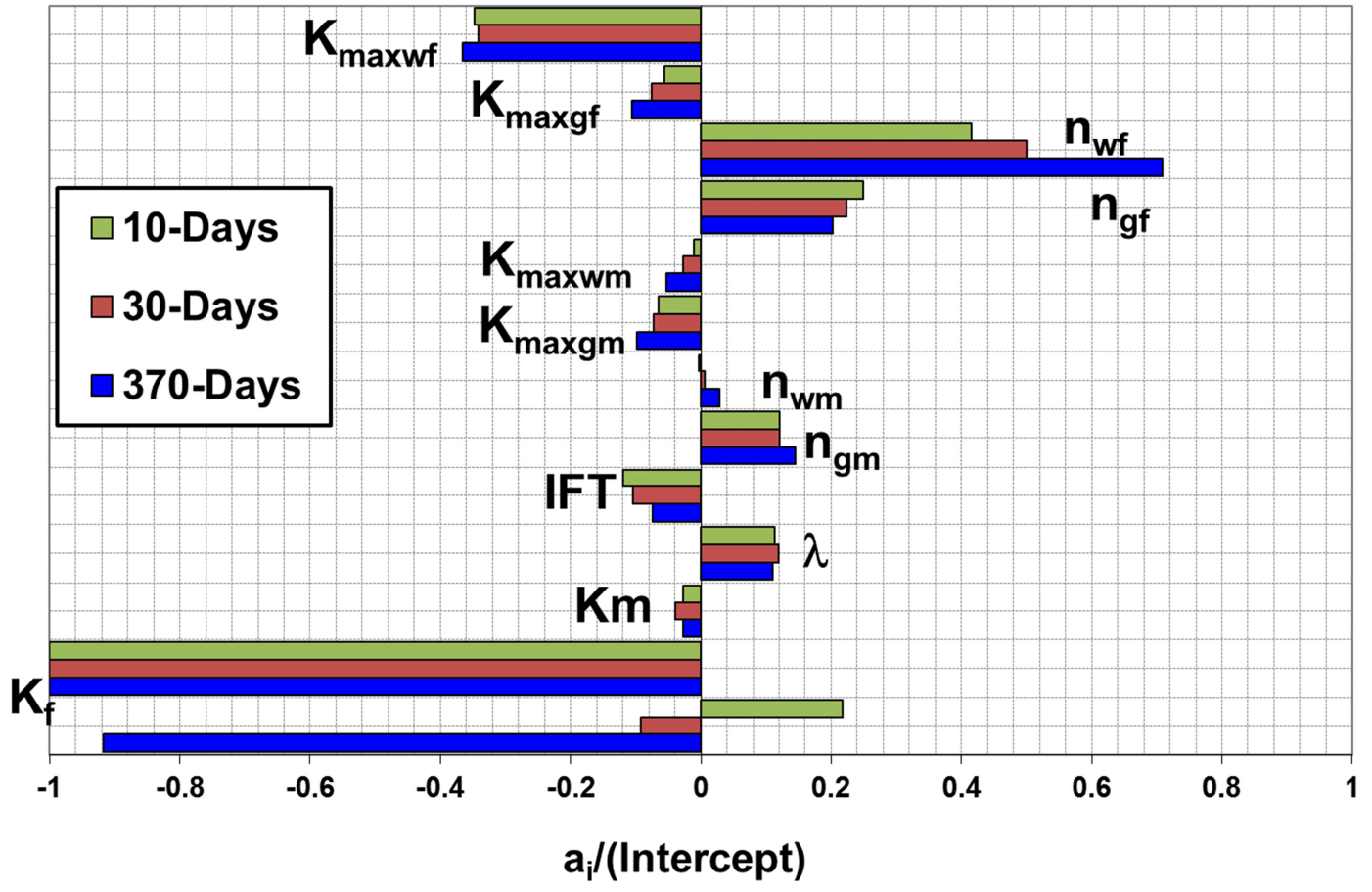

Figure 29 LRSM coefficients, MFHW-Set15 Nf7-L600m DP4000 
MFHW-set17 Nf7-L600 Kmr10DP4000, Gas Production Loss (GPL) - LRSM

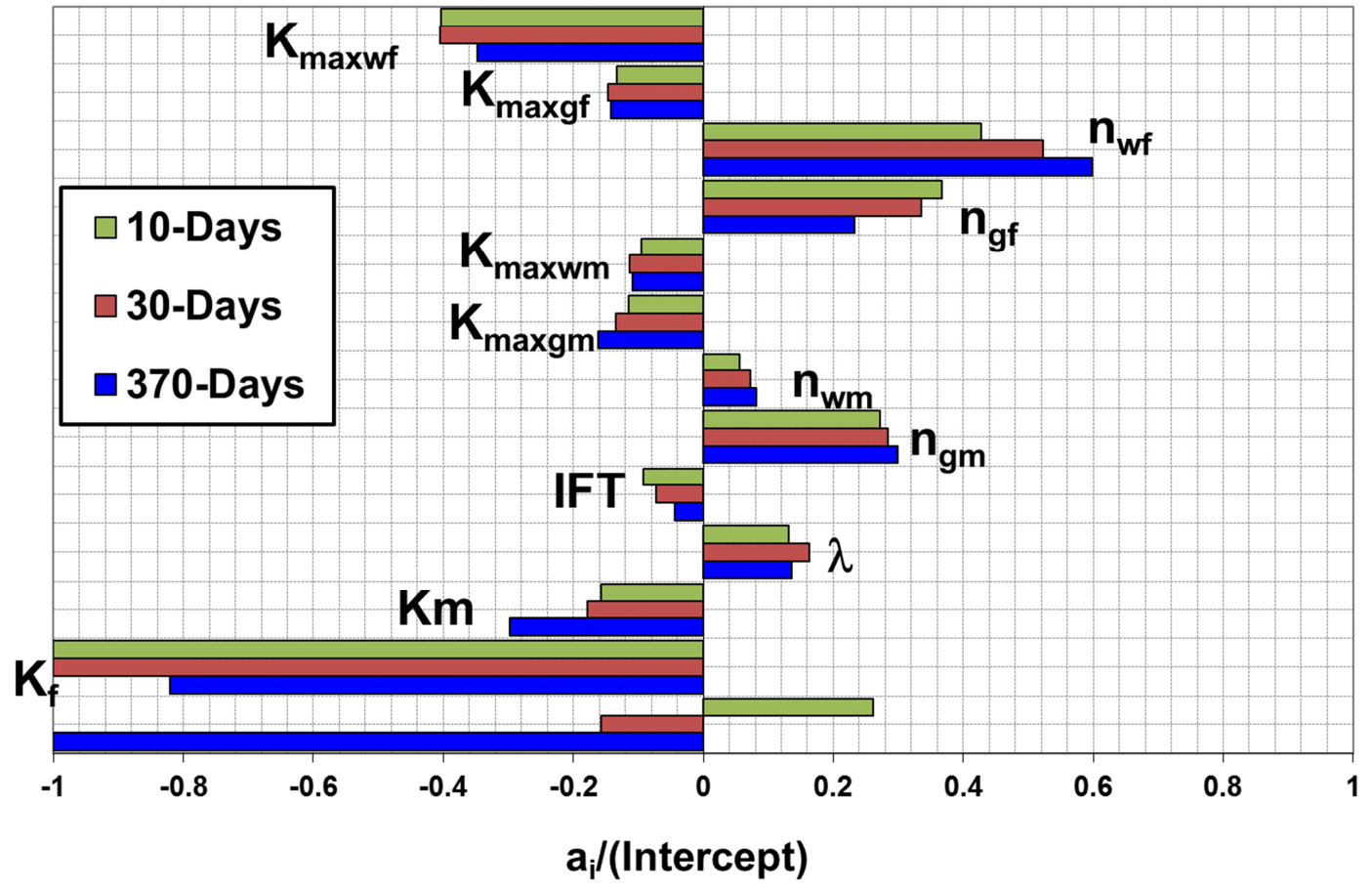

Figure 30 LRSM coefficients, MFHW-Set17 Nf7-L600m KMR10DP4000

MFHW-set19 Nf7-L600 Kmr100DP4000, Gas Production Loss (GPL) - LRSM

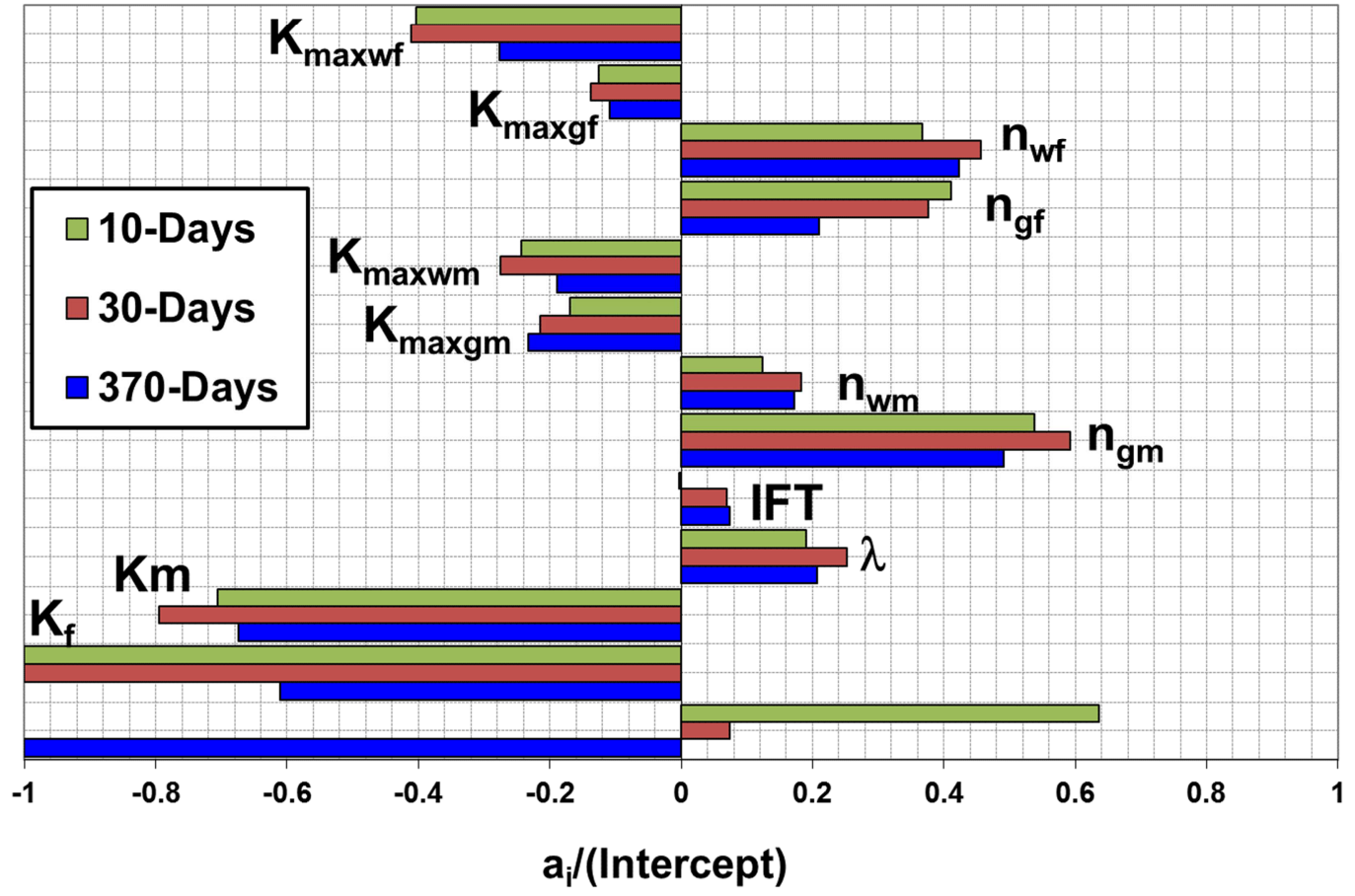

Figure 31 LRSM coefficients, MFHW-Set19 Nf7-L600m KMR100 DP4000 


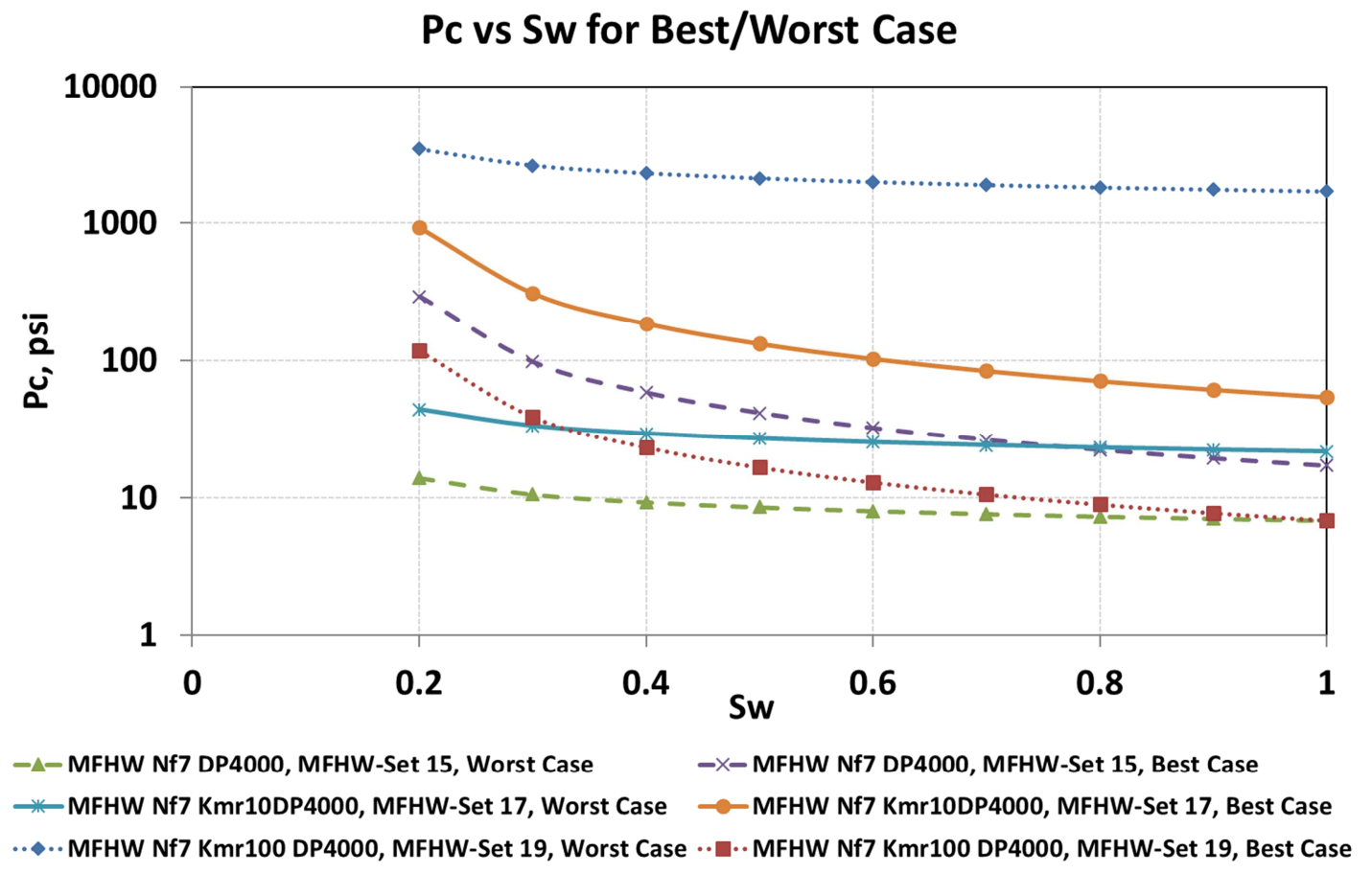

Figure 32 Pc vs. Sw for best/Worst Case of MFHW-Set15, MFHW-Set17 and MFHW-Set19

MFHW-set11 Nf7 L600DP=100, Gas Production Loss (GPL) - LRSM

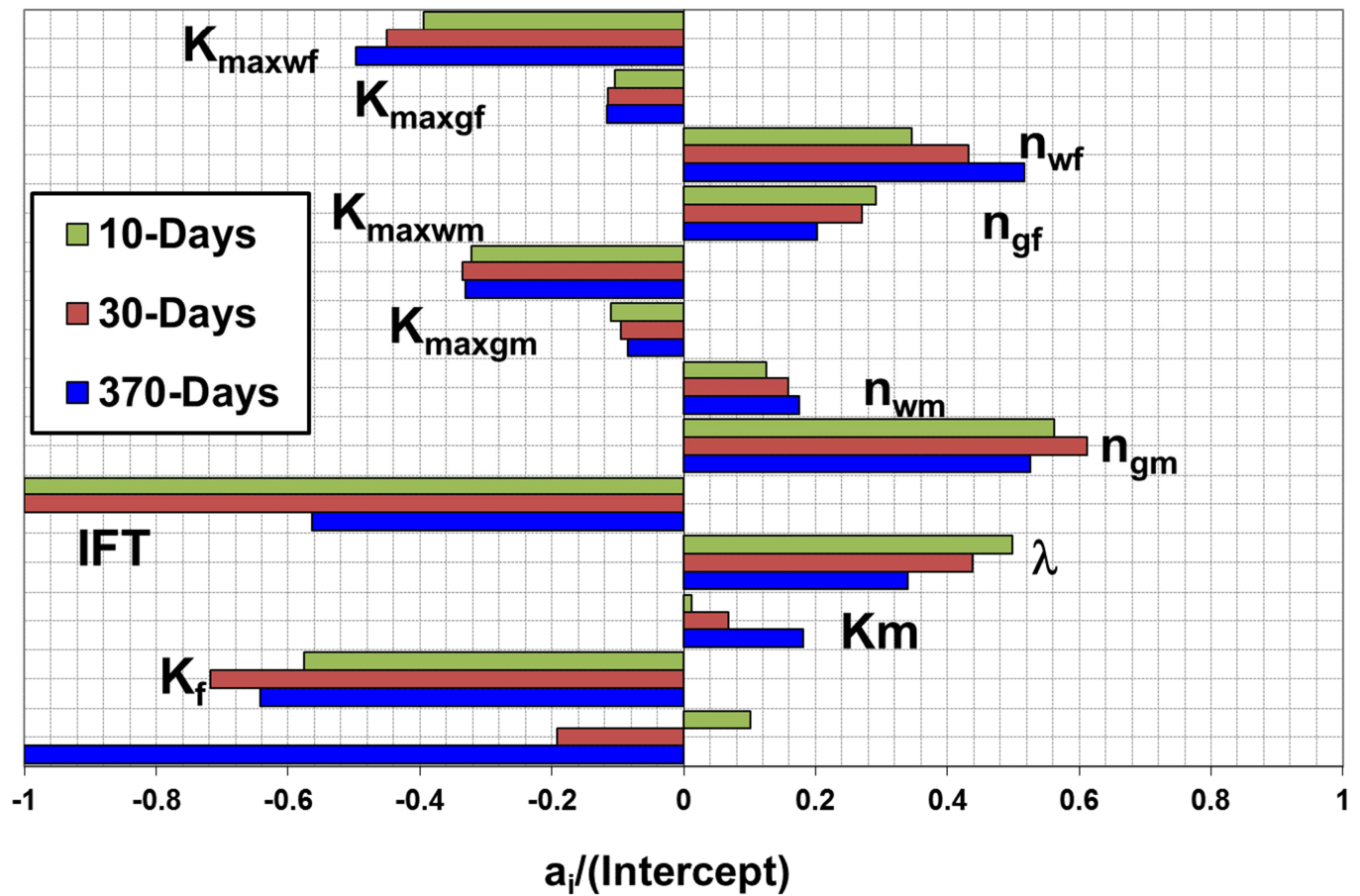

Figure 33 LRSM coefficients, MFHW-Set11 Nf7-L600m DP100 
MFHW-set16 Nf7 L600 Kmr=10DP100, Gas Production Loss (GPL) - LRSM

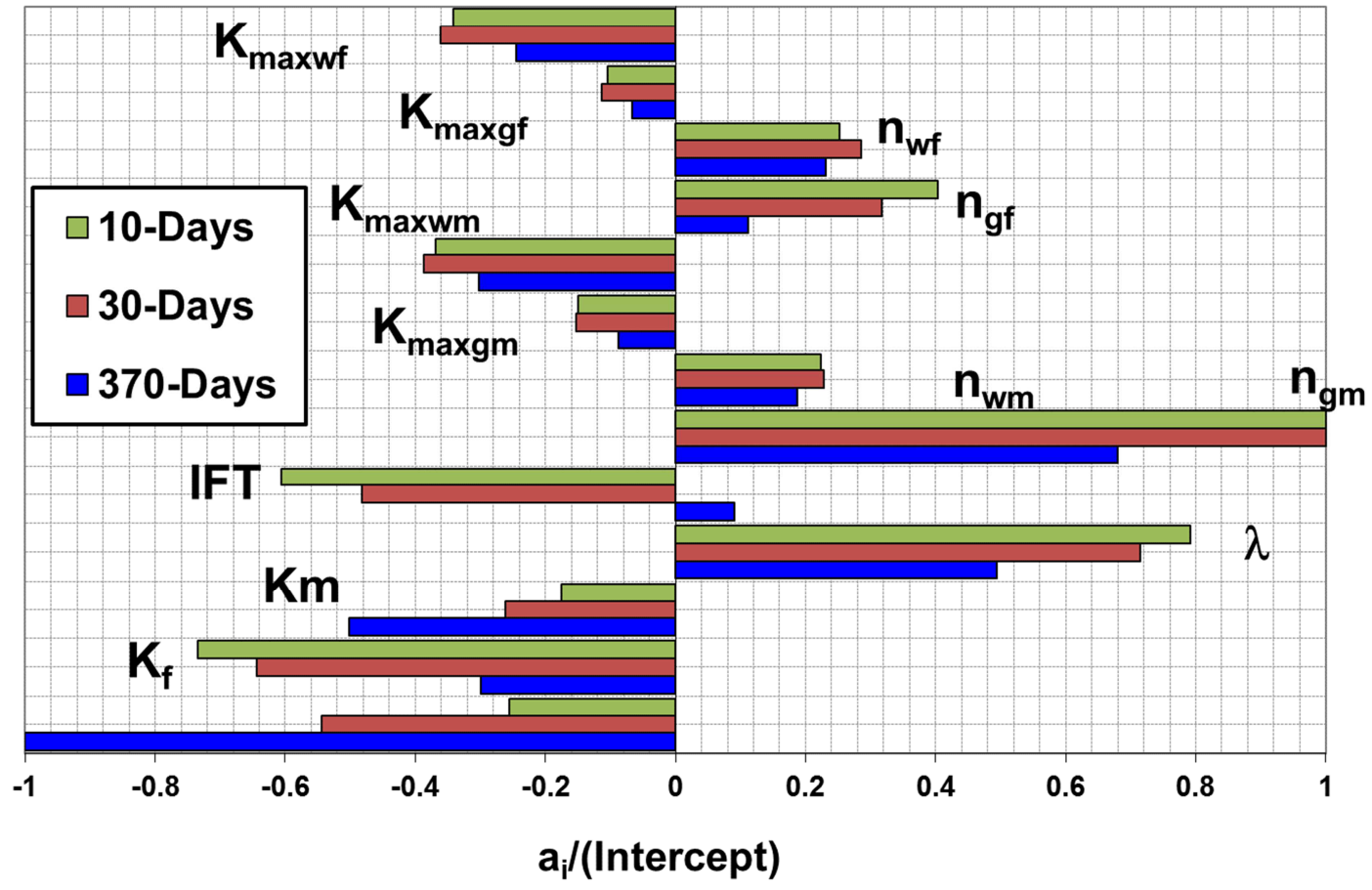

Figure 34 LRSM coefficients, MFHW-Set16 Nf7-L600m KMR10DP100

MFHW-set18 Nf7-L600 Kmr=100DP100, Gas Production Loss (GPL) - LRSM

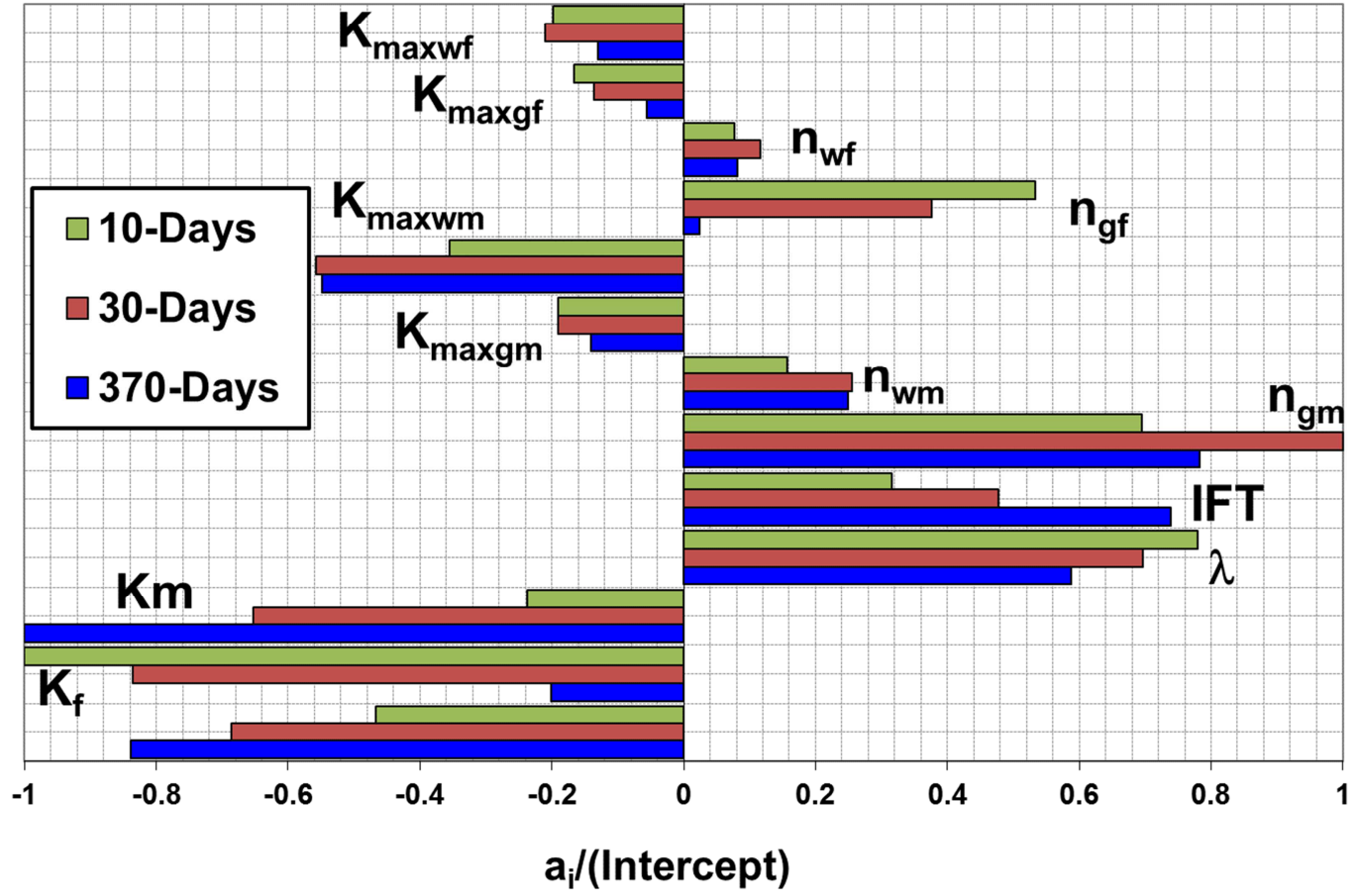

Figure 35 LRSM coefficients, MFHW-Set18 Nf7-L600m KMR100DP100 


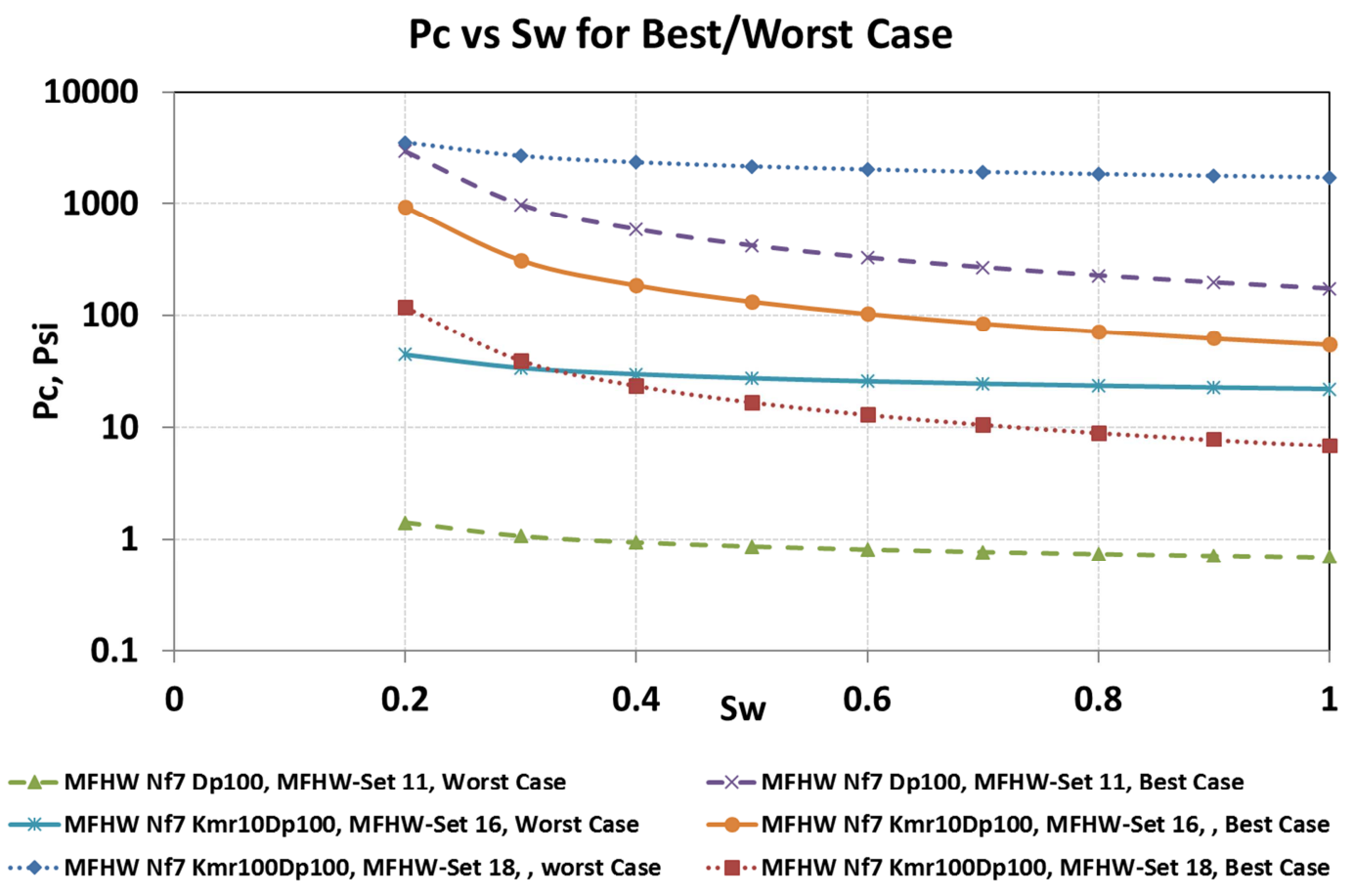

Figure 36 Pc vs. Sw for best/Worst Case of MFHW-Set11, MFHW-Set16 and MFHW-Set18 


\section{Highlights}

- An integrated investigation of clean-up efficiency of fractures was performed (in 30 new sets).

- Near wellbore choking effect in multiple fractured horizontal wells affects the cleanup mechanisms in a different way compared to vertical wells.

- Using IFT reducing agents is not recommended in tight formations whilst it is highly recommended to use such agents in ultratight formations.

- Although the impact of fracture interference/fracture spacing on flow is significant, its impact on clean-up performance is minimal.

- Latin Hypercube is a more realistic and reliable sampling approach compared to the twolevel full-factorial experimental design. 